\title{
Five Nitrogen Oxidation States from Nitro to Amine: Stabilization and Reactivity of a Metastable Arylhydroxylamine Complex
}

Joseph Zsombor-Pindera, ${ }^{a, b, \ddagger}$ Farshid Effaty, ${ }^{a, \ddagger}$ Léon Escomel, ${ }^{a}$ Brian Patrick, ${ }^{b}$ Pierre Kennepohl, ${ }^{*}$, and Xavier Ottenwaelder, a

a Department of Chemistry and Biochemistry, Concordia University, Montreal, H4B 1R6, Canada.

b Department of Chemistry, University of British Columbia, Vancouver, BC V6T 1Z1, Canada

‡ Equal contributions

\section{Table of Contents}

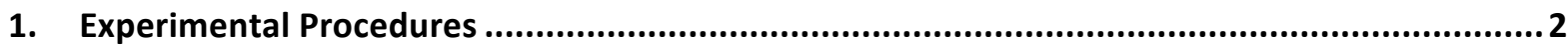

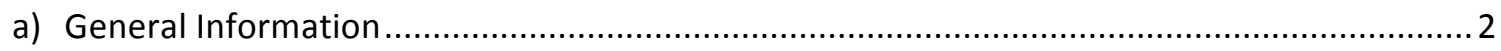

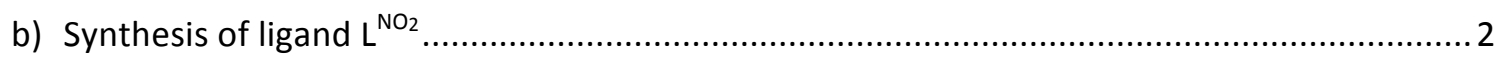

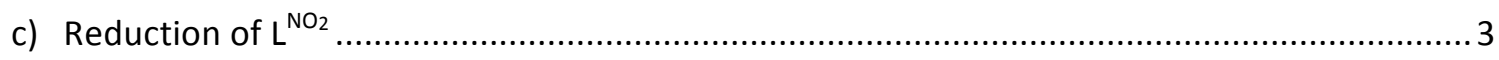

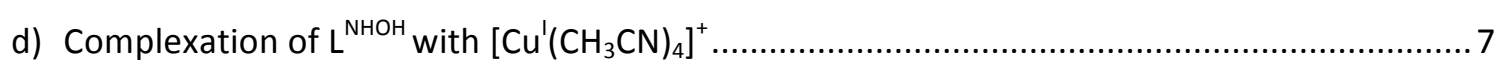

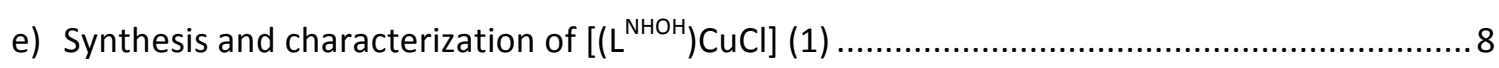

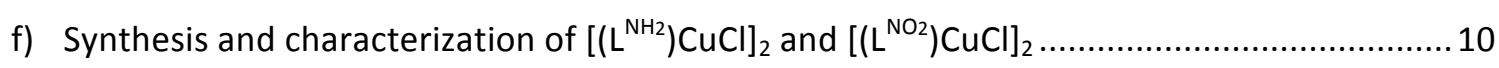

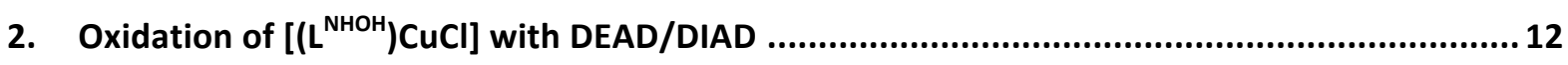

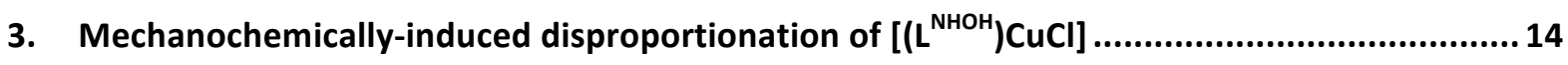

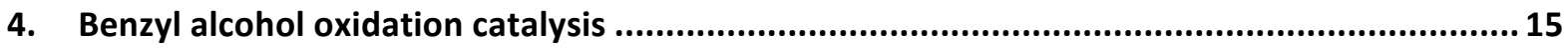

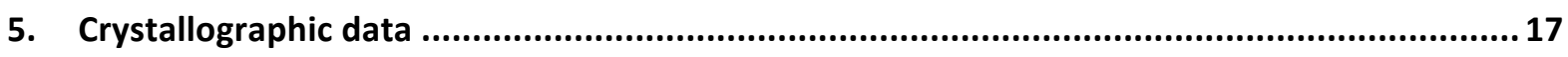

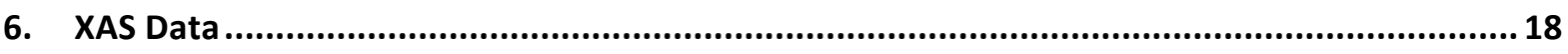

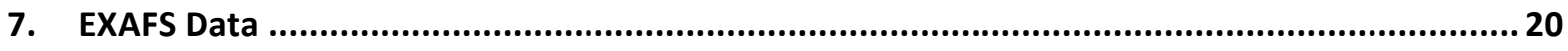

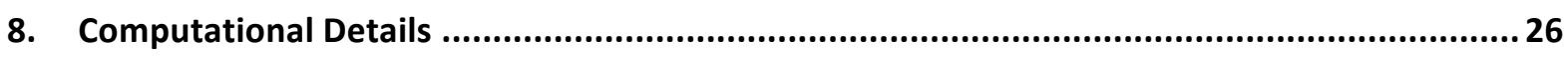

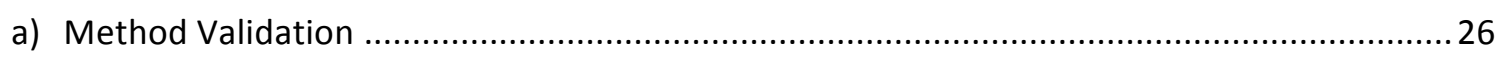

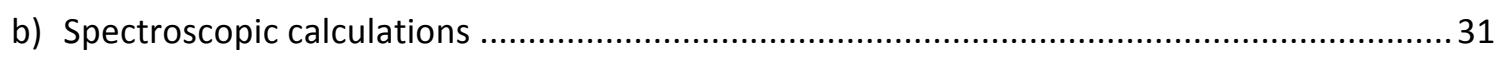

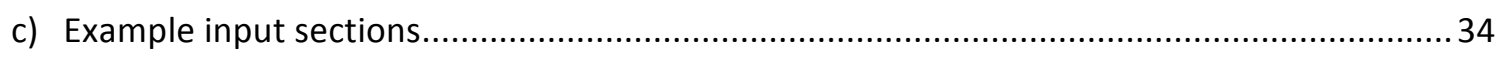

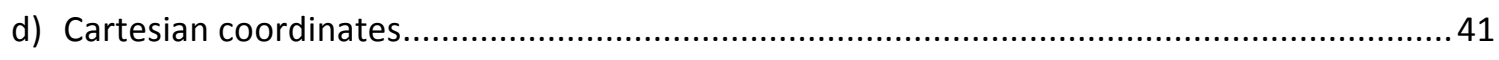

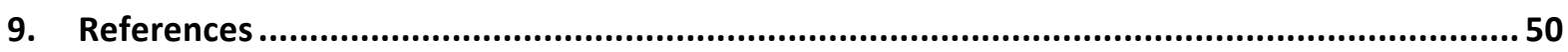




\section{Experimental Procedures}

\section{a) General Information}

Materials. Organics reagents and metal salts were obtained from commercial sources and used as received unless indicated otherwise. Inhibitor-free solvents were degassed, dried over a MBraun SPS 800 solvent purification system, and then stored over activated $4 \AA$ molecular sieves inside an inert-atmosphere glovebox filled with a dry nitrogen atmosphere (MBraun Labmaster, $<1 \mathrm{ppm}$ of $\mathrm{O}_{2}$ and $\mathrm{H}_{2} \mathrm{O}$, filled with a dry $\mathrm{N}_{2}$ atmosphere).

Characterization. ${ }^{1} \mathrm{H}$ and ${ }^{13} \mathrm{C}-\mathrm{NMR}$ spectra were recorded on a Varian VNMRS $500 \mathrm{MHz}$ or Inova $300 \mathrm{MHz}$ and referenced to internal tetramethylsilane (TMS). NMR samples of air-sensitive compounds were prepared under a $\mathrm{N}_{2}$ atmosphere in a $5 \mathrm{~mm}$ air-tight tube. UV-visible spectra were recorded on a B\&W Tek iTrometer equipped with fiber optic cables. Mass spectrometry data for samples were obtained by direct injection of their acetonitrile solutions into a Micromass Quattro LC triple-quad instrument equipped with an electrospray ionization (ESI) chamber.

X-Ray Crystallography. Crystallographic analysis was performed using the Mo Ka or microfocus $\mathrm{Cu} \mathrm{K \alpha}$ source of a Bruker APEX-DUO or APEX-II diffractometer. The frames were integrated with the Bruker SAINT software package using a narrow-frame algorithm. Data were corrected for absorption effects using the multiscan method (SADABS). The structures were solved by SHELXT and refined using the Bruker APEX3 software package (SHELXL instructions). All non-hydrogen atoms were refined with anisotropic thermal parameters. $\mathrm{H}$ atoms were generated in idealized positions, riding on the carrier atoms with isotropic thermal parameters. Further details in the CIFs.

\section{b) Synthesis of ligand $\mathrm{L}^{\mathrm{NO} 2}$}

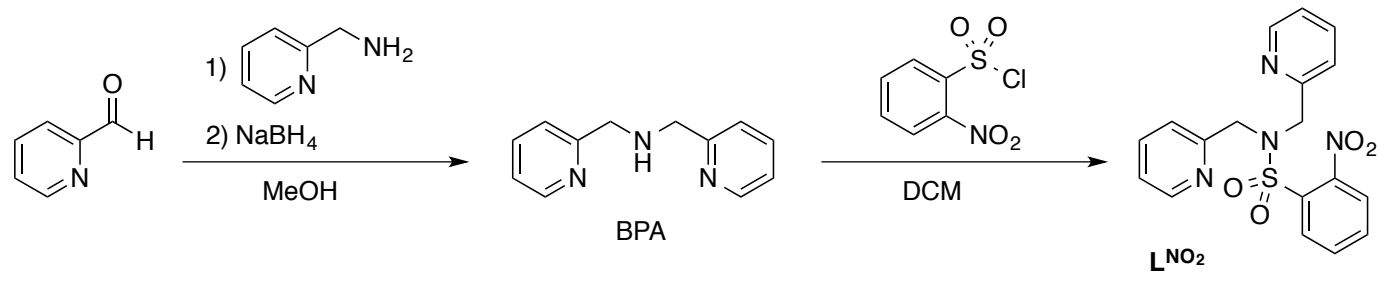

Scheme S1. Synthesis of 2-nitro- $N, N$-bis(2-pyridinylmethyl)benzenesulfonamide $\left(\mathrm{L}^{\mathrm{NO}_{2}}\right)$.

Bis(2-picolyl)amine (BPA): $10 \mathrm{~mL}$ 2-pyridinecarboxaldehyde (0.106 mol, 1 eq.) was dissolved in $110 \mathrm{~mL}$ $\mathrm{MeOH}$ and cooled to $0^{\circ} \mathrm{C}$ in an ice-water bath. $11.0 \mathrm{~mL}$ of 2-pyridylmethylamine $(0.106 \mathrm{~mol}, 1$ eq.) was added to the solution with stirring, the ice-water bath was removed, and the reaction mixture was allowed to stir for 
$1 \mathrm{~h}$. The solution was then re-cooled to $0^{\circ} \mathrm{C}$ in an ice-water bath, and $4.927 \mathrm{~g} \mathrm{NaBH}_{4}(0.127 \mathrm{~mol}, 1.2$ eq.) were added slowly, in small portions. After reaction completion was indicated by TLC, the reaction mixture was cooled to $0^{\circ} \mathrm{C}$ and the product was purified by acid/base extraction, extracted with DCM, and washed with distilled water, followed by brine. The combined organic portions were dried over $\mathrm{MgSO}_{4}$ and concentrated under reduced pressure, then the product was dried under high-vacuum, yielding bis(2-picolyl)amine (BPA) as a yellow oil in $80 \%$ yield. ${ }^{1} \mathrm{H}$ NMR $\left(\mathrm{CDCl}_{3}, 500 \mathrm{MHz}\right): \delta 8.37\left(\mathrm{~m}, 2 \mathrm{H}, \mathrm{H}_{\mathrm{Py}}\right), 7.42\left(\mathrm{td}, 2 \mathrm{H}, \mathrm{H}_{\mathrm{Py}}\right), 7.12\left(\mathrm{~d}, 2 \mathrm{H}, \mathrm{H}_{\mathrm{Py}}\right), 6.93$ $\left(\mathrm{m}, 2 \mathrm{H}, \mathrm{H}_{\mathrm{Py}}\right), 3.80\left(\mathrm{~s}, 4 \mathrm{H}, \mathrm{CH}_{2}-\mathrm{Py}\right), 2.80(\mathrm{~b}, 1 \mathrm{H}, \mathrm{NH})$.

$\mathrm{L}^{\mathrm{NO}_{2}}: 1.46 \mathrm{~g}$ of triethylamine ( $\left.12 \mathrm{mmol}, 1.2 \mathrm{eq}.\right)$ was added to a solution of $1.99 \mathrm{~g}$ BPA (10 mmol, 1.0 eq.) in $100 \mathrm{~mL} \mathrm{DCM}$. The mixture was placed in an ice-water bath and allowed to cool to $0^{\circ} \mathrm{C}$ with stirring. $2.66 \mathrm{~g}$ of 2nitrobenzenesulfonyl chloride (12 mmol, 1.2 eq.) dissolved in $40 \mathrm{~mL} \mathrm{DCM}$ were then added dropwise over 5 min. When the addition was complete, the ice-water bath was removed and the reaction was left stirring at $25^{\circ} \mathrm{C}$ for $14 \mathrm{~h}$. The mixture was then quenched with $100 \mathrm{~mL}$ of a saturated aqueous $\mathrm{NaHCO}_{3}$ solution and left to stir at $25^{\circ} \mathrm{C}$ for $24 \mathrm{~h}$. The organic phase was then isolated and washed with distilled water, followed by brine. The combined organic portions were dried over $\mathrm{MgSO}_{4}$ and concentrated under reduced pressure, leaving behind a light-brown oily residue, which was dried under high-vacuum. Trituration in ether produced an offwhite powder in $65 \%$ yield. ${ }^{1} \mathrm{H} N M R\left(\mathrm{CDCl}_{3}, 500 \mathrm{MHz}\right): \delta 8.40\left(\mathrm{~d}, 1 \mathrm{H}, \mathrm{H}_{\mathrm{Py}}\right), 8.05\left(\mathrm{~d}, 1 \mathrm{H}, \mathrm{H}_{\mathrm{Ar}}\right), 7.65\left(\mathrm{~m}, 2 \mathrm{H}, \mathrm{H}_{\mathrm{Py}}\right)$, $7.55\left(\mathrm{~m}, 3 \mathrm{H}, \mathrm{H}_{\mathrm{Ar}}\right), 7.33\left(\mathrm{~d}, 2 \mathrm{H}, \mathrm{H}_{\mathrm{Py}}\right), 7.12\left(\mathrm{~m}, 2 \mathrm{H}, \mathrm{H}_{\mathrm{Py}}\right), 4.75\left(\mathrm{~s}, 4 \mathrm{H}_{\mathrm{CH}_{2}}\right) \cdot{ }^{13} \mathrm{C}$ NMR: $\left(\mathrm{CDCl}_{3}, 125 \mathrm{MHz}, 512\right.$ scans): $\delta$ $155.80\left(1 \mathrm{C}, \mathrm{C}_{\mathrm{Ar}}\right), 149.26\left(2 \mathrm{C}, \mathrm{C}_{\mathrm{Ar}}\right), 136.66\left(2 \mathrm{C}, \mathrm{C}_{\mathrm{Py}}\right), 133.97\left(1 \mathrm{C}, \mathrm{C}_{\mathrm{Ar}}\right), 133.28\left(1 \mathrm{C}, \mathrm{C}_{\mathrm{Ar}}\right), 131.52\left(1 \mathrm{C}, \mathrm{C}_{\mathrm{Ar}}\right), 131.20(1 \mathrm{C}$, $\left.\mathrm{C}_{\mathrm{Ar}}\right), 124.07\left(1 \mathrm{C}, \mathrm{C}_{\mathrm{Ar}}\right), 122.51\left(2 \mathrm{C}, \mathrm{C}_{\mathrm{Ar}}\right), 122.38\left(2 \mathrm{C}, \mathrm{C}_{\mathrm{Ar}}\right), 53.20\left(2 \mathrm{C}, \mathrm{C}_{\mathrm{CH} 2}\right)$.

\section{c) Reduction of $\mathrm{L}^{\mathrm{NO}_{2}}$}

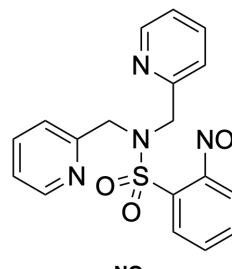

$\mathrm{LNO}_{2}$

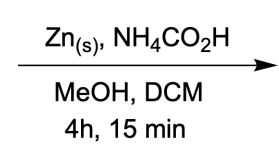

4h, $15 \mathrm{~min}$

(2)

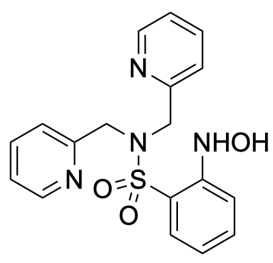

$\mathrm{L}^{\mathrm{NHOH}}$

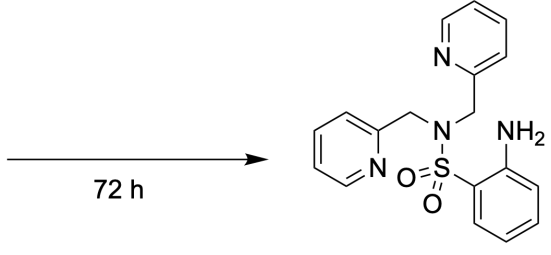

$\mathrm{L}^{\mathrm{NH}_{2}}$

Scheme S2. Reduction of $\mathrm{L}^{\mathrm{NO} 2}$ to 2-hydroxylamine- $N, N$-bis(2-pyridinylmethyl)benzenesulfonamide $\left(\mathrm{L}^{\mathrm{NHOH}}\right)$ or 2amine- $N, N$-bis(2-pyridinylmethyl)benzenesulfonamide $\left(\mathrm{L}^{\mathrm{NH}}\right)$.

Reduction of $\mathrm{L}^{\mathrm{NO} 2}$ was carried out by heterogeneous zinc-catalyzed transfer hydrogenation from $\mathrm{NH}_{4} \mathrm{CO}_{2} \mathrm{H}$ using fine $\mathrm{Zn}_{(\mathrm{s})}$ powder (purum (>95\%), 100-300 mesh). The final product of this reaction is the amine $\mathbf{L}^{\mathrm{NH} 2}$. The hydroxylamine, $\mathrm{L}^{\mathrm{NHOH}}$, is an intermediate that can be isolated by early quenching of the reaction. Due to the heterogeneous nature of the reaction, the precise time at which the reaction mixture contains purely $\mathbf{L}^{\mathrm{NHOH}}$ is 
dependent on the grade and activation of the zinc powder, the flask, and the rate of agitation. We found that activating the $\mathrm{Zn}$ powder makes it harder to stop the reaction at the partial-reduction stage. Isolation of pure $\mathrm{L}^{\mathrm{NHOH}}$ thus requires careful monitoring of the reaction; both TLC and ${ }^{1} \mathrm{H}$ NMR were used for this purpose. For TLC monitoring, the following retention factors were used (stationary phase: $\mathrm{SiO}_{2}$, mobile phase: DCM:Et ${ }_{3} \mathrm{~N}$ :hexanes = 5:3:2): $\mathrm{R}_{\mathrm{f}}\left(\mathrm{L}^{\mathrm{NO}_{2}}\right)=0.60, \mathrm{R}_{\mathrm{f}}\left(\mathrm{L}^{\mathrm{NHOH}}\right)=0.85, \mathrm{R}_{\mathrm{f}}\left(\mathrm{L}^{\mathrm{NH}_{2}}\right)=0.63$. For NMR monitoring, a comparison of the methylene peaks of $\mathrm{L}^{\mathrm{NO}_{2}}(\delta 4.75), \mathrm{L}^{\mathrm{NHOH}}(\delta 4.59)$, and $\mathrm{L}^{\mathrm{NH}_{2}}(\delta 4.64)$ is shown in Figure $\mathrm{S} 1\left(\mathrm{CDCl}_{3}, 500 \mathrm{MHz}\right)$.

$\mathrm{L}^{\mathrm{NHOH}}$ : A solution of $28.0 \mathrm{mg}$ of $\mathrm{NH}_{4} \mathrm{CO}_{2} \mathrm{H}(0.438 \mathrm{mmol}, 1.6$ eq.) was dissolved in $3 \mathrm{~mL} \mathrm{MeOH}$ and added to a solution of $104.9 \mathrm{mg} \mathrm{L} \mathrm{NO}_{2}(0.273 \mathrm{mmol}, 1$ eq.) in $4 \mathrm{~mL} \mathrm{DCM}$, stirred at $600 \mathrm{rpm}$ in a teardrop-shaped $25 \mathrm{~mL}$ boiling flask. The mixture was cooled to $0^{\circ} \mathrm{C}$ in an ice-water bath and $35.5 \mathrm{mg}(0.546 \mathrm{mmol}, 2$ eq.) of $\mathrm{Zn}$ powder were added. Over the first $90 \mathrm{~min}$ of the reaction, 6 further 9-mg (0.5 eq.) aliquots of Zn were added every 15 min. After $90 \mathrm{~min}$, the reaction was closely monitored by TLC and ${ }^{1} \mathrm{H}-\mathrm{NMR}$. In a typical experiment, complete consumption of the starting material was observed after $255 \mathrm{~min}$. The reaction should be monitored frequently and quenched when complete consumption of $\mathrm{L}^{\mathrm{NO} 2}$ is observed, but before $\mathbf{L}^{\mathrm{NH} 2}$ starts to form. The reaction was then immediately filtered over Celite. The filtrate was washed twice with $15 \mathrm{~mL}$ of $0.5 \mathrm{M}$ EDTA, followed by distilled water and brine. The organic layer was dried over $\mathrm{MgSO}_{4}$, concentrated under reduced pressure, and dried under high-vacuum, yielding the product as a yellow-orange powder (up to 93\% yield). The product was stored under vacuum or inert gas. TLC: (stationary phase: $\mathrm{SiO}_{2}$, mobile phase: $\mathrm{DCM}: \mathrm{Et}_{3} \mathrm{~N}$ :hexanes $=5: 3: 2$ ) $\mathrm{R}_{\mathrm{f}}$ $\left(\mathrm{L}^{\mathrm{NO}}\right)=0.60, \mathrm{R}_{\mathrm{f}}\left(\mathrm{L}^{\mathrm{NHOH}}\right)=0.85, \mathrm{R}_{\mathrm{f}}\left(\mathrm{L}^{\mathrm{NH}}\right)=0.63 .{ }^{1} \mathrm{H} \mathrm{NMR}\left(\mathrm{CDCl}_{3}, 500 \mathrm{MHz}\right): \delta 8.90-9.50(\mathrm{~b}, 1 \mathrm{H}, \mathrm{OH}), 8.39(\mathrm{~d}, 1 \mathrm{H}$, $\left.\mathrm{H}_{\mathrm{Py}}\right), 7.79\left(\mathrm{~d}, 1 \mathrm{H}, \mathrm{H}_{\mathrm{Ar}}\right), 7.70(\mathrm{~b}, 1 \mathrm{H}, \mathrm{NH}), 7.42-7.52\left(\mathrm{~m}, 4 \mathrm{H}, 2 \mathrm{H}_{\mathrm{Py}} \& 2 \mathrm{H}_{\mathrm{Ar}}\right), 7.23\left(\mathrm{~d}, 2 \mathrm{H}, \mathrm{H}_{\mathrm{Py}}\right), 7.06\left(\mathrm{~m}, 2 \mathrm{H}, \mathrm{H}_{\mathrm{Py}}\right), 6.87$ $\left(\mathrm{t}, 1 \mathrm{H}, \mathrm{H}_{\mathrm{Ar}}\right), 4.59\left(\mathrm{~s}, 4 \mathrm{H}, \mathrm{H}_{\mathrm{CH}_{2}}\right)$. HRMS m/z $\left(\mathrm{MeOH}, \mathrm{ESI}^{+}\right)$calcd for $\left[\mathrm{C}_{18} \mathrm{H}_{18} \mathrm{~N}_{4} \mathrm{O}_{3} \mathrm{~S}\right] \mathrm{H}^{+} 371.12$, found $371.3(100 \%)$, calcd for $\left[\mathrm{C}_{18} \mathrm{H}_{18} \mathrm{~N}_{4} \mathrm{O}_{3} \mathrm{~S}\right] \mathrm{Na}^{+} 393.10$, found 393.2 (15\%).

$\mathbf{L}^{\mathrm{NH}_{2}}$ : As shown in Scheme S2, letting the reduction of $\mathbf{L}^{\mathrm{NO}_{2}}$ by heterogeneous zinc-mediated transfer hydrogenation from $\mathrm{NH}_{4} \mathrm{CO}_{2} \mathrm{H}$ for longer times affords $\mathrm{L}^{\mathrm{NH}_{2}}$. $126.1 \mathrm{mg} \mathrm{NH}_{4} \mathrm{CO}_{2} \mathrm{H}$ (2 mmol, 2 eq.) was dissolved in $1.5 \mathrm{~mL} \mathrm{MeOH}$ and added to a stirred solution of $384.4 \mathrm{mg} \mathrm{L} \mathrm{NO}_{2}(1 \mathrm{mmol}, 1 \mathrm{eq})$ in $1.5 \mathrm{~mL} \mathrm{DCM}$. To this mixture was added $130.8 \mathrm{mg}$ of $\mathrm{Zn}$ powder ( $2 \mathrm{mmol}, 2$ eq.). At 15-20 min intervals of the reaction, 10 further 0.5 eq. aliquots of $\mathrm{Zn}(32.7 \mathrm{mg}, 0.5 \mathrm{mmol}, 0.5 \mathrm{eq}$. each) were added to the reaction mixture. The mixture was left stirring at RT for $72 \mathrm{~h}$, at which point only $\mathrm{L}^{\mathrm{NH}_{2}}$ was observed by TLC. The reaction mixture was then filtered over Celite. The filtrate was then washed twice with $15 \mathrm{~mL} 0.5 \mathrm{M}$ EDTA, followed by distilled water and brine. The organic layer was then dried over $\mathrm{MgSO}_{4}$, concentrated under reduced pressure, and dried under highvacuum, yielding the product was a thick brown oil in $45 \%$ yield. 
Alternately, $\mathrm{L}^{\mathrm{NH}_{2}}$ can be obtained by standard hydrogenation. In a Parr shaker, $100 \mathrm{mg} \mathrm{Pd} / \mathrm{C}$ (10\% w/w) was added, followed by absolute ethanol $(30 \mathrm{~mL})$, followed by $385 \mathrm{mg} \mathrm{L}^{\mathrm{NO}_{2}}(1 \mathrm{mmol})$ dissolved in absolute ethanol $(10 \mathrm{~mL})$. The mixture was shaken under $30 \mathrm{psi}$ of $\mathrm{H}_{2}$ for $24 \mathrm{~h}$, at which point completion of the reduction was confirmed by TLC. The mixture was filtered over Celite, rinsed with ethanol, and the solvent was evaporated in vacuo, affording $\mathrm{L}^{\mathrm{NH}_{2}}$ as an thick, light-yellow oil (91\% yield).

${ }^{1} \mathrm{H}$ NMR $\left(\mathrm{CDCl}_{3}, 500 \mathrm{MHz}\right): \delta 8.40\left(\mathrm{qd}, 2 \mathrm{H}, \mathrm{H}_{\mathrm{Py}}\right), 7.67-7.71\left(\mathrm{dd}, 1 \mathrm{H}, \mathrm{H}_{\mathrm{Ar}}\right), 7.49-7.56\left(\mathrm{dt}, 2 \mathrm{H}, \mathrm{H}_{\mathrm{Ar}}\right), 7.25-7.30(\mathrm{~m}$, $\left.3 \mathrm{H}, 1 \mathrm{H}_{\mathrm{Ar}} \& 2 \mathrm{H}_{\mathrm{Py}}\right), 7.05-7.10\left(\mathrm{qd}, 2 \mathrm{H}, \mathrm{H}_{\mathrm{Py}}\right), 6.70-6.73\left(\mathrm{~m}, 2 \mathrm{H}, \mathrm{H}_{\mathrm{Py}}\right), 4.90-5.40\left(\mathrm{~b}, 2 \mathrm{H}, \mathrm{NH}_{2}\right), 4.64\left(\mathrm{~s}, 4 \mathrm{H}, \mathrm{H}_{\mathrm{CH} 2}\right)$. HRMS $\mathrm{m} / \mathrm{z}\left(\mathrm{MeOH}, \mathrm{ESI}^{+}\right)$cacld for $\left[\mathrm{C}_{18} \mathrm{H}_{18} \mathrm{~N}_{4} \mathrm{O}_{2} \mathrm{~S}\right] \mathrm{H}^{+} 355.12$, found 355.1 (100\%)

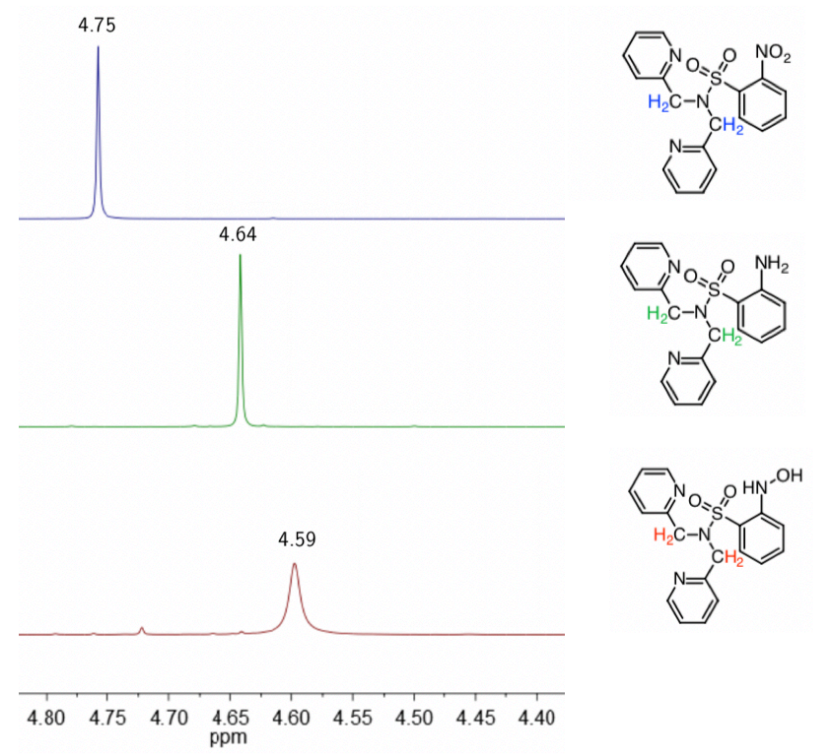

Figure S1. Diagnostic peaks for monitoring of reduction of $\mathrm{L}^{\mathrm{NO}_{2}}$ to $\mathrm{L}^{\mathrm{NHOH}}$ by ${ }^{1} \mathrm{H}-\mathrm{NMR}$. 


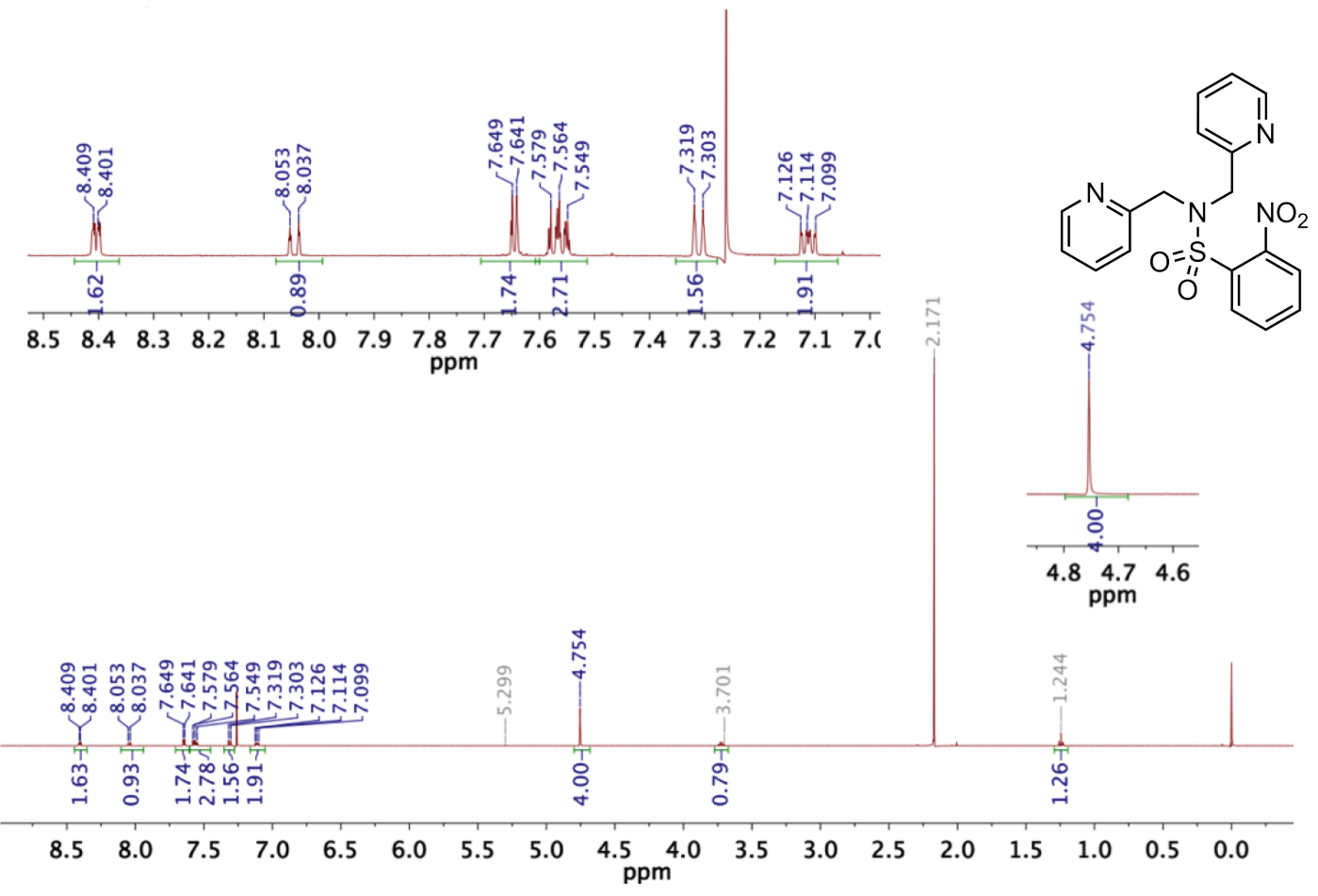

Figure S2. $500 \mathrm{MHz}{ }^{1} \mathrm{H}-\mathrm{NMR}$ of $\mathrm{L}^{\mathrm{NO}_{2}}$ in $\mathrm{CDCl}_{3}$, insets showing aromatic region and methylene.

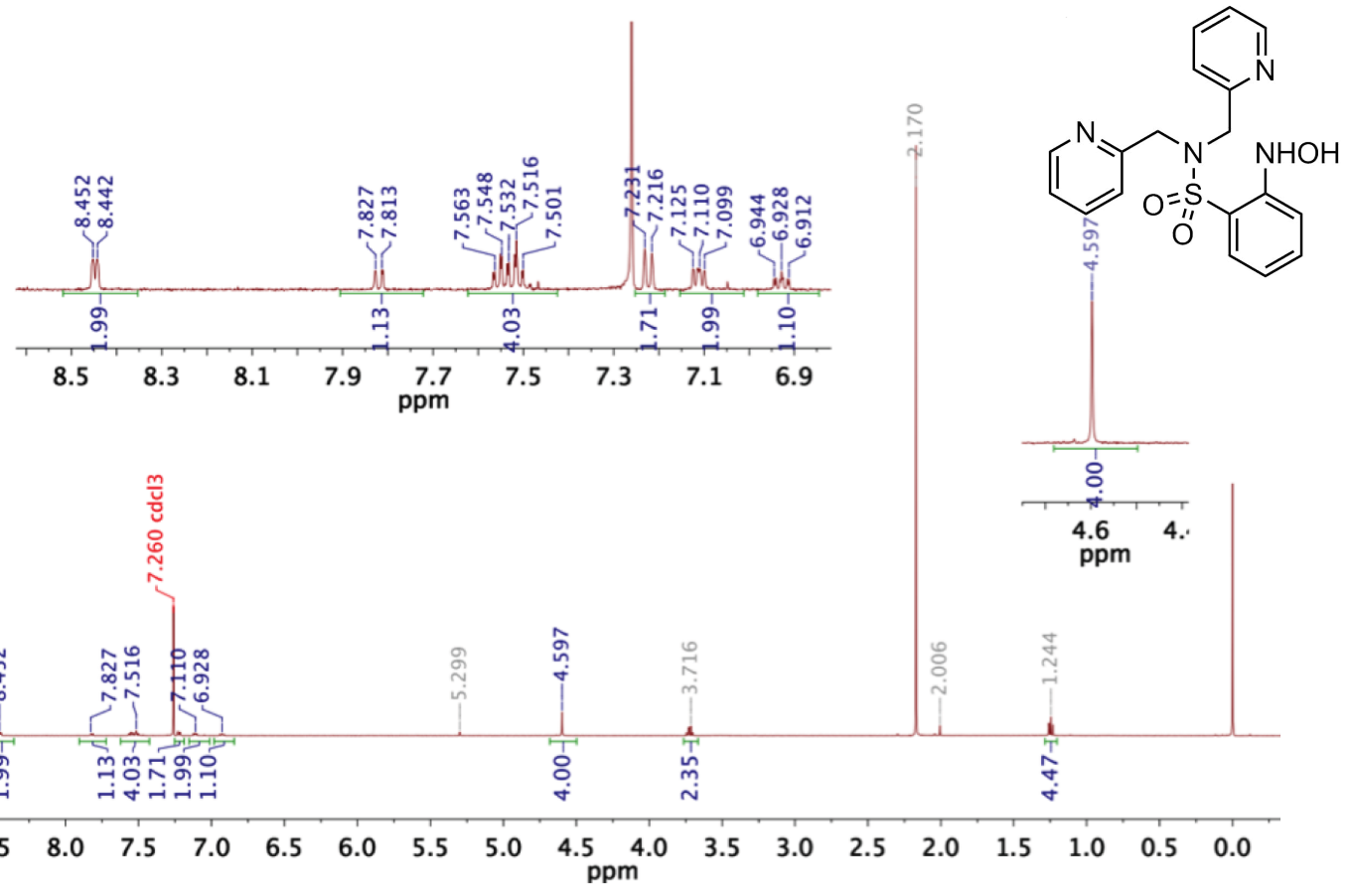

Figure S3. $500 \mathrm{MHz}{ }^{1} \mathrm{H}-\mathrm{NMR}$ of $\mathrm{L}^{\mathrm{NHOH}}$ in $\mathrm{CDCl}_{3}$, insets showing aromatic region and methylene. 


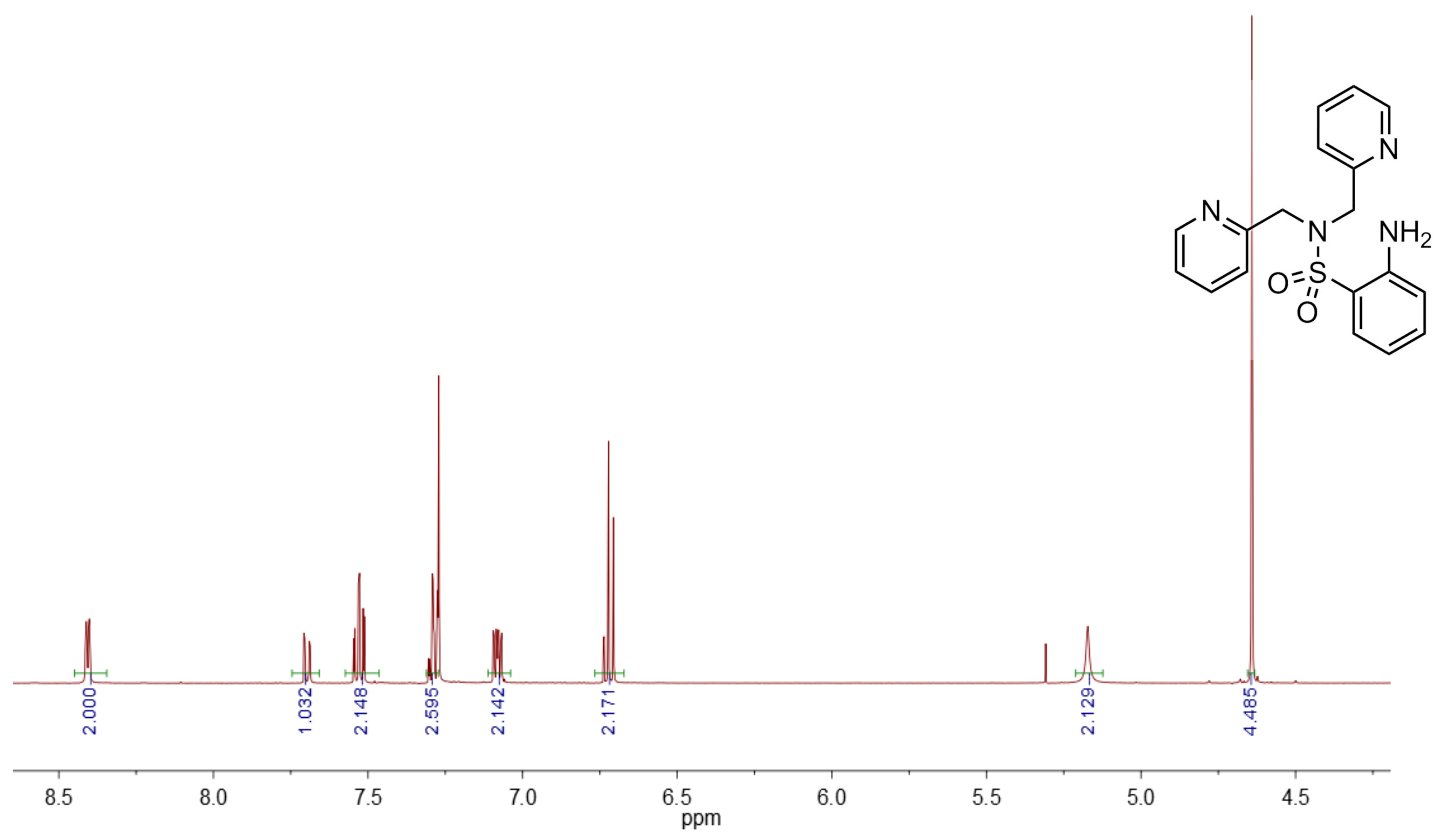

Figure S4. $500 \mathrm{MHz}{ }^{1} \mathrm{H}-\mathrm{NMR}$ of $\mathrm{L}^{\mathrm{NH}_{2}}$ in $\mathrm{CDCl}_{3}$, focusing on the aromatic and methylene regions.

\section{d) Complexation of $\mathrm{L}^{\mathrm{NHOH}}$ with $\left[\mathrm{Cu}^{\mathrm{I}}\left(\mathrm{CH}_{3} \mathrm{CN}\right)_{4}\right]^{+}$}

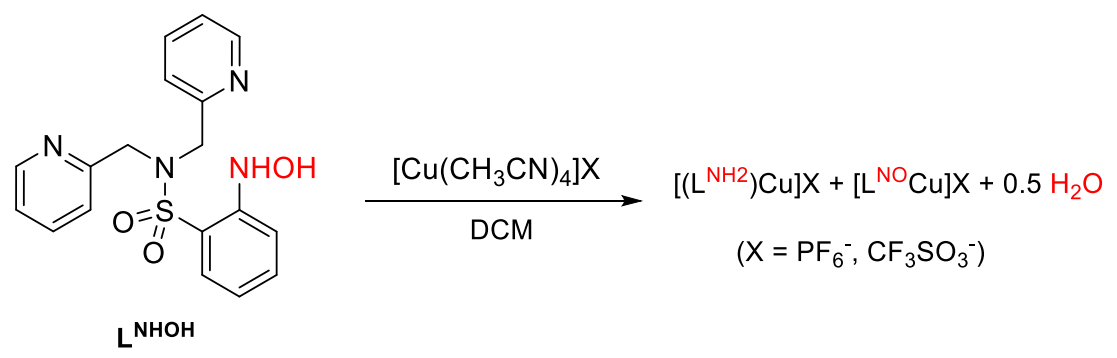

Scheme S3. Complexation of $\mathbf{L}^{\mathrm{NHOH}}$ with copper(I) tetrakis(acetonitrile) salts. 


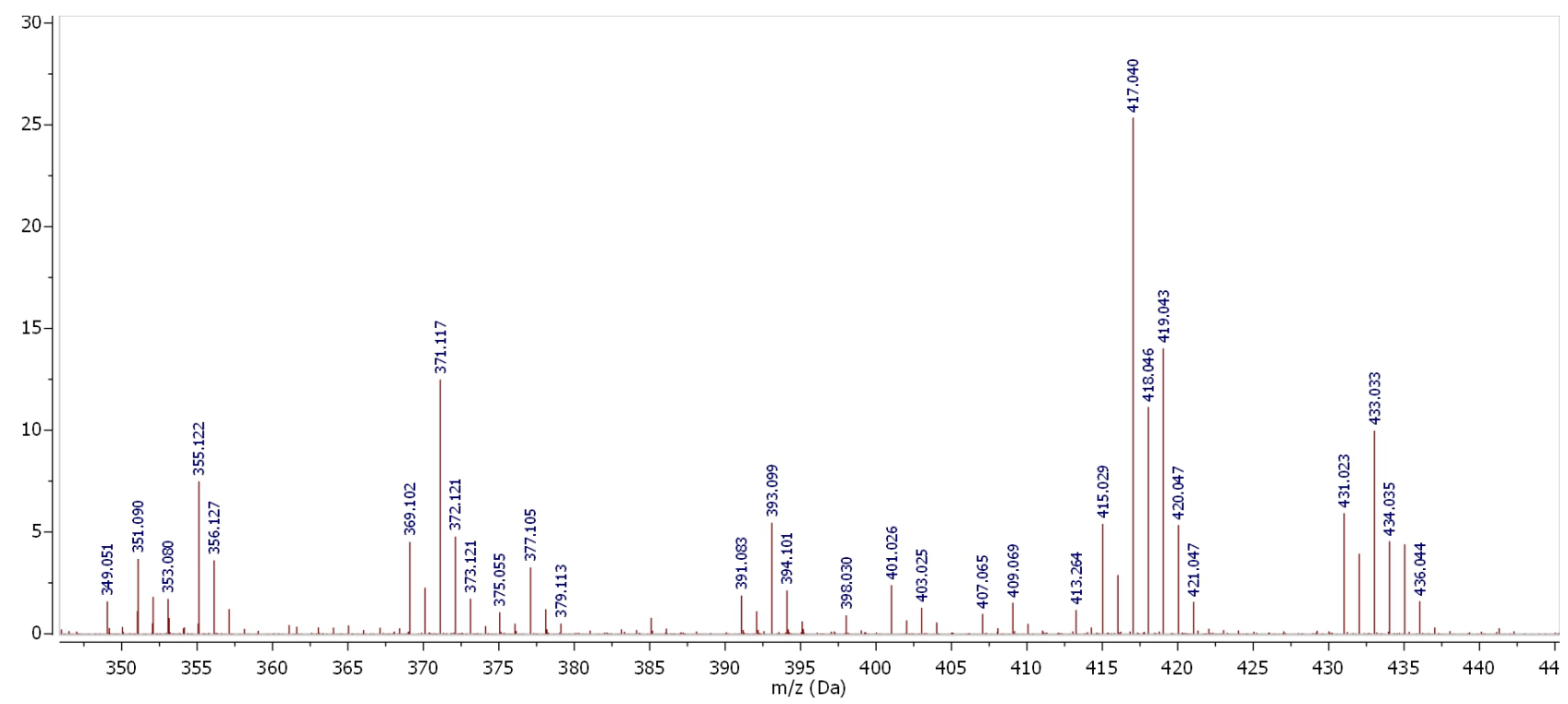

Figure S5. ESI-MS positive mode data for $\mathrm{L}^{\mathrm{NHOH}}+1$ equiv. of $\left[\mathrm{Cu}^{\prime}\left(\mathrm{CH}_{3} \mathrm{CN}\right)_{4}\right]\left(\mathrm{CF}_{3} \mathrm{SO}_{3}\right)$ reacted in $\mathrm{HPLC}$-grade DCM and diluted in HPLC-grade MeCN. The peak at 431.1 corresponds to $\left[\mathrm{L}^{\mathrm{NO}} \mathrm{Cu}\right]^{+} ; 417.01$ to $\left[\mathrm{L}^{\mathrm{NH}_{2}} \mathrm{Cu}\right]^{+}$, the peaks at 369.1 and 391.1 corresponds to $\left[\mathrm{L}^{\mathrm{NO}}\right] \mathrm{H}^{+}$and $\left[\mathrm{L}^{\mathrm{NO}}\right] \mathrm{Na}^{+}, 355.1$ and 377.1 corresponds to $\left[\mathrm{L}^{\mathrm{NH}_{2}}\right] \mathrm{H}^{+}$and $\left[\mathrm{L}^{\mathrm{NH}_{2}}\right] \mathrm{Na}^{+}$.

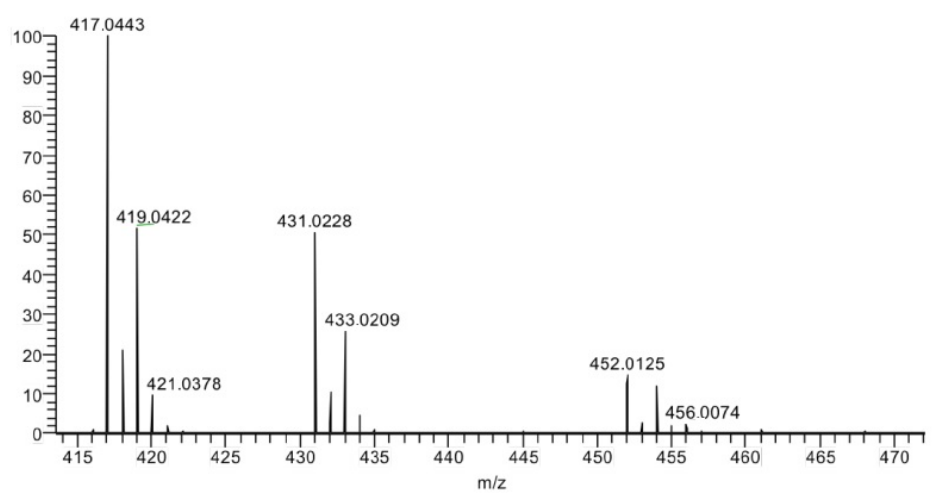

Figure S6. ESI-MS positive mode data for $\mathrm{L}^{\mathrm{NHOH}}+1$ equiv. of $\left[\mathrm{Cu}^{\prime}\left(\mathrm{CH}_{3} \mathrm{CN}\right)_{4}\right]\left(\mathrm{PF}_{6}\right)$ reacted in $\mathrm{HPLC}$ grade-DCM and diluted in HPLC-grade MeCN. The peak at 431.02 corresponds to $\left[\mathrm{L}^{\mathrm{NO}} \mathrm{Cu}\right]^{+} ; 417.04$ to $\left[\mathrm{L}^{\mathrm{NH}_{2}} \mathrm{Cu}\right]^{+}$.

\section{e) Synthesis and characterization of $\left[\left(\mathrm{L}^{\mathrm{NHOH}}\right) \mathrm{CuCl}\right](1)$}

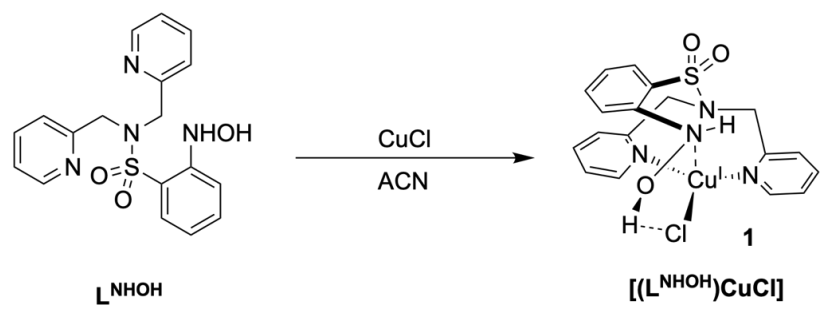

Scheme S4. Synthesis of $\left[\left(\mathrm{L}^{\mathrm{NHOH}}\right) \mathrm{CuCl}\right](1)$ from $\mathrm{L}^{\mathrm{NHOH}}$. 
[( $\left.\left.{ }^{\mathrm{NHOH}}\right) \mathrm{CuCl}\right](1)$ : In the $\mathrm{N}_{2}$ glovebox, $10.0 \mathrm{mg} \mathrm{CuCl}(0.101 \mathrm{mmol})$ was suspended in $400 \mu \mathrm{L}$ of dry ACN and stirred. To this suspension, $37.5 \mathrm{mg}$ of $\mathrm{L}^{\mathrm{NHOH}}(0.101 \mathrm{mmol}, 1$ eq.) dissolved in $600 \mu \mathrm{L}$ was added, leading to immediate formation of a bright yellow precipitate. The mixture was allowed to stir for another $15 \mathrm{~min}$, then $500 \mu \mathrm{L}$ of dry diethyl ether was added dropwise to the reaction mixture until the solution lost its yellow color. The bright yellow powder was filtered over a fritted funnel, then washed with pentane, dried and collected (75\%). ${ }^{1} \mathrm{H}$ NMR $\left(\mathrm{CD}_{3} \mathrm{CN}, 500 \mathrm{MHz}\right.$, assigned with COSY): $\delta 8.60-8.61\left(\mathrm{~d}, 2 \mathrm{H}, \mathrm{H}_{\mathrm{Py}}\right), 8.49\left(\mathrm{~s}, \mathrm{br} .1 \mathrm{H}, \mathrm{OH}_{\mathrm{NHOH}}\right), 8.04(\mathrm{~s}$, br. $\left.1 \mathrm{H}, \mathrm{NH}_{\mathrm{NHOH}}\right), 7.67-7.71\left(\mathrm{t}, 2 \mathrm{H}, \mathrm{H}_{\mathrm{Py}}\right), 7.60-7.61\left(\mathrm{~d}, 1 \mathrm{H}, \mathrm{H}_{\mathrm{Ar}}\right), 7.38-7.43\left(\mathrm{t}, 1 \mathrm{H}, \mathrm{H}_{\mathrm{Ar}}\right), 7.21-7.25\left(\mathrm{~m}, 4 \mathrm{H}, \mathrm{H}_{\mathrm{Py}}\right), 6.81-$ $6.84\left(\mathrm{t}, 1 \mathrm{H}, \mathrm{H}_{\mathrm{Ar}}\right), 4.55\left(\mathrm{~s}, 4 \mathrm{H}, \mathrm{H}_{\mathrm{CH} 2}\right)$.

Crystallization of [( $\left.\left.\mathrm{L}^{\mathrm{NHOH}}\right) \mathrm{CuCl}\right]$ : Crystals of 1 can be grown by slow vapor diffusion of pentane into a DCM solution of 1 at room temperature. However, this procedure yields very thin needles from which it is difficult to obtain a good dataset at the X-ray diffractometer. Alternatively, crystals of $\mathbf{1}$ can be formed by addition of a solution of $\mathrm{L}^{\mathrm{NHOH}}$ in $\mathrm{ACN}$ directly to $\mathrm{CuCl}_{(\mathrm{s})}$, followed by brief swirling $(5 \mathrm{~s})$ and immediate transfer to the $-30^{\circ} \mathrm{C}$ freezer. This procedure led to formation of crystals suitable for X-ray diffraction in the form of bright yellow needles after $24 \mathrm{~h}$.

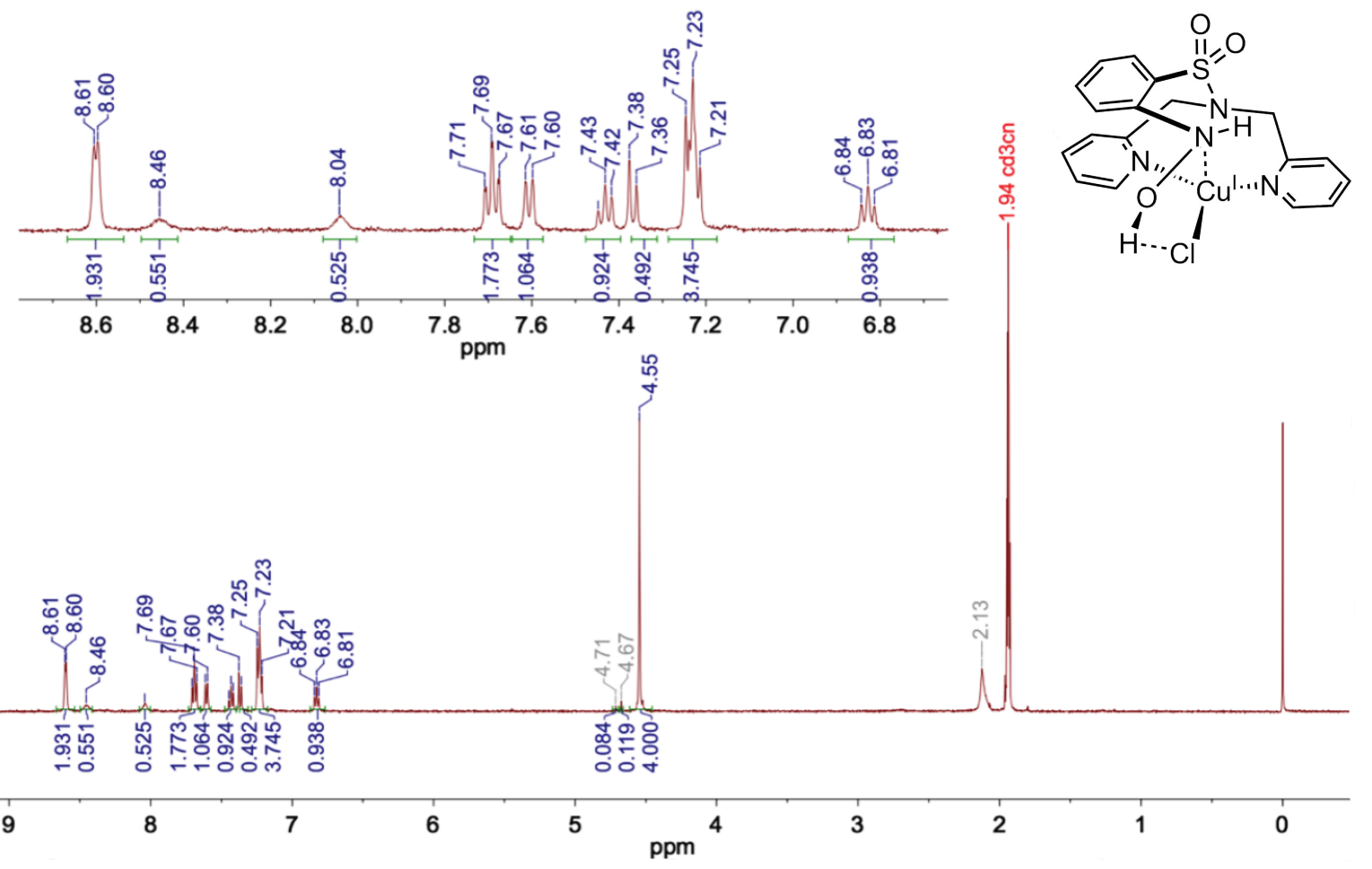

Figure S7. $500 \mathrm{MHz}{ }^{1} \mathrm{H}-\mathrm{NMR}$ of 1 in $\mathrm{CD}_{3} \mathrm{CN}$ (where it is sparingly soluble), inset showing zoom of aromatic region. 


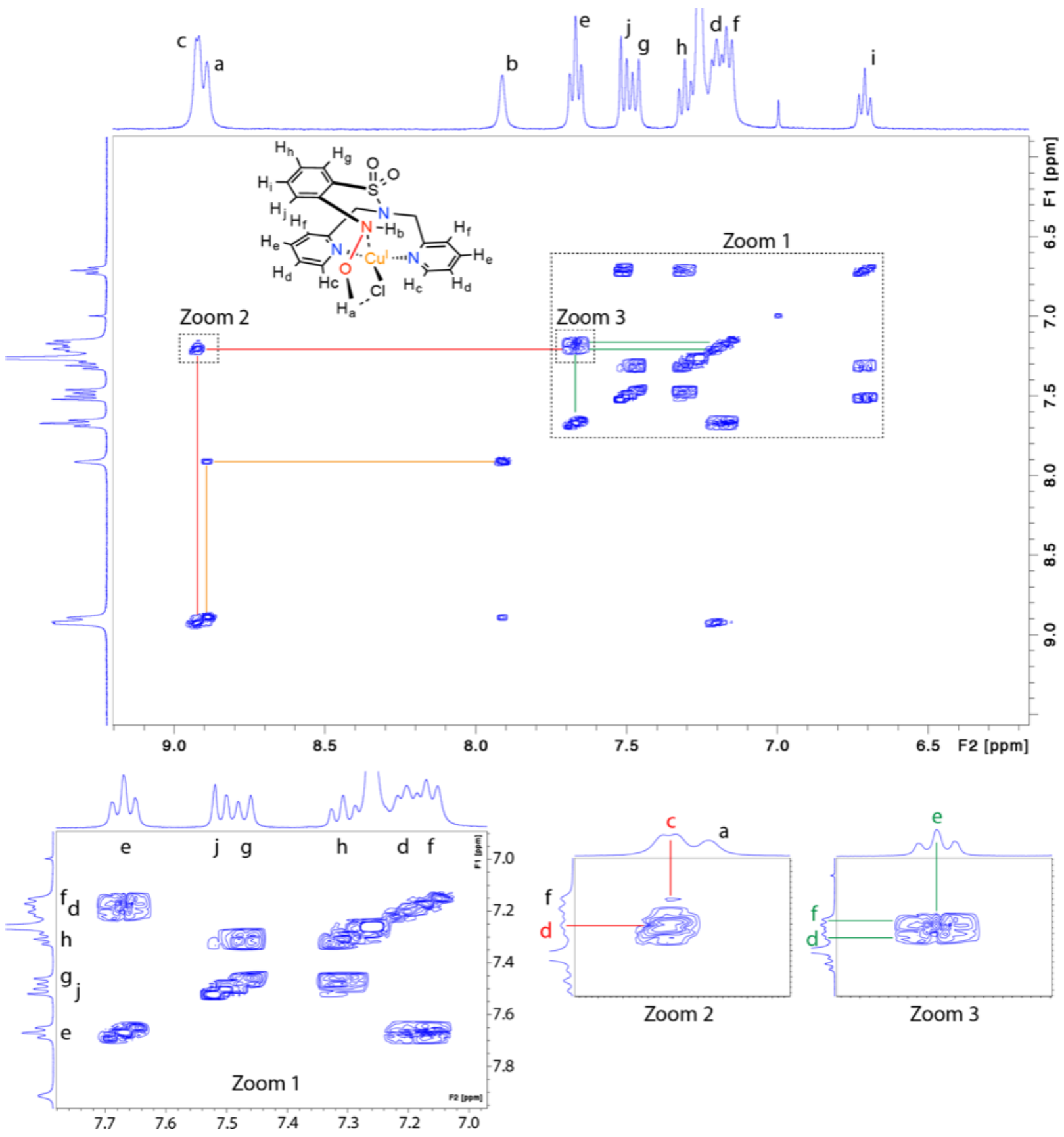

Figure S8. ${ }^{1} \mathrm{H}-\mathrm{NMR}$ COSY experiment for $1, \mathrm{CDCl}_{3}, 25^{\circ} \mathrm{C}$, showing the magnetic coupling topology.

\section{f) Synthesis and characterization of $\left[\left(\mathrm{L}^{\mathrm{NH}_{2}}\right) \mathrm{CuCl}\right]_{2}$ and $\left[\left(\mathrm{L}^{\mathrm{NO}_{2}}\right) \mathrm{CuCl}\right]_{2}$}

For comparison with 1, we also investigated the structure of the $\mathrm{Cu}^{\prime} \mathrm{Cl}$ complexes of the reduced or oxidized forms of the ligand, $\mathbf{L}^{\mathrm{NH}_{2}}$ and $\mathbf{L}^{\mathrm{NO}_{2}}$, therefore the complexations shown in Scheme $\mathbf{S 5}$ were carried out and their products were crystallized for X-ray diffraction analysis. 


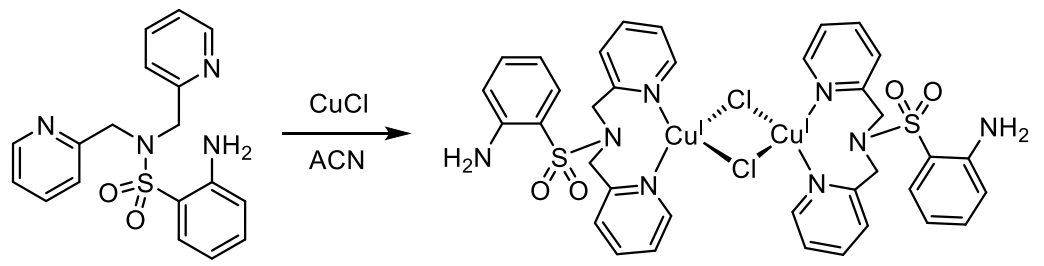

L $^{\mathrm{NH} 2}$

$\left[\left(\mathrm{L}^{\mathrm{NH}}\right) \mathrm{CuCl}_{2}\right.$

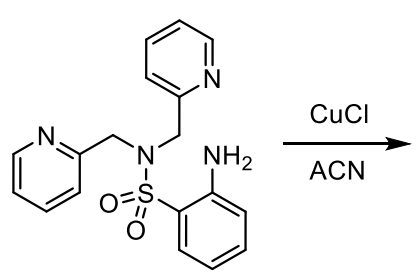

L NO2 $^{\text {No }}$

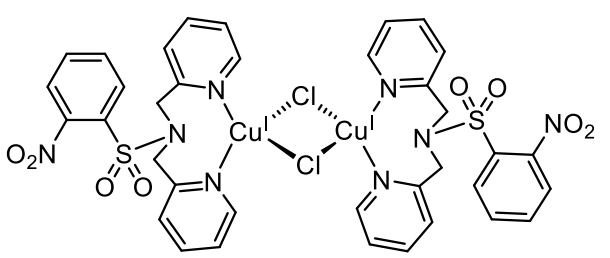

$\left[\left(\mathrm{L}^{\mathrm{NO} 2}\right) \mathrm{CuCl}_{2}\right.$

Scheme S5. Synthesis of $\left[\left(\mathrm{L}^{\mathrm{NH} 2}\right) \mathrm{CuCl}\right]_{2}$ from $\mathrm{L}^{\mathrm{NH} 2}$ (top) and of $\left[\left(\mathrm{L}^{\mathrm{NO} 2}\right) \mathrm{CuCl}\right]_{2}$ from $\mathrm{L}^{\mathrm{NO} 2}$ (bottom).

[( $\left.\left.\mathrm{L}^{\mathrm{NH}_{2}}\right) \mathrm{CuCl}\right]:$ In the $\mathrm{N}_{2}$ glovebox, $10.0 \mathrm{mg} \mathrm{L}^{\mathrm{NH}_{2}}$ dissolved in $2.0 \mathrm{~mL} \mathrm{ACN}$ was slowly added to a slurry of $2.8 \mathrm{mg}$ ( $0.028 \mathrm{mmol}, 1$ eq.) $\mathrm{Cu} \mathrm{Cl}^{\prime}$ in a few drops of $\mathrm{ACN}$, yielding a light green solution. The solution was layered with $\mathrm{Et}_{2} \mathrm{O}$ followed by a few drops of pentane and transferred to the $-30^{\circ} \mathrm{C}$ glovebox freezer. After 1 week, crystalline plates had grown. These crystals were used for X-ray diffraction analysis.

[( $\left.\left.\mathrm{L}^{\mathrm{NO}_{2}}\right) \mathrm{CuCl}\right]$ : In the $\mathrm{N}_{2}$ glovebox, $9.4 \mathrm{mg} \mathrm{L} \mathrm{NO}^{\mathrm{NO}_{2}}$ dissolved in $1.0 \mathrm{~mL} \mathrm{ACN}$ was slowly added to a slurry of $2.4 \mathrm{mg}$ ( $0.024 \mathrm{mmol}, 1$ eq.) $\mathrm{Cu}^{\prime} \mathrm{Cl}$ in a few drops of $\mathrm{ACN}$, yielding a light yellow solution. The solution was layered with $\mathrm{Et}_{2} \mathrm{O}$ followed by a few drops of pentane and transferred to the $-30^{\circ} \mathrm{C}$ glovebox freezer. After ca. $24 \mathrm{~h}$, polycrystalline urchins not suitable for X-ray diffraction had grown. These crystals were redissolved in $2 \mathrm{~mL} \mathrm{ACN}$ and $\mathrm{Et}_{2} \mathrm{O}$ was added dropwise until the saturation. The saturated solution was then transferred to the $-30^{\circ} \mathrm{C}$ glovebox freezer. After 1 week, large, high -uality needles were obtained. These crystals were used for X-ray diffraction analysis.

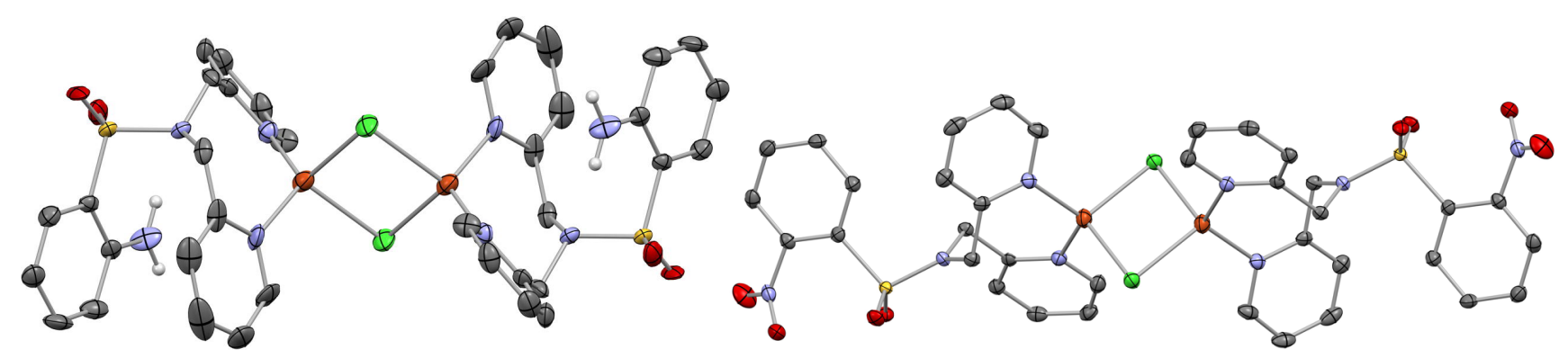

Figure S9. ORTEP at $50 \%$ ellipsoid probability of $\left[\left(\mathrm{L}^{\mathrm{NH}}\right) \mathrm{CuCl}\right]_{2}$ (left) and $\left[\left(\mathrm{L}^{\mathrm{NO}}\right) \mathrm{CuCl}\right]_{2}$ (right). Crystallization solvents and hydrogen atoms were removed for clarity, except on the $\mathrm{NH}_{2}$ groups. 
2. Oxidation of $\left[\left(\mathrm{L}^{\mathrm{NHOH}}\right) \mathrm{CuCl}\right]$ with DEAD/DIAD
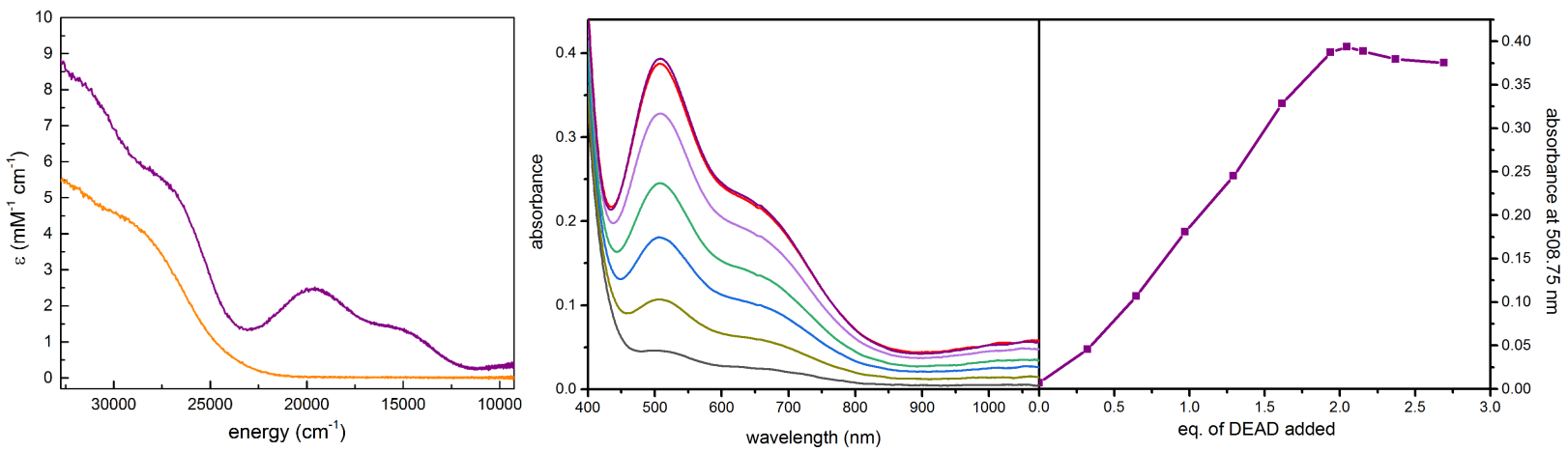

Figure S10. (Left) Comparison of the UV-Vis spectra of $\left[\left(\mathrm{L}^{\mathrm{NHOH}}\right) \mathrm{CuCl}\right]$ (yellow) and $\left[\left(\mathrm{L}^{\mathrm{NO}}\right) \mathrm{CuCl}\right]$ (purple). (Right) Titration of a $1.69 \mathrm{mM}$ solution of 1 with $0-2.5$ equiv. DEAD in DCM (pathlength $1.0 \mathrm{~mm}, 25^{\circ} \mathrm{C}$ ), showing in situ formation of 2 and the absorbance profile at $508 \mathrm{~nm}$.
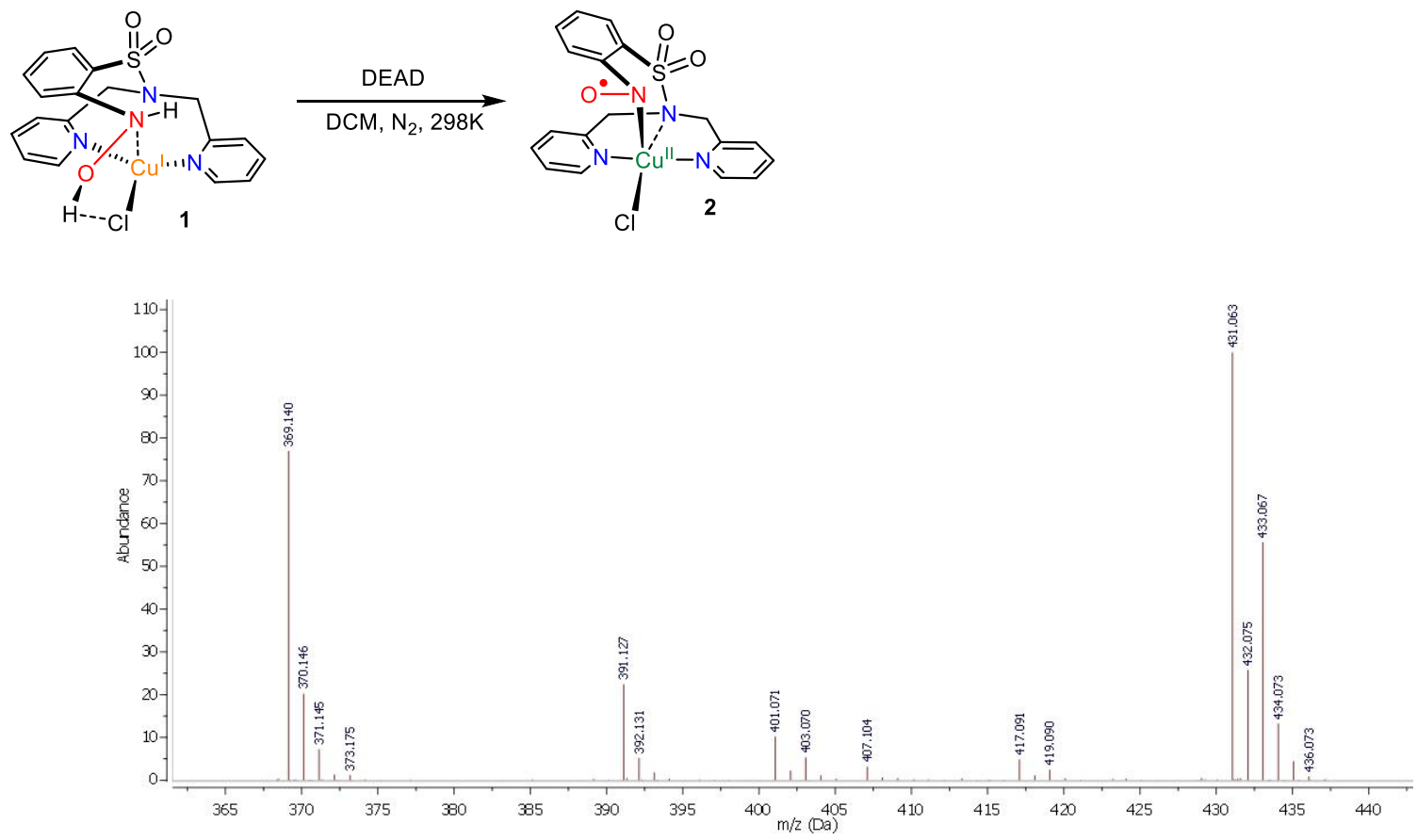

Figure S11. ESI-MS positive mode data for $\left[\mathrm{L}^{\mathrm{NHOH}} \mathrm{CuCl}\right]+2$ eq. of $D E A D$ in $\mathrm{MeCN}$. The peak at 431.1 corresponds to $\left[\mathrm{L}^{\mathrm{NO}} \mathrm{Cu}\right]^{+}$; peaks at 391.1 and 369.1 correspond to $\left[\mathrm{L}^{\mathrm{NO}}\right] \mathrm{Na}^{+}$and $\left[\mathrm{L}^{\mathrm{NO}}\right] \mathrm{H}^{+}$, respectively.

S12 


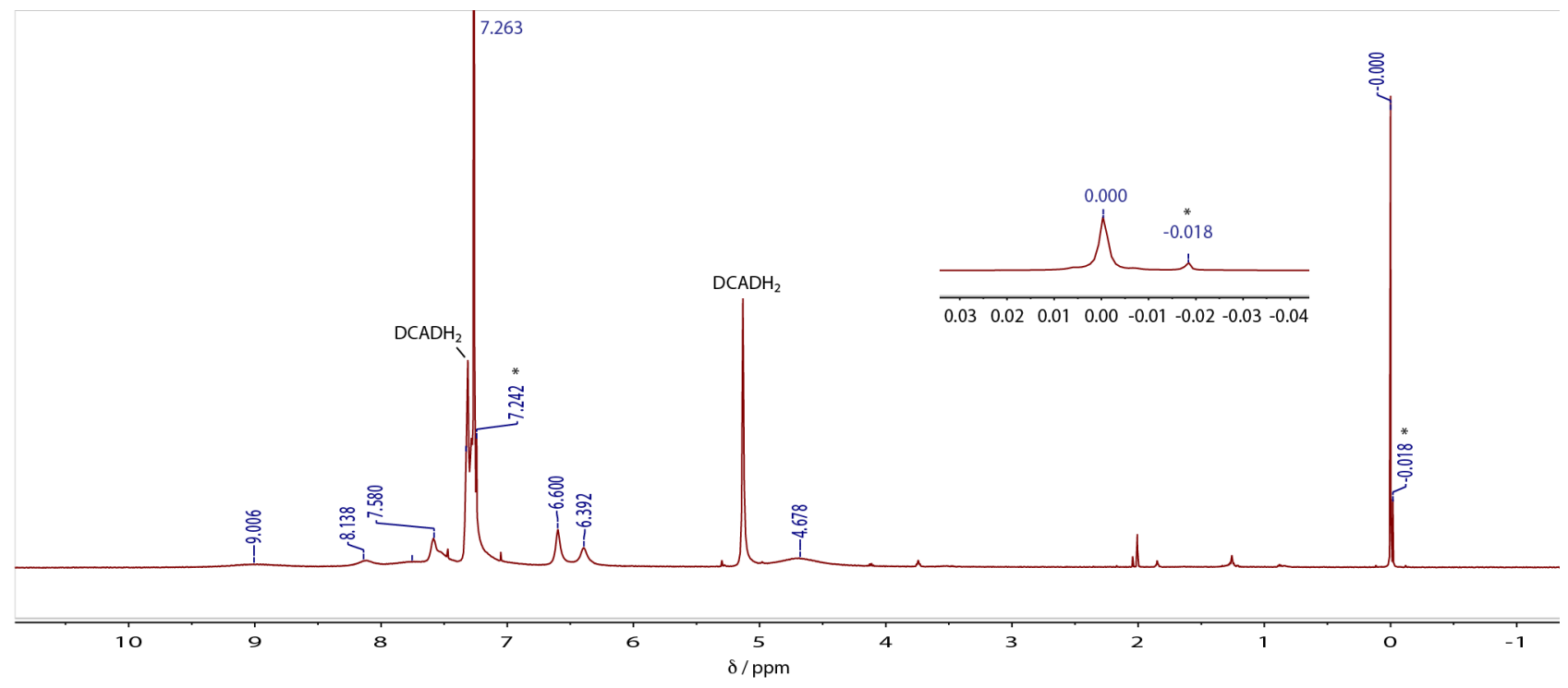

Figure S12. Evans ${ }^{1} \mathrm{H}-\mathrm{NMR}$ of a $20.0 \mathrm{mM} \mathrm{CDCl}$ solution of 2 prepared by oxidation of 1 with DCAD (di-(4cholorbenzyl)azodicarboxylate), at $25^{\circ} \mathrm{C}$. Inset: zoom of the TMS region. The * symbols indicate signals from the Evans capillary tube $\left(\mathrm{CHCl}_{3}\right.$ at 7.263 and TMS at $\left.-0.018 \mathrm{ppm}\right)$. Using $\chi_{M}^{\text {dia }}=201 \times 10^{-6} \mathrm{emu} \mathrm{mol}^{-1}$ for the diamagnetic correction, the $0.018 \mathrm{ppm}$ paramagnetic shift converts into $\chi_{M}=440 \times 10^{-6} \mathrm{emu} \mathrm{mol}^{-1}$, hence $\chi_{M} T=$ 0.13 emu K mol${ }^{-1}$.

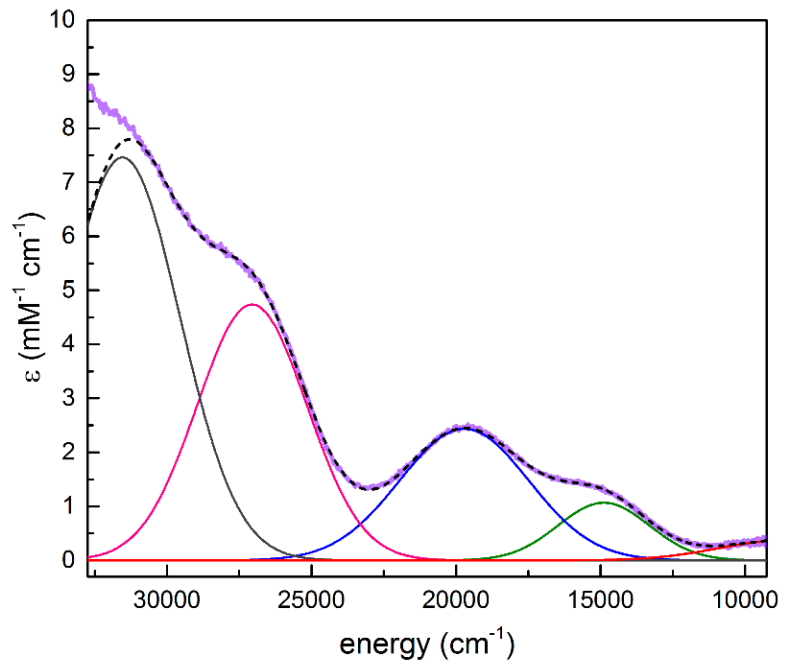

Figure S13. A Gaussian deconvolution of the UV-Vis spectrum of $\left[\left(\mathrm{L}^{\mathrm{NO}}\right) \mathrm{CuCl}\right]$ made by addition of 2 eq. of DEAD.

Table S1. Fit parameters for Gaussian deconvolution shown above.

\begin{tabular}{lll}
\hline Energy $\left(\mathrm{cm}^{-1}\right)$ & $\begin{array}{l}\text { peak width at } \\
\text { half-maximum }\left(\mathrm{cm}^{-1}\right)\end{array}$ & $\begin{array}{l}\text { Peak amplitude } \\
\left(\varepsilon\left(\mathrm{mM}^{-1} \mathrm{~cm}^{-1}\right)\right)\end{array}$ \\
\hline 8600 & 4660 & 0.38 \\
14900 & 3160 & 1.1 \\
19700 & 4470 & 2.4 \\
27000 & 3800 & 4.7 \\
31500 & 3970 & 7.4 \\
\hline
\end{tabular}




\section{Mechanochemically-induced disproportionation of $\left[\left(\mathrm{L}^{\mathrm{NHOH}}\right) \mathrm{CuCl}\right]$}

The mechanochemically-induced disproportionation of $\mathrm{L}^{\mathrm{NHOH}} \mathrm{CuCl}(\mathbf{1})$ to amine and nitroso derivatives

performed by adding $20 \mathrm{mg}$ of microcrystalline sample of $\mathrm{L}^{\mathrm{NHOH}} \mathrm{CuCl}$ in small plastic jar with one zirconia ball inside the glovebox under nitrogen atmosphere. The jar then sealed and token out and placed on vibratory ball miller and ground at $30 \mathrm{~Hz}$ for $15 \mathrm{~min}$. After that the jar transferred inside back to the glovebox. The resulting fine purple powder has been dissolved in oxygen free anhydrous MeCN and directly injected to the ESI-QTOF Mass Spectrometer to analyze the products. The same transformation has been observed by taking the 1:1 mixture of $\mathrm{L}^{\mathrm{NHOH}}$ and $\mathrm{CuCl}$ with total mass of $20 \mathrm{mg}$ and grinding in the exact same condition. Both ways ended up giving the same MS profile which suggests the complexation and disproportionation transformation can happen in one pot under mechanical solid-state grinding condition. 

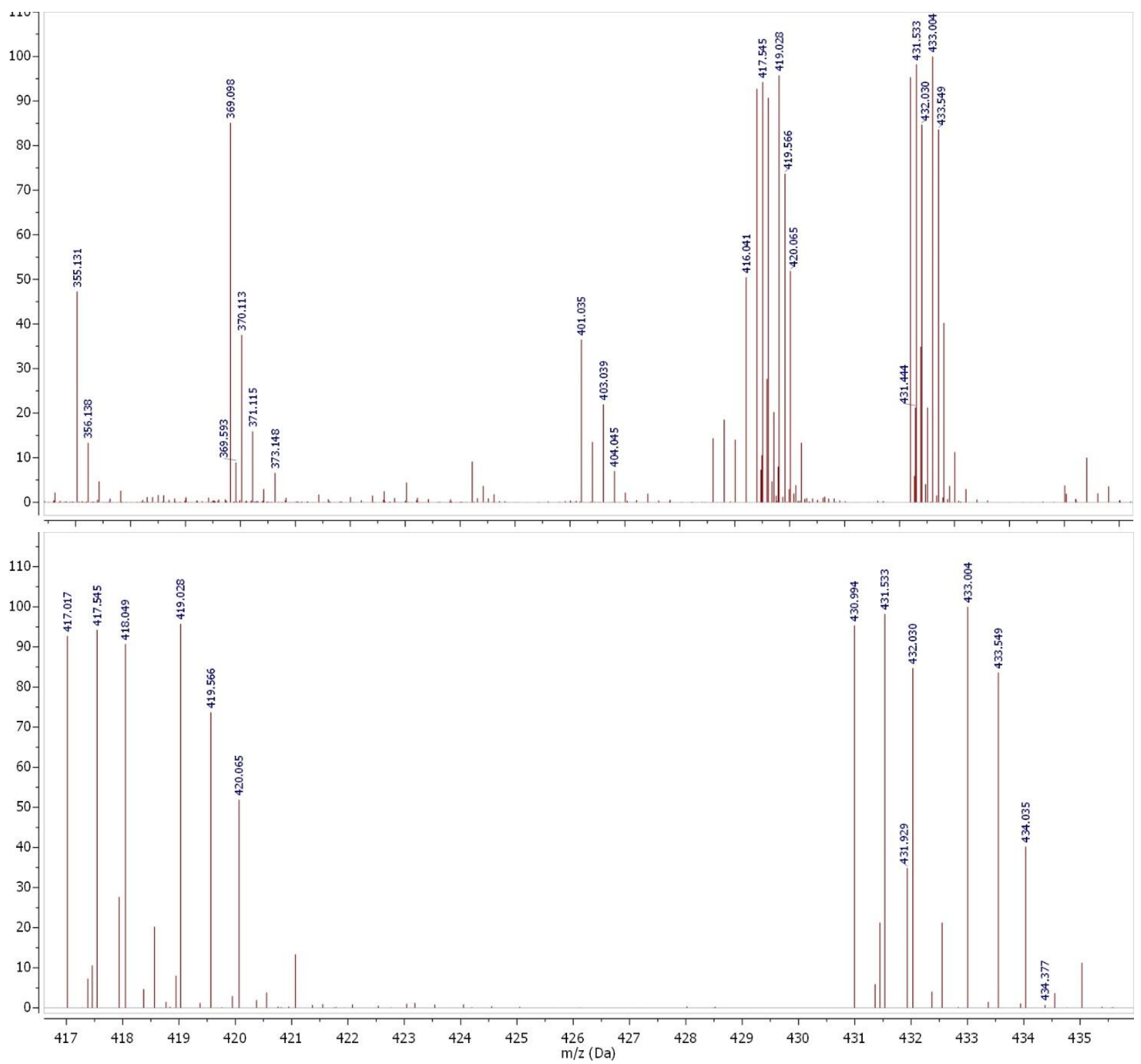

Figure S14. ESI-MS data for $\mathrm{L}^{\mathrm{NHOH}} \mathrm{CuCl}+$ ground in plastic jar with zirconia ball under $\mathrm{N}_{2}$ at $30 \mathrm{~Hz}$ for 15 minutes. The peak at 431.1 corresponds to $\left[\mathrm{L}^{\mathrm{NO}} \mathrm{Cu}\right]^{+}, 417.01$ to $\left[\mathrm{L}^{\mathrm{NH} 2} \mathrm{Cu}\right]^{+}$, the peak at 369.1 corresponds to $\left[\mathrm{L}^{\mathrm{NO}}\right] \mathrm{H}^{+}$and 355.1 to $\left[\mathrm{L}^{\mathrm{NH}}{ }^{2} \mathrm{H}^{+}\right.$.

\section{Benzyl alcohol oxidation catalysis}

Along with syringes of substrate, which must be stored under $\mathrm{N}_{2}$ in order to ensure proper control, $50 \mathrm{~mL}$ Radley ${ }^{\circledR}$ tubes were charged with $5 \mathrm{~mL}$ solutions of catalyst and base (if solid) in the $\mathrm{N}_{2}$ environment of the GB and capped. A Radley ${ }^{\circledast}$ temperature controlled carrousel was heated to $50^{\circ} \mathrm{C}$ and the tubes were inserted, with magnetic stirring. The tubes were purged with $\mathrm{O}_{2}\left(+1 \mathrm{~atm}\right.$ from atmosphere $=2 \mathrm{~atm}$ total) and the $\left[\mathrm{L}^{\mathrm{NHOH}} \mathrm{CuCl}\right]$ complex was allowed to pre-oxidize for 1 minute in THF as solvent, until the solutions turned dark purple, at which point substrates were injected through the septum, followed by the base (if liquid). The reaction was monitored by taking $0.10 \mathrm{~mL}$ samples using a long-needled syringe. The samples were passed over $\mathrm{SiO}_{2} \mathrm{micro}$ 
columns (in a Pasteur pipettes), followed by $0.90 \mathrm{~mL} \mathrm{HPLC}$-grade $\mathrm{MeOH}$. The resulting $\mathrm{MeOH}$-diluted reaction mixture samples were put in GC vials and injected into the GC-FID. The retention times for starting material and product were confirmed by injection of sample including mixture of benzyl alcohol and benzaldehyde from commercial bottles. The following table includes the reaction conditions and their corresponding conversion yields in percentage obtained by the standard method.

Base selection and concentration, solvent, and temperature were varied amongst $\mathrm{K}_{2} \mathrm{CO}_{3}, \mathrm{Cs}_{2} \mathrm{CO}_{3}, \mathrm{Et}_{3} \mathrm{~N}$, and $t$-BuOK, DCM and THF, and $25^{\circ} \mathrm{C}$ and $50^{\circ} \mathrm{C}$, but only two conclusive, fully controlled experiments are reported herein, with reaction conditions shown in Table S2. Two sets of control experiments have been performed to make sure the catalysis in due to the presence of redox active $\mathrm{L}^{\mathrm{NHOH}}$ moiety in the vicinity of copper center. Control experiments were performed in same reaction conditions but only either in absence of any copper complex or in presence of $\mathrm{L}^{\mathrm{NO} 2} \mathrm{CuCl}$ instead of $\mathrm{L}^{\mathrm{NHOH}} \mathrm{CuCl}$. In both cases $0 \%$ conversion were obtained.

Table S2. Aerobic oxidation of benzyl alcohol ${ }^{a}$

\begin{tabular}{|c|c|c|c|c|}
\hline Run & Copper complex & Base & Time (minutes) & Conversion \\
\hline \multirow[t]{3}{*}{1} & $\mathrm{~L}^{\mathrm{NHOH}} \mathrm{CuCl}(\mathbf{1})$ & $\mathrm{Et}_{3} \mathrm{~N}$ (1 eq.) & 50 & 20 \\
\hline & $\mathrm{L}^{\mathrm{NHOH}} \mathrm{CuCl}(\mathbf{1})$ & $\mathrm{Et}_{3} \mathrm{~N}$ (1 eq.) & 140 & 60 \\
\hline & $\mathrm{L}^{\mathrm{NHOH}} \mathrm{CuCl}(\mathbf{1})$ & $\mathrm{Et}_{3} \mathrm{~N}$ (1 eq.) & 200 & 70 \\
\hline \multirow[t]{3}{*}{2} & $\mathrm{~L}^{\mathrm{NHOH}} \mathrm{CuCl}(\mathbf{1})$ & $\mathrm{K}_{2} \mathrm{CO}_{3}$ (2 eq.) & 50 & 40 \\
\hline & $\mathrm{L}^{\mathrm{NHOH}} \mathrm{CuCl}(\mathbf{1})$ & $\mathrm{K}_{2} \mathrm{CO}_{3}$ (2 eq.) & 140 & 40 \\
\hline & $\mathrm{L}^{\mathrm{NHOH}} \mathrm{CuCl}(\mathbf{1})$ & $\mathrm{K}_{2} \mathrm{CO}_{3}$ (2 eq.) & 200 & 40 \\
\hline 3 & $\mathrm{~L}^{\mathrm{NO}_{2}} \mathrm{CuCl}$ & $\mathrm{Et}_{3} \mathrm{~N}$ (1 eq.) & 200 & 0 \\
\hline 4 & $\mathrm{~L}^{\mathrm{NO}_{2}} \mathrm{CuCl}$ & $\mathrm{K}_{2} \mathrm{CO}_{3}$ (2 eq.) & 200 & 0 \\
\hline 5 & No complex added & $\mathrm{Et}_{3} \mathrm{~N}$ (1 eq.) & 200 & 0 \\
\hline 6 & No complex added & $\mathrm{K}_{2} \mathrm{CO}_{3}$ (2 eq.) & 200 & 0 \\
\hline
\end{tabular}

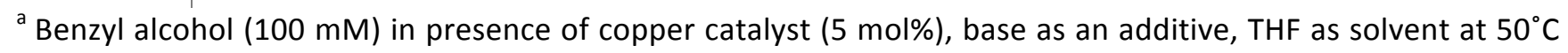
under $\mathrm{O}_{2}(2 \mathrm{~atm})$. Pre-oxidation time for copper catalyst for all the runs is $1 \mathrm{~min}$. Conversions obtained by analyzing samples with GC-FID. 


\section{Crystallographic data}

Table S3. Crystallographic data for 1, 3, 4, $\left[\mathrm{LH}^{\mathrm{NH}} \mathrm{CuCl}\right]_{2}$ and $\left[\mathrm{L}^{\mathrm{NO}}{ }^{2} \mathrm{CuCl}\right]_{2}$.

\begin{tabular}{|c|c|c|c|c|c|}
\hline & 1 & 3 & $4^{a}$ & {$\left[\mathrm{~L}^{\mathrm{NH}_{2}} \mathrm{CuCl}\right]_{2}$} & {$\left[\mathrm{~L}^{\mathrm{NO}_{2}} \mathrm{CuCl}\right]_{2}$} \\
\hline CCDC number & 1962820 & 1962821 & 1962822 & 1962858 & 1962859 \\
\hline Formula & $\begin{array}{l}\mathrm{C}_{18} \mathrm{H}_{18} \mathrm{ClCuN}_{4} \mathrm{O}_{3} \mathrm{~S} \cdot \mathrm{C}_{2} \\
\mathrm{H}_{3} \mathrm{~N}\end{array}$ & $\begin{array}{l}\mathrm{C}_{18} \mathrm{H}_{16} \mathrm{Cl}_{1.119} \mathrm{CuN}_{3.881} \mathrm{O} \\
{ }_{2.881} \mathrm{~S}\end{array}$ & $\begin{array}{l}\mathrm{C}_{100} \mathrm{H}_{57} \mathrm{~B}_{2} \mathrm{Cu}_{2} \mathrm{~F}_{48} \mathrm{~N}_{8} \\
\mathrm{O}_{5} \mathrm{~S}_{2}\end{array}$ & $\begin{array}{l}\mathrm{C}_{19} \mathrm{H}_{19} \mathrm{Cl}_{4} \mathrm{CuN}_{4} \mathrm{O}_{2} \\
\mathrm{~S}\end{array}$ & $\begin{array}{l}\mathrm{C}_{18} \mathrm{H}_{16} \mathrm{ClCuN}_{4} \mathrm{O}_{4} \\
\mathrm{~S}\end{array}$ \\
\hline Formula Weight & 510.47 & 467.40 & 2575.35 & 572.78 & 483.40 \\
\hline$T / \mathrm{K}$ & $150(2)$ & $150(2)$ & $100(2)$ & $150(2)$ & $150(2)$ \\
\hline Wavelength/Å & $1.54178(\mathrm{Cu} \mathrm{K \alpha})$ & $1.54178(\mathrm{Cu} \mathrm{K \alpha})$ & 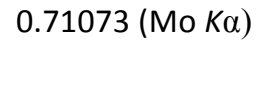 & $1.54178(\mathrm{Cu} \mathrm{K \alpha})$ & $\begin{array}{l}1.54178(\mathrm{Cu} \\
\mathrm{K \alpha})\end{array}$ \\
\hline Size $/ \mathrm{mm}^{3}$ & $0.51 \times 0.29 \times 0.27$ & $0.153 \times 0.122 \times 0.065$ & $0.25 \times 0.20 \times 0.13$ & $\begin{array}{l}0.275 \times 0.146 \times 0 . \\
038\end{array}$ & $\begin{array}{l}0.651 \times 0.134 \times 0 . \\
052\end{array}$ \\
\hline Crystal System & Monoclinic & Triclinic & Triclinic & Monoclinic & Monoclinic \\
\hline Space Group & $P 2_{1} / n$ & $P-1$ & $P-1$ & $P 2_{1} / c$ & $P 2_{1} / c$ \\
\hline$a / \AA ̊$ & $10.8103(2)$ & $7.71840(10)$ & $15.243(2)$ & $7.9754(3)$ & $13.7726(5)$ \\
\hline$b / \AA ̊$ & $13.6690(2)$ & $9.4477(2)$ & $18.200(2)$ & $9.6467(3)$ & $8.9756(3)$ \\
\hline$c / A ̊$ & $15.5083(3)$ & $13.9101(3)$ & $20.812(2)$ & 29.6489(9) & $15.8948(6)$ \\
\hline$\alpha /^{\circ}$ & 90 & $71.6860(10)$ & $94.964(7)$ & 90 & 90 \\
\hline$\beta /^{\circ}$ & $110.304(1)$ & $79.1810(10)$ & $105.186(7)$ & $93.529(2)$ & $108.792(2)$ \\
\hline$\gamma /{ }^{\circ}$ & 90 & $78.9680(10)$ & $106.059(7)$ & 90 & 90 \\
\hline$V / \AA^{3}$ & $2149.21(7)$ & $936.27(3)$ & $5275.7(11)$ & $2276.75(13)$ & $1860.13(12)$ \\
\hline$Z$ & 4 & 2 & 2 & 4 & 4 \\
\hline$D_{\text {calc. }} / \mathrm{g} \mathrm{cm}^{-3}$ & 1.578 & 1.658 & 1.621 & 1.671 & 1.726 \\
\hline$\mu / \mathrm{mm}^{-1}$ & 3.77 & 4.254 & 0.584 & 6.750 & 4.347 \\
\hline$\Theta_{\min } /^{\circ}$ & 4.4 & 3.38 & 1.029 & 2.986 & 3.390 \\
\hline$\Theta_{\max } /{ }^{\circ}$ & 68.3 & 66.72 & 22.603 & 68.321 & 68.360 \\
\hline Measured Refl's. & 32095 & 5757 & 35495 & 4164 & 27236 \\
\hline $\begin{array}{l}\text { Independent } \\
\text { reflections }\end{array}$ & 3883 & 5757 & 13745 & 4164 & 3407 \\
\hline $\begin{array}{l}\text { Reflexions with I } \\
>2(\mathrm{I})\end{array}$ & 3546 & 5332 & 8599 & 3322 & 2984 \\
\hline$R_{\text {int }}$ & 0.055 & 0.057 & 0.0552 & 0.109 & 0.087 \\
\hline Parameters & 286 & 258 & 1777 & 280 & 262 \\
\hline Restraints & 0 & 0 & 3704 & 0 & 0 \\
\hline Largest Peak & 0.24 & 0.79 & 1.836 & 0.52 & 0.29 \\
\hline Deepest Hole & -0.50 & -0.39 & -0.929 & -0.66 & -0.49 \\
\hline Goodness of fit & 1.034 & 1.088 & 1.024 & 1.064 & 1.059 \\
\hline$w R_{2}$ (all data) & 0.828 & 0.1354 & 0.2714 & 0.1525 & 0.0867 \\
\hline$w R_{2}$ & 0.806 & 0.1328 & 0.2209 & 0.1441 & 0.0834 \\
\hline$R_{1}$ (all data) & 0.0349 & 0.0509 & 0.1401 & 0.0830 & 0.0382 \\
\hline$R_{1}$ & 0.0319 & 0.0475 & 0.0884 & 0.0655 & 0.0327 \\
\hline
\end{tabular}

${ }^{a}$ Details for the solution of 4: The material crystallizes with considerable disorder in the two BArF anions, as well as with solvent in the lattice. The solvent could not be modeled satisfactorily, so the PLATON/SQUEEZE program was employed to generate a 'solvent-free' data set. Disorder in the BArF anions was modeled using appropriate restraints on bond lengths. Rigid groups were employed to model six-membered rings in the BArF anions. All non-hydrogen atoms were refined anisotropically. Most hydrogen atom positions were calculated geometrically and refined using the riding model, but some hydrogen atom $\mathrm{H} 7$ was located in a difference map and refined freely. 


\section{XAS Data}

All $\mathrm{Cu}$ K-edge XAS spectra were recorded at beamline 7-3 of the Stanford Synchrotron Radiation Lightsource (SSRL) using a 32 element Ge detector. All spectra were recorded at $4 \mathrm{~K}$ using a liquid helium cryostat and all samples were prepared in an argon glovebox. All data were processed using Athena, from the Demeter software package. ${ }^{[1]}$ The Cu K-edge XAS of 1 was measured using the microcrystalline powder formed by precipitation upon reaction of $\mathrm{L}^{\mathrm{NHOH}}$ with $\mathrm{Cu}^{\prime} \mathrm{Cl}$ in $\mathrm{ACN}$. This reaction was performed on-site in the argon glovebox and the precipitate was sealed into a sample holder using Tygon ${ }^{\circledR}$ tape. The Cu K-edge XAS of 2, which tends to dimerize upon concentration, was measured in a frozen $15 \mathrm{mM}$ solution in DCM. To produce this solution, 3 eq. of DIAD, dissolved in DCM, was added dropwise to a $15 \mathrm{mM}$ solution of 1 in DCM in an argon glovebox. This solution was injected into an acrylic sample cell tightly sealed with Tygon ${ }^{\circledR}$ tape and immediately frozen in liquid nitrogen before transfer to the experimental apparatus and further cooling to $4 \mathrm{~K}$ by liquid helium. An unoxidized sample of a $15 \mathrm{mM}$ solution of 1 in DCM was prepared similarly and its Cu K-edge XAS was also measured. Samples of the solid products of mechanochemically induced disproportionation of $\mathbf{1}$ were measure prepared similarly to 1 . The solid mixtures produced by grinding 1 in a ball miller under three different conditions were measured. These conditions included grinding 1 under an inert nitrogen atmosphere, grinding

1 under air, and grinding an equimolar mixture of $\mathrm{L}^{\mathrm{NHOH}}$ and $\mathrm{Cu}^{\prime} \mathrm{Cl}$ under nitrogen. the $\mathrm{Cu}$ K-edge XAS of 1, measured in the solid state, had a rising edge at $8982.4 \mathrm{eV}$, and that of $\mathbf{2}$ had a rising edge of $8985.0 \mathrm{eV}$. This edge shift of $2.6 \mathrm{eV}$ is consistent with a change in oxidation state from $\mathrm{Cu}^{\prime}$ to $\mathrm{Cu}^{\prime \prime}$. Interestingly, the frozen solution of 1 in DCM exhibited damaging as the XAS was measured. Over the course of 30 scans, the clear Cu' spectrum of $\mathbf{1}$ converted to a $\mathrm{Cu}^{\prime \prime}$ spectrum with features identical to those of $\mathbf{2}$ produced by chemical oxidation (Figure S16). This suggests that oxidation of 1 to $\mathbf{2}$ can be photochemically initiated, at least using Xrays in the energy range of the Cu K-edge. This damaging was not, however, observed with successive scans of the solid precipitate of $\mathbf{1}$, therefore the photochemically induced oxidation must be environment-dependent, and possibly solvent-dependent. 


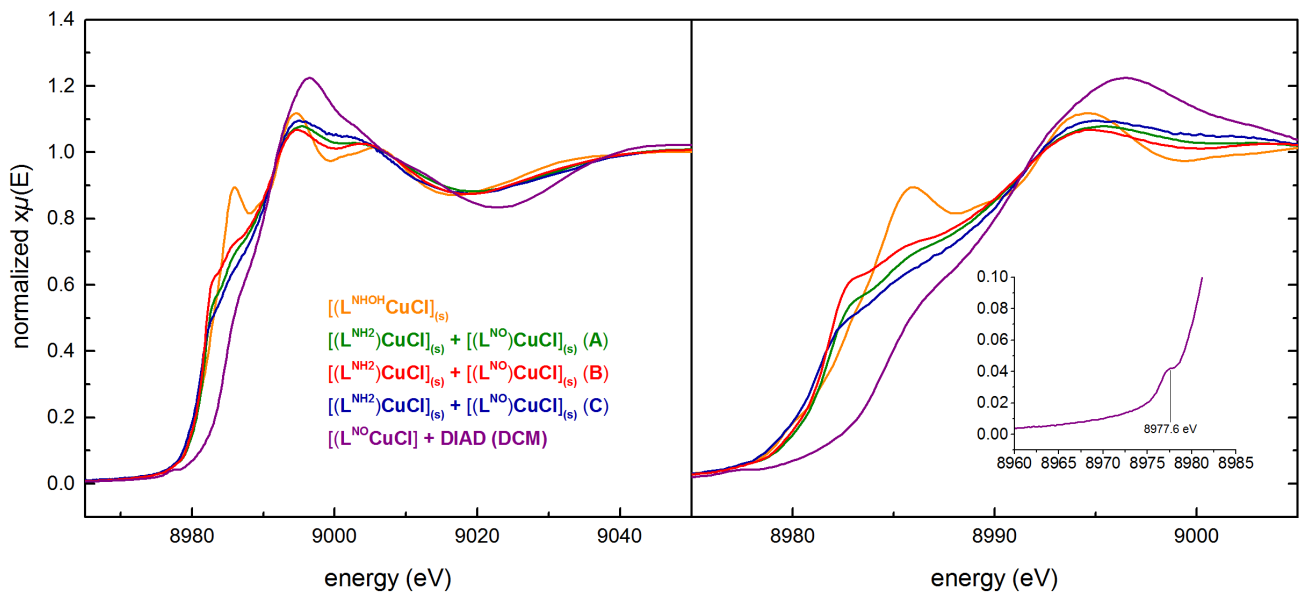

Figure S15. Normalized $\mathrm{Cu}$ K-edge XAS (left) and zoom into XANES region (right) for solid [( $\left.\left.{ }^{\mathrm{NHOH}}\right) \mathrm{CuCl}\right](\mathbf{1})$, alongside $\left[\left(\mathrm{L}^{\mathrm{NH} 2}\right) \mathrm{CuCl}\right]+\left[\left(\mathrm{L}^{\mathrm{NO}}\right) \mathrm{CuCl}\right]$, the products of mechanochemically-induced disproportionation of $\left[\left(\mathrm{L}^{\mathrm{NHOH}}\right) \mathrm{CuCl}\right],(\mathrm{A})$ under a $\mathrm{N} 2$ environment, $(\mathrm{B})$ under an $\mathrm{O}_{2}$ environment, and $(\mathrm{C})\left[\left(\mathrm{L}^{\mathrm{NH}}\right) \mathrm{CuCl}\right]+\left[\left(\mathrm{L}^{\mathrm{NHOH}}\right) \mathrm{CuCl}\right]$ formed by mechanochemical grinding of equal portions of $\mathrm{L}^{\mathrm{NHOH}}$ and $\mathrm{CuCl}$ in the solid state, and a frozen $15 \mathrm{mM}$ solution of $\left[\left(\mathrm{L}^{\mathrm{NO}}\right) \mathrm{CuCl}\right]$ in $\mathrm{DCM}$, formed by reaction with 3 eq. (excess) DIAD (inset shows pre-edge region with peak at $8977.6 \mathrm{eV})$.

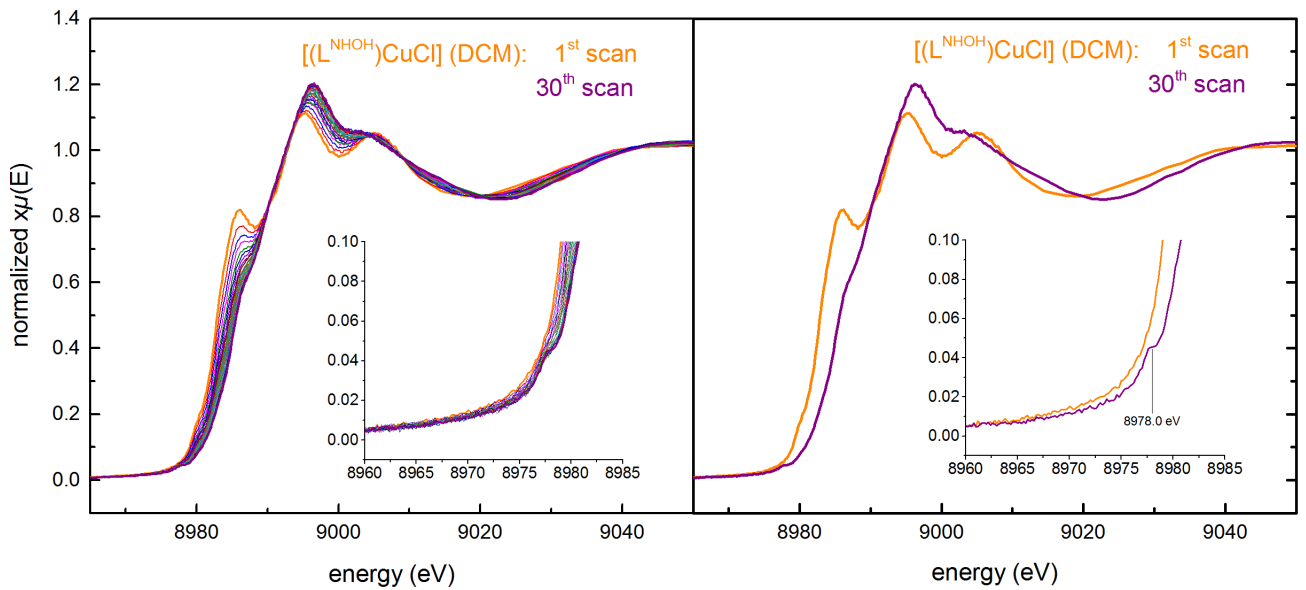

Figure S16. Normalized Cu K-edge XAS (left) of 30 scans of a frozen $15 \mathrm{mM}$ solution of [( $\left.\left.\mathrm{L}^{\mathrm{NHOH}}\right) \mathrm{CuCl}\right]$ in DCM and (right) the $1^{\text {st }}$ and $30^{\text {th }}$ of those scans, with inset showing copper(II) pre-edge feature at $8978 \mathrm{eV}$. See comparison of $\mathrm{Cu}$ K-edge XAS of $\left[\left(\mathrm{L}^{\mathrm{NO}}\right) \mathrm{CuCl}\right]$ produced by reaction of $\left[\left(\mathrm{L}^{\mathrm{NHOH}}\right) \mathrm{CuCl}\right]$ with $\mathrm{DIAD}$ to the photooxidized $30^{\text {th }}$ scan in Figure S15 (right)). 


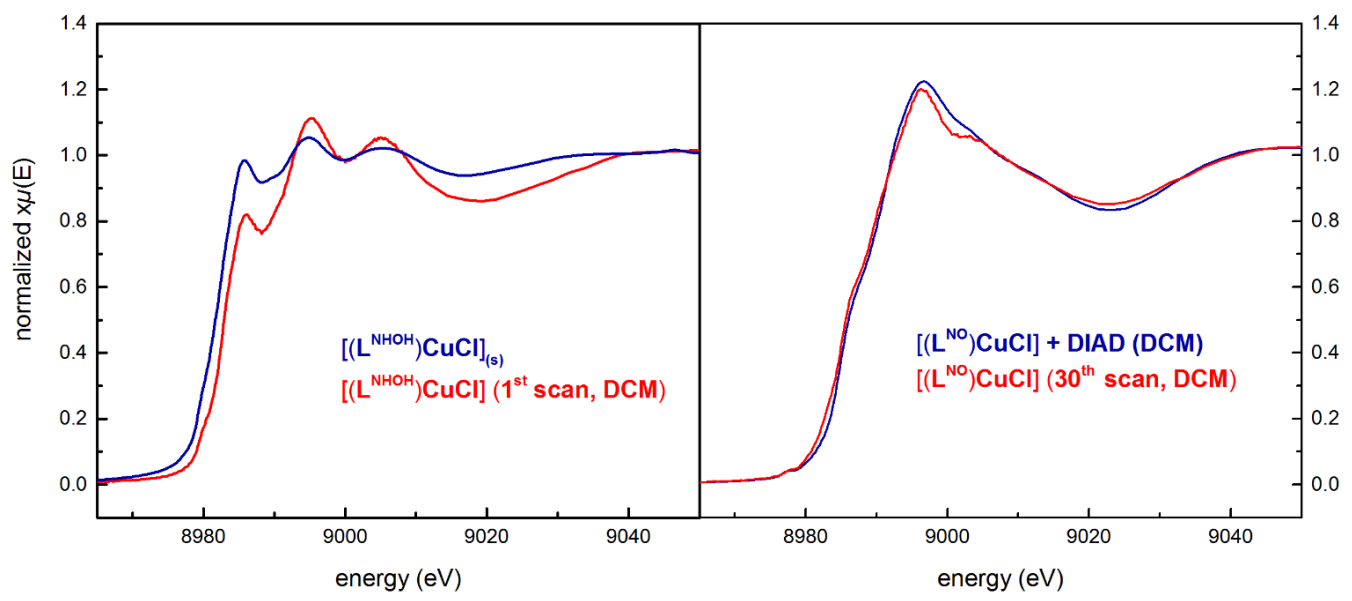

Figure S17. A comparison of the normalized $1^{\text {st }}$ scan of the $\mathrm{Cu}$ K-edge XAS of a frozen $15 \mathrm{mM}$ solution of $\left[\left(\mathrm{L}^{\mathrm{NHOH}}\right) \mathrm{CuCl}\right]$ in DCM (before photooxidation, red) to the normalized Cu K-Edge XAS of solid [( $\left.\left.\mathrm{L}^{\mathrm{NHOH}}\right) \mathrm{CuCl}\right]$ (blue) (left) and a comparison of the normalized $30^{\text {th }}$ scan (after photooxidation, red) to the normalized Cu K-Edge XAS of a frozen $15 \mathrm{mM}$ solution of $\left[\left(\mathrm{L}^{\mathrm{NO}}\right) \mathrm{CuCl}\right]$ in $\mathrm{DCM}$, formed by reaction with 3 eq. DIAD (blue) (right).

\section{EXAFS Data}

The EXAFS data for the $\mathrm{Cu}$ K-edge XAS of a frozen $10 \mathrm{mM}$ solution of $\left[\left(\mathrm{L}^{\mathrm{NHOH}}\right) \mathrm{CuCl}\right]$, oxidized in situ with 3 equivalents of DIAD in DCM, $\left[\left(\mathrm{L}^{\mathrm{NO}}\right) \mathrm{CuCl}\right]_{(\mathrm{DCM})}$, were fit using Artemis, from the Demeter software package ${ }^{[1]}$. All fitting was performed using a $k$ range of $2.0-12 \AA^{-1}$ and an $R$ range of 1.1-2.1 $\AA$. $S_{0}^{2}$ was set to 0.9 , and a single $\Delta \mathrm{E}_{0}$ value was guessed for all paths in each fit. In case where restraining $\sigma^{2}$ was necessary, a range of $1.00 \times 10^{-3}-$ $6.00 \times 10^{-3}$ was used. Paths were predicted using the Feff program ${ }^{[2]}$, based on input from a DFT-optimized geometry.

The goal of this fitting was to investigate the consistency of the experimental EXAFS of $\left[\left(\mathrm{L}^{\mathrm{NO}}\right) \mathrm{CuCl}\right]_{(\mathrm{DCM})}$, with an optimized DFT model. Since this complex cannot be crystalized as a monomer due to dimerization at high concentrations, these data were used to confirm the coordination of $\mathrm{N}_{\mathrm{NO}}$ and the predicted contraction of the other bond distances on oxidation. In the tables on the following pages, restrained parameters are shown in blue, unphysical parameters are shown in red, $\mathrm{N}$ refers to "degeneracy", $\mathrm{N}_{\text {in }}$ refers to the inner nitrogen shell, including the two $\mathrm{N}_{\mathrm{Py}}$ and $\mathrm{N}_{\mathrm{NO}}$, and $\mathrm{N}_{\text {out }}$ refers to the outer nitrogen shell, including $\mathrm{N}_{\text {backbone, }}$ and in some cases $\mathrm{O}_{\mathrm{NO}}$.

Fit 1 is the most minimalist fit, showing that the bond distances of the inner sphere of coordinating are generally consistent with those predicted by the DFT model. Fit 2 is unphysical and serves to show that an $\mathrm{N}_{\text {in }}$ with degeneracy of 2 is much less consistent with the data than one with degeneracy of 3, supporting the hypothesis that $N_{N O}$ is coordinated in solution at $10 \mathrm{mM}$. Fit 3 shows that, although the chloride $\sigma^{2}$ in fit 1 is rather large, the model doesn't change significantly if its value is restrained. Taken together, these fits suggest that a model of $\left[\left(\mathrm{L}^{\mathrm{NO}}\right) \mathrm{CuCl}\right]_{(\mathrm{DCM})}$ with a coordinated nitroso and inner bond distances similar to those predicted by DFT is consistent with the EXAFS data, but they fail to account for the scattering of $\mathrm{O}_{\text {NO}}$. 


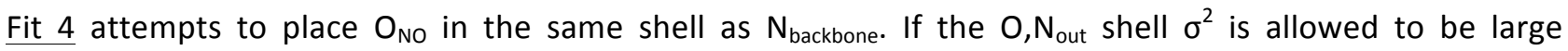
$\left(12.76 \times 10^{-3} \AA^{-1}\right.$ ), then this is actually more consistent with the data than fit 1 (R-factor of 0.009100 vs. 0.009511). The DFT model predicts distances of $2.43 \AA$ and $2.71 \AA$ for $\mathrm{N}_{\text {out }}$ and $\mathrm{O}$, respectively, whereas the distance for $N_{\text {out }}$ in fit 3 and $0, N_{\text {out }}$ in fit 4 are in-between those distances ( $0.02 \AA$ aboe the average of $2.57 \AA$ ), suggesting that the fit is accounting for both of them. Since each term in the EXAFS equation scales linearly with increasing degeneracy and inverse-logarithmically with the Debye-Waller factor, the Debye-Waller factor must increase to scale down the contribution of the shell's overestimated degeneracy to the shell's contribution the EXAFS amplitude in $k$-space. Thus, given the use of a shell at an intermediate distance with artificially increased degeneracy to fit two atoms that cannot easily be distinguished, this large Debye-Waller seems reasonable. Fit 5 is equivalent to fit 4 , but with restrained $\sigma^{2}$ for $\mathrm{Cu}-\mathrm{Cl}$ and $\mathrm{Cu}-\mathrm{O}, \mathrm{N}_{\text {out }}$. Since the R-factor increases significantly when restraining these $\sigma^{2}$ to reasonable values, this suggests that restraining $\mathrm{O}_{\mathrm{No}}$ and $\mathrm{N}_{\text {backbone }}$ to a single radial distance is inconsistent with the data. Fit 6 separates $\mathrm{O}_{\mathrm{No}}$ and $\mathrm{N}_{\text {backbone }}$ into discrete shells, $\mathrm{O}$, and $\mathrm{N}_{\text {out }}$, but yields unphysical $\sigma^{2}$ values when no restraints are imposed.

Fit 7 restrains $\sigma^{2}$ for $\mathrm{Cu}-\mathrm{Cl}$ and $\mathrm{Cu}-\mathrm{O}, \mathrm{N}_{\text {out }}$ from fit 6 , leading to a reasonably good fit (R-factor of 0.009285 vs. 0.013069 of fit 5 and 0.009511 of fit 1), and good agreement with the theoretically-predicted bond distances (see Table S10). With $k$-space from 2-10 $\AA^{-1}$, the expected resolution of $\pi / 2 \Delta k$ is $0.157 \AA$ so it is reasonable based on these data that these atoms should be distinguishable. Besides, $O$ and $N_{\text {out, }}$ all other shells are separated by more than $0.157 \AA$ except $\mathrm{Cl}$ and $\mathrm{N}_{\text {out }}$, which are separated by $0.14 \AA$ in fit 7. This explains the necessity of restraining their $\sigma^{2}$ values. Due to the large difference in effective scattering amplitude and phase shift between $\mathrm{Cl}$ and $\mathrm{N}$, however, these two shells must be separated to obtain a good fit. It should also be pointed out that the radial distances of $\mathrm{O}$ and $\mathrm{N}_{\text {out }}$, which are separated by $0.26 \AA$, are only $41.3 \%$ correlated in fit 7. Taken together, these data suggest that the structure of $\left[\left(\mathrm{L}^{\mathrm{NO}}\right) \mathrm{CuCl}\right]_{(\mathrm{DCM})}$ in solution at $10 \mathrm{mM}$ is very similar to that predicted by DFT with conductor-like polarizable continuum (CPCM) solvent corrections using $\varepsilon=$ 9.08 (see Table S10 and Figure S19). Figure S18 shows the decomposition of fit 7 into the contribution functions from each fit shell in both-signed R-space and K-space. See Table S11 for a comparison of all the fits discussed above. 
$\mathrm{SO}^{2}=0.900, \mathrm{k}_{\min }=2.00, \mathrm{k}_{\max }=12.00, \mathrm{R}_{\min }=1.1, \mathrm{R}_{\max }=3.1$,

Restrained parameters shown in blue.

Unphysical parameters shown in red.

$\mathrm{N}=$ "degeneracy"

$N_{\text {in }}=$ inner nitrogen shell

$\mathrm{N}_{\text {out }}=$ outer nitrogen shell

Table S4. Fit 1 ( $\mathrm{N}_{\text {out }}=1$; totally unrestrained)

\begin{tabular}{llllll}
\hline R-factor & $\mathrm{E}_{0}(\mathrm{eV})$ & Path & $\mathrm{N} \sigma^{2}\left(\times 10^{-3} \AA^{2}\right)$ & $\mathrm{R}(\AA)$ \\
\hline 0.009511 & \multirow{2}{*}{8989.53} & $\mathrm{Cu}-\mathrm{N}_{\text {in }}$ & 3 & 2.82 & 1.98 \\
& & $\mathrm{Cu}-\mathrm{Cl}$ & 1 & 7.04 & 2.26 \\
& & $\mathrm{Cu}-\mathrm{N}_{\text {out }}$ & 1 & 6.15 & 2.58 \\
& & $\mathrm{Cu}-\mathrm{C}$ & 4 & 2.72 & 2.91 \\
\hline
\end{tabular}

Table S5. Fit 2 ( $\mathrm{N}_{\text {out }}=1$; totally unrestrained; with $\mathrm{N}_{\text {in }}=2$ )

\begin{tabular}{llllll}
\hline R-factor & $\mathrm{E}_{0}(\mathrm{eV})$ & Path & $\mathrm{N}$ & $\sigma^{2}\left(\times 10^{-3} \AA^{2}\right)$ & $\mathrm{R}(\AA)$ \\
\hline 0.015970 & \multirow{2}{*}{8989.03} & $\mathrm{Cu}-\mathrm{N}_{\text {in }}$ & 2 & -0.24 & 1.96 \\
& & $\mathrm{Cu}-\mathrm{Cl}$ & 1 & 3.42 & 2.24 \\
& & $\mathrm{Cu}-\mathrm{N}_{\text {out }}$ & 1 & -0.15 & 2.60 \\
& & $\mathrm{Cu}-\mathrm{C}$ & 4 & 2.50 & 2.90 \\
\hline
\end{tabular}

Table S6. Fit 3 ( $\mathrm{N}_{\text {out }}=1 ; \mathrm{Cl} \sigma^{2}$-restrained)

\begin{tabular}{llllll}
\hline R-factor & $\mathrm{E}_{0}(\mathrm{eV})$ & Path & $\mathrm{N}$ & $\sigma^{2}\left(\times 10^{-3} \AA^{2}\right)$ & $\mathrm{R}(\AA)$ \\
\hline 0.010223 & \multirow{2}{*}{8989.34} & $\mathrm{Cu}-\mathrm{N}_{\text {in }}$ & 3 & 2.66 & 1.98 \\
& & $\mathrm{Cu}-\mathrm{Cl}$ & 1 & 6.00 & 2.26 \\
& & $\mathrm{Cu}-\mathrm{N}_{\text {out }}$ & 1 & 4.68 & 2.59 \\
& & $\mathrm{Cu}-\mathrm{C}$ & 4 & 2.56 & 2.90 \\
\hline
\end{tabular}
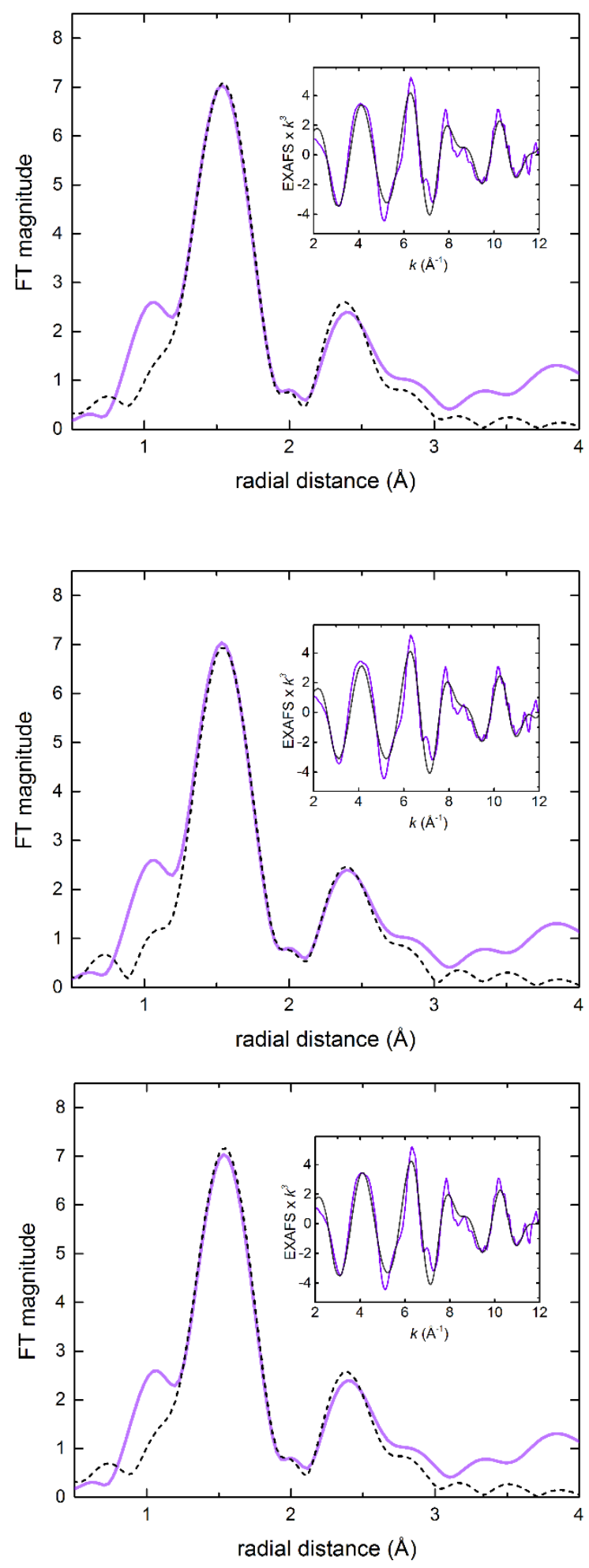
Table S7. Fit 4 ( $\mathrm{N}_{\text {out }}=2$; totally unrestrained)

\begin{tabular}{llllll}
\hline R-factor & $\mathrm{E}_{0}(\mathrm{eV})$ & Path & $\mathrm{N}$ & $\sigma^{2}\left(\times 10^{-3} \AA^{2}\right)$ & $\mathrm{R}(\AA)$ \\
\hline 0.009100 & \multirow{2}{*}{8989.01} & $\mathrm{Cu}-\mathrm{N}_{\text {in }}$ & 3 & 2.90 & 1.98 \\
& & $\mathrm{Cu}-\mathrm{Cl}$ & 1 & 7.71 & 2.26 \\
& & $\mathrm{Cu}\left(\mathrm{O}, \mathrm{N}_{\text {out }}\right)$ & 2 & 12.76 & 2.59 \\
& & $\mathrm{Cu}-\mathrm{C}$ & 4 & 2.47 & 2.91 \\
\hline
\end{tabular}

Table S8. Fit $5\left(\mathrm{~N}_{\text {out }}=2 ; \mathrm{Cl}, \mathrm{N}_{\text {out }} \sigma^{2}\right.$-restrained)

\begin{tabular}{llllll}
\hline R-factor & $\Delta \mathrm{E}_{0}(\mathrm{eV})$ & Path & $\mathrm{N}$ & $\sigma^{2}\left(\times 10^{-3} \AA^{2}\right)$ & $\mathrm{R}(\AA)$ \\
\hline 0.013069 & \multirow{2}{*}{8987.84} & $\mathrm{Cu}-\mathrm{N}_{\text {in }}$ & 3 & 3.01 & 1.97 \\
& & $\mathrm{Cu}-\mathrm{Cl}$ & 1 & 6.01 & 2.24 \\
& & $\mathrm{Cu}-\left(\mathrm{O}, \mathrm{N}_{\text {out }}\right)$ & 2 & 6.00 & 2.59 \\
& & $\mathrm{Cu}-\mathrm{C}$ & 4 & 2.66 & 2.90 \\
\hline
\end{tabular}

Table S9. Fit 6 ( $\mathrm{N}_{\text {out }}=1, \mathrm{O}=1$; totally unrestrained)

\begin{tabular}{llllll}
\hline R-factor & $\Delta \mathrm{E}_{0}(\mathrm{eV})$ & Path & $\mathrm{N}$ & $\sigma^{2}\left(\times 10^{-3} \AA^{2}\right)$ & $\mathrm{R}(\AA)$ \\
\hline 0.003647 & \multirow{2}{*}{8986.41} & $\mathrm{Cu}-\mathrm{N}_{\text {in }}$ & 3 & 5.03 & 1.97 \\
& & Cu-Cl & 1 & 5.77 & 2.18 \\
& & Cu-N $\mathrm{N}_{\text {out }}$ & 1 & -7.80 & 2.49 \\
& & Cu-O & 1 & -6.55 & 2.62 \\
& & Cu-C & 4 & 0.74 & 2.88 \\
\hline
\end{tabular}

Table S10. Fit $7\left(\mathrm{~N}_{\text {out }}=1, \mathrm{O}=1 ; \mathrm{Cl}, \mathrm{NB} \sigma^{2}\right.$-restrained)

\begin{tabular}{llllll}
\hline R-factor & $\Delta \mathrm{E}_{0}(\mathrm{eV})$ & Path & $\mathrm{N}$ & $\sigma^{2}\left(\times 10^{-3} \AA^{2}\right)$ & $\mathrm{R}(\AA)$ \\
\hline 0.009285 & 8989.51 & $\mathrm{Cu}-\mathrm{N}_{\text {in }}$ & 3 & 3.01 & 1.98 \\
& & $\mathrm{Cu}-\mathrm{Cl}$ & 1 & 6.00 & 2.28 \\
& & $\mathrm{Cu}-\mathrm{N}_{\text {out }}$ & 1 & 6.00 & 2.42 \\
& & $\mathrm{Cu}-\mathrm{O}$ & 1 & 5.48 & 2.61 \\
& & $\mathrm{Cu}-\mathrm{C}$ & 4 & 1.95 & 2.91 \\
\hline
\end{tabular}
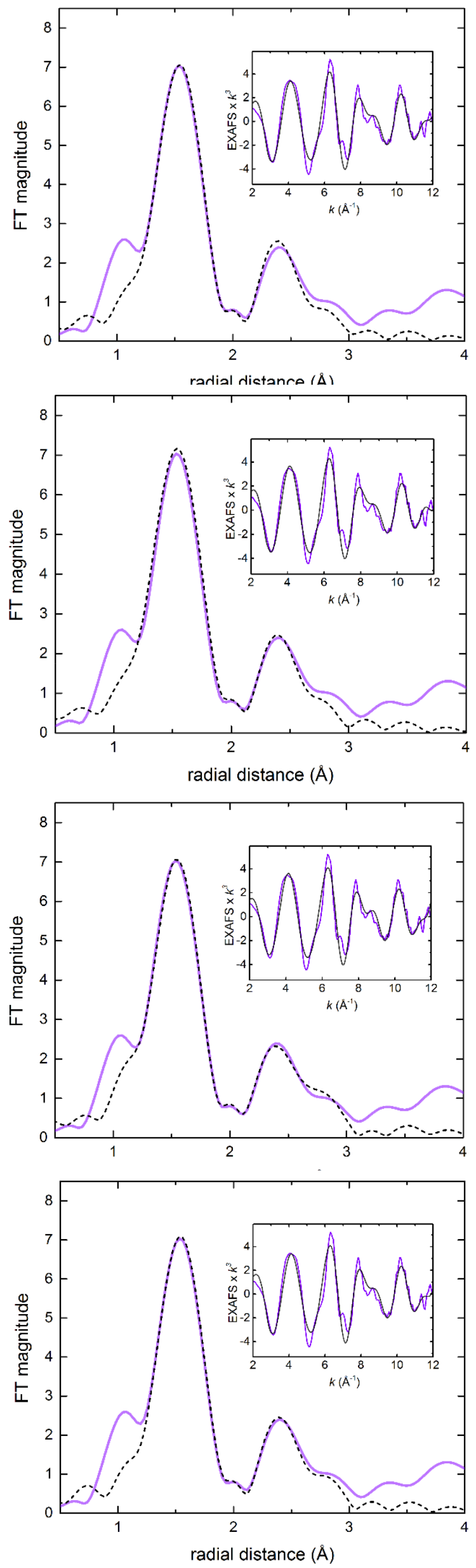
Table S11. A comparison of all EXAFS fits considered

\begin{tabular}{|c|c|c|c|c|c|c|}
\hline Fit \# & $E_{0}(e V)$ & Path & degeneracy & $\sigma^{2}\left(x 10^{-3} \AA^{2}\right)$ & $\mathrm{R}(\AA)$ & R-factor \\
\hline \multirow[t]{4}{*}{1} & 8989.53 & Cu-N & 3 & 2.82 & 1.98 & 0.009511 \\
\hline & & $\mathrm{Cu}-\mathrm{Cl}$ & 1 & 7.04 & 2.26 & \\
\hline & & $\mathrm{Cu}-\mathrm{N}_{\text {out }}$ & 1 & 6.15 & 2.58 & \\
\hline & & $\mathrm{Cu}-\mathrm{C}$ & 4 & 2.72 & 2.91 & \\
\hline \multirow[t]{4}{*}{2} & 8989.03 & Cu-N & 2 & -0.24 & 1.96 & 0.015970 \\
\hline & & $\mathrm{Cu}-\mathrm{Cl}$ & 1 & 3.42 & 2.24 & \\
\hline & & Cu-N $\mathrm{N}_{\text {out }}$ & 1 & -0.15 & 2.60 & \\
\hline & & $\mathrm{Cu}-\mathrm{C}$ & 4 & 2.50 & 2.90 & \\
\hline \multirow[t]{4}{*}{3} & 8989.34 & Cu-N & 3 & 2.66 & 1.98 & 0.010223 \\
\hline & & $\mathrm{Cu}-\mathrm{Cl}$ & 1 & 6.00 & 2.26 & \\
\hline & & $\mathrm{Cu}-\mathrm{N}_{\text {out }}$ & 1 & 2.46 & 2.59 & \\
\hline & & $\mathrm{Cu}-\mathrm{C}$ & 4 & 2.56 & 2.90 & \\
\hline \multirow[t]{4}{*}{4} & 8989.01 & Cu-N & 3 & 2.90 & 1.98 & 0.009100 \\
\hline & & $\mathrm{Cu}-\mathrm{Cl}$ & 1 & 7.71 & 2.26 & \\
\hline & & $\mathrm{Cu}-\left(\mathrm{O}, \mathrm{N}_{\text {out }}\right)$ & 2 & 12.76 & 2.59 & \\
\hline & & $\mathrm{Cu}-\mathrm{C}$ & 4 & 2.47 & 2.91 & \\
\hline \multirow[t]{4}{*}{5} & 8987.84 & Cu-N & 3 & 3.01 & 1.97 & 0.013069 \\
\hline & & $\mathrm{Cu}-\mathrm{Cl}$ & 1 & 6.01 & 2.24 & \\
\hline & & $\mathrm{Cu}-\left(\mathrm{O}, \mathrm{N}_{\text {out }}\right)$ & 2 & 6.00 & 2.59 & \\
\hline & & $\mathrm{Cu}-\mathrm{C}$ & 4 & 2.66 & 2.66 & \\
\hline \multirow[t]{5}{*}{6} & 8986.41 & Cu-N & 3 & 5.03 & 1.97 & 0.003647 \\
\hline & & $\mathrm{Cu}-\mathrm{Cl}$ & 1 & 5.77 & 2.18 & \\
\hline & & $\mathrm{Cu}-\mathrm{N}_{\text {out }}$ & 1 & -7.80 & 2.49 & \\
\hline & & $\mathrm{Cu}-\mathrm{O}$ & 1 & -6.55 & 2.62 & \\
\hline & & $\mathrm{Cu}-\mathrm{C}$ & 4 & 0.74 & 2.88 & \\
\hline \multirow[t]{5}{*}{7} & 8989.51 & Cu-N & 3 & 3.01 & 1.98 & 0.009285 \\
\hline & & $\mathrm{Cu}-\mathrm{Cl}$ & 1 & 6.00 & 2.28 & \\
\hline & & $\mathrm{Cu}-\mathrm{N}_{\text {out }}$ & 1 & 6.00 & 2.42 & \\
\hline & & $\mathrm{Cu}-\mathrm{O}$ & 1 & 5.48 & 2.61 & \\
\hline & & $\mathrm{Cu}-\mathrm{C}$ & 4 & 1.95 & 2.91 & \\
\hline
\end{tabular}



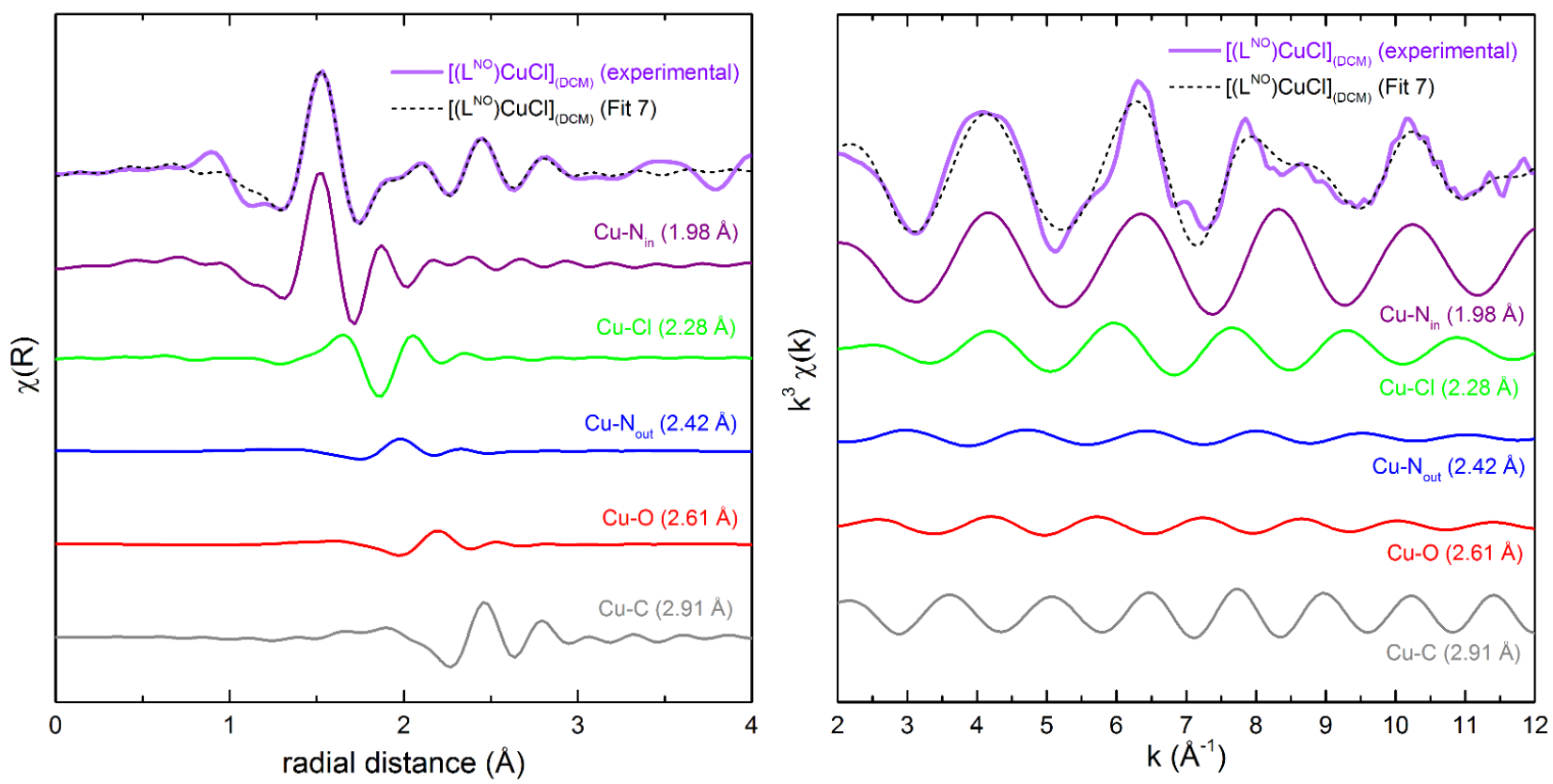

Figure S18. Decomposition of both-signed Fourier transform (left) and K-space (right) for fit 7.
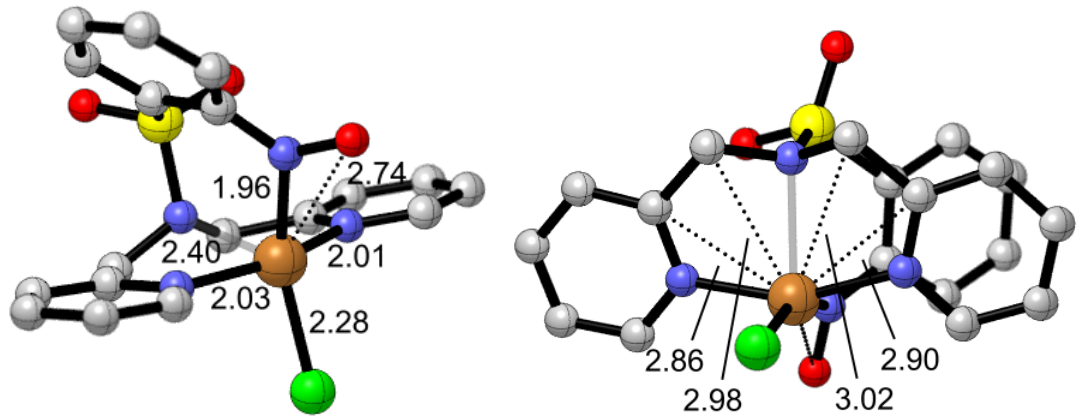

Figure S19. DFT model of ${ }^{3} \mathbf{2}$ optimized at the CAM-B3LYP/Def2-TZVP level of theory with zero-order regular approximation (ZORA) relativistic corrections and CPCM $(\varepsilon=9.08)$ solvation corrections (vide infra), showing bond distances about the inner sphere of coordination.

Table S12. A comparison of the DFT model of ${ }^{3} \mathbf{2}$ to EXAFS fit 7.

\begin{tabular}{lll}
\hline Path & EXAFS (Fit 7, $\AA$ ) & DFT model of ${ }^{3} \mathbf{2}(\AA)$ \\
\hline $\mathrm{Cu}-\mathrm{N}_{\text {in }}$ & 1.98 & $2.01,2.03,1.96(\bar{x}=2.00)$ \\
$\mathrm{Cu}-\mathrm{Cl}$ & 2.28 & 2.28 \\
$\mathrm{Cu}-\mathrm{N}_{\text {out }}$ & 2.42 & 2.40 \\
$\mathrm{Cu}-\mathrm{O}$ & 2.61 & 2.74 \\
$\mathrm{Cu}-\mathrm{C}$ & 2.91 & $2.88,3.01,2.98,2.87(\bar{x}=2.94)$ \\
\hline
\end{tabular}




\section{Computational Details}

All DFT calculations were performed using ORCA 4.2.0 $0^{[3]}$ on either ComputeCanada's Graham cluster, ComputeCanada's Cedar cluster, or The Max Planck Institute für Chemsiche Energiekonversion's Odin cluster. All calculations were performed using Zero Order Regular Approximation (ZORA) relativistic corrections ${ }^{[4,5]}$ and atom-pairwise dispersion correction with Becke-Johnson damping (D3BJ ${ }^{[6]}$, and tight SCF convergence criteria. Calculations used relativistically recontracted versions of the all-electron Ahlrichs basis sets ${ }^{[7],[8]}$ with appropriate auxiliary basis sets for the RI-J and RIJCOSX approximations; a decontracted version of the generalpurpose Coulomb fitting auxiliary basis set by Weigend (REF), called SARC/J in ORCA, was used.

With pure-DFT functionals, i.e., non-hybrid functionals, including no Hartree-Fock (HF)exchange, the RI-J approximation was applied, and with functionals including HF exchange, the RIJCOSX approximation was applied. The Grid5 integration grid, with a Grid6 final integration grid was used in all cases. The relativisticallycontracted triple- $\zeta$ Ahlrichs basis set, ZORA-Def2-TZVP, was applied to all atoms in all calculations. All calculations were initially performed either purely in the gas phase or using the Conductor-like Polarizable Continuum Model (CPCM) with $\varepsilon=9.08$, to describe the DCM solvent environment. All calculations that included CPCM corrections used the Van der Waals Gaussian surface type, calling the surfacetype vdw_gaussian option in the CPCM section. For the spin-coupled system ${ }^{\mathbf{1}} \mathbf{2}_{\mathrm{AFC}}$, a neutral triplet was selected and the flipspin keyword was called in the SCF input section, flipping the spin of the unpaired electron residing on the copper center and requesting optimization to a broken-symmetry wavefunction with a final $\mathrm{M}_{\mathrm{s}}$ of 0.0 .

\section{a) Method Validation}

In order to rule out errors due to significant functional-dependence in the systems of interest, geometry optimizations of $\mathbf{1},{ }^{\mathbf{3}} \mathbf{2}$, and ${ }^{\mathbf{1}} \mathbf{2}_{\mathrm{AFC}}$ were initially performed using a variety of functionals. The functionals tested included the Generalized Gradient Approximation (GGA) functional BP86, ${ }^{[9],[10]}$ the meta-GGA functional TPSS, ${ }^{[11]}$ the hybrid meta-GGA functionals TPSSh ${ }^{[11,12]}$, TPSSO ${ }^{[13]}$, the hybrid functionals B3LYP ${ }^{[14],[15],[16]}$ and $\mathrm{PBEO}^{[17,18]}$ and the range-separated hybrid functionals CAM-B3LYP ${ }^{[19],[20]}$, and $\omega \mathrm{B} 97 \mathrm{X}-\mathrm{D} 3 \mathrm{~B} \mathrm{~J}^{[21],[22]}$. With $\omega \mathrm{B97X-}$ D3BJ no additional dispersion correction was called, since the function was modified to include D3BJ corrections. Selected geometries of 1 were re-calculated with the finer GridX6 integration grid for the RIJCOSX approximation used with the hybrid functionals, and significant changes in bond distance were observed, particularly with the range-seperated hybrids, therefore all geometries calculated using hybrid functionals were re-optimized calling the GridX6 keyword. A representative input section for the geometry optimizations of 1, ${ }^{\mathbf{3}} \mathbf{2}$, and ${ }^{\mathbf{1}} \mathbf{2}_{\text {AFC }}$ with non-hybrid functionals is shown in subsection 18.3 parts $\mathrm{I}, \mathrm{II}$, and III, respectively, and representative input sections for the equivalent geometry optimizations using hybrid functionals is shown in subsection 18.3, parts IV, V, and VI. 
Although the inner sphere bond distances stayed relatively stable across most functionals for ${ }^{\mathbf{3}} \mathbf{2}$, and ${ }^{\mathbf{1}} \mathbf{2}_{\mathrm{AFC}}$, major functional-dependence of the bond distances was noted with 1 . This was especially true of the Cu-N $\mathrm{N}_{\mathrm{NHOH}}$ and $\mathrm{Cu}-\mathrm{N}_{\mathrm{SO} 2}$, and $\mathrm{Cu}-\mathrm{Cl}$ bonds. Both with- and without implicit solvation, all GGA functionals drastically underestimated the $\mathrm{Cu}-\mathrm{N}_{\mathrm{NHOH}}$ bond distance and overestimated the $\mathrm{Cu}-\mathrm{Cl}$ bond distance, with respect to the crystal structure. This trend was also seen, albeit to a lesser extent with the hybrid functionals and with $\omega \mathrm{B} 97 \mathrm{X}-$ D3BJ. The functional that gave geometries most similar to that of the crystal structure was CAM-B3LYP. The CAM-B3LYP geometry was most similar to that of the crystal structure both without implicit solvation and with CPCM $(\varepsilon=9.08)$. With implicit solvation, however, the $\mathrm{Cu}-\mathrm{N}_{\mathrm{NHOH}}$ and $\mathrm{Cu}-\mathrm{N}_{\mathrm{SO}}$ distances were underestimated with respect to the crystal structure whereas the $\mathrm{Cu}-\mathrm{Cl}$ distance was very close to that of the crystal structure, and in the gas phase, these two distances were closer to those seen in the crystal structure, but the $\mathrm{Cu}-\mathrm{Cl}$ distance was underestimated. A comparison of these distances, alongside the RMSD for all $\mathrm{N}, \mathrm{Cl}$, and $\mathrm{Cu}$ atoms, i.e., the inner sphere of coordination, is shown in Table S13. Despite these differences, CAM-B3LYP clearly described the $\mathbf{1}$ geometry best out of the functionals tested and the geometries of ${ }^{\mathbf{3}} \mathbf{2}$ and ${ }^{\mathbf{1}} \mathbf{2}_{\mathrm{AFC}}$ showed minimal functional-dependence, therefore it was concluded that CAM-B3LYP would provide the best compromise in describing both the copper(I) and copper(II) systems, thus the CAM-B3LYP/ZORA-Def2-TZVP level of theory was selected for the remainder of the study.

Table S13. CAM-B3LYP predicted $\mathrm{Cu}-\mathrm{N}_{\mathrm{NHOH}}, \mathrm{Cu}-\mathrm{N}_{\mathrm{SO} 2}$, and $\mathrm{Cu}-\mathrm{Cl}$ distance and RMSD of the inner sphere of coordination (all $\mathrm{N}, \mathrm{Cl}$, and $\mathrm{Cu}$ atoms) vs. the crystal structure of 1.

\begin{tabular}{lllll}
\hline Model of 1 & $\mathrm{~d}\left(\mathrm{Cu}-\mathrm{N}_{\mathrm{NHOH}}\right)(\AA)$ & $\mathrm{d}\left(\mathrm{Cu}-\mathrm{N}_{\mathrm{SO} 2}\right)(\AA)$ & $\mathrm{d}(\mathrm{Cu}-\mathrm{Cl})(\AA)$ & $\mathrm{RMSD}(\mathrm{Cu}, \mathrm{N}, \mathrm{Cl})(\AA)$ \\
\hline CAM-B3LYP $(\varepsilon=9.08)$ & 2.58 & 2.72 & 2.45 & 0.05196 \\
CAM-B3LYP $(\varepsilon=1)$ & 2.63 & 2.79 & 2.33 & 0.04701 \\
Crystal structure & 2.66 & 2.67 & 2.44 & 0.00000 \\
\hline
\end{tabular}

These trends indicate that the geometry of $\mathbf{1}$ is highly sensitive to its environment, suggesting that crystal packing effects might be significant. In order to estimate the effect of the electrostatic environment of the crystal on the geometry of $\mathbf{1}$, geometry optimizations were performed systematically varying the value of $\varepsilon$ used for the CPCM implicit solvation corrections from 1 to 40 , with more data points at smaller values. The results are summarized in Table S12 and Figure S20 and Figure S21. 

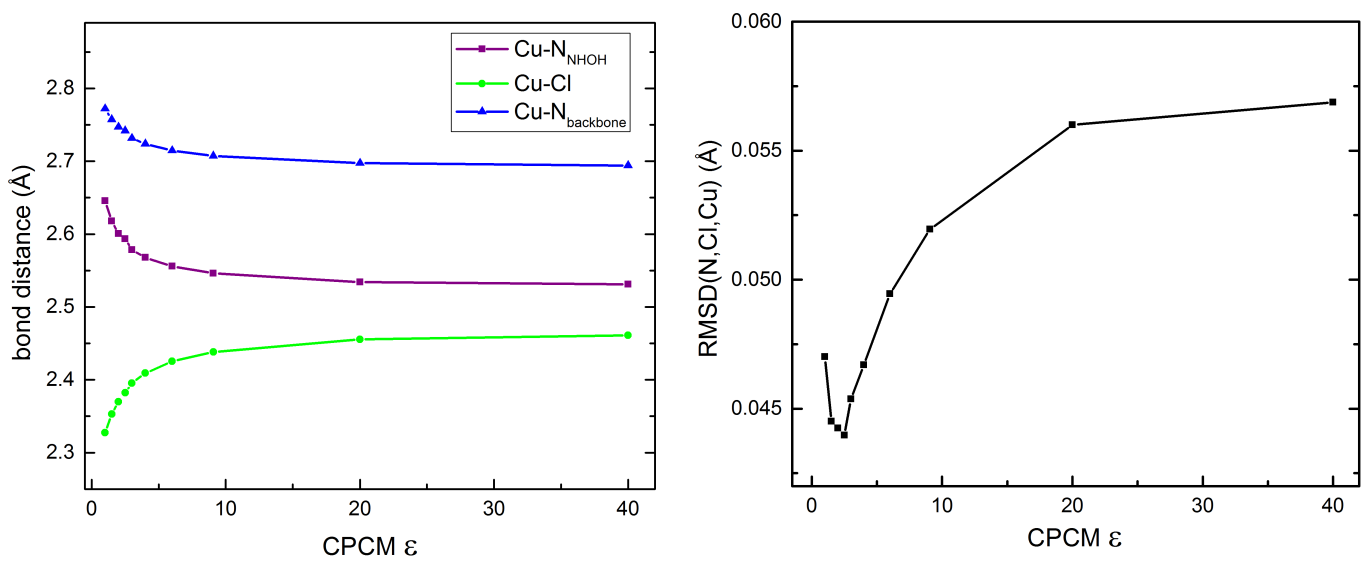

Figure S20. Dependence of the CAM-B3LYP-calculated $\mathrm{Cu}-\mathrm{N}_{\mathrm{NHOH}}, \mathrm{Cu}-\mathrm{N}_{\mathrm{SO}}$, and $\mathrm{Cu}-\mathrm{Cl}$ distances on the value of $\varepsilon$ used for CPCM implicit solvation corrections (left) and dependence of RMSD of the inner sphere of coordination vs. the crystal structure on CPCM $\varepsilon$ (right), from $\varepsilon=1$ to $\varepsilon=40$.
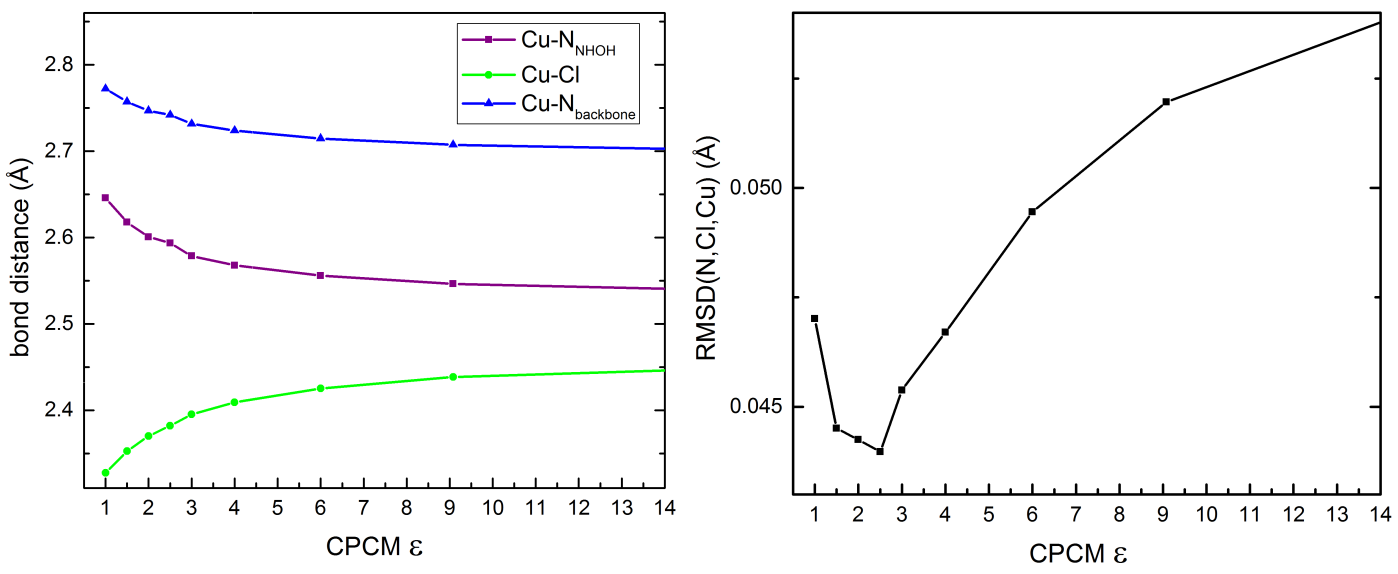

Figure S21. Dependence of the CAM-B3LYP-calculated $\mathrm{Cu}-\mathrm{N}_{\mathrm{NHOH}}, \mathrm{Cu}-\mathrm{N}_{\mathrm{SO}}$, and $\mathrm{Cu}-\mathrm{Cl}$ distances on the value of $\varepsilon$ used for CPCM implicit solvation corrections (left) and dependence of RMSD of the inner sphere of coordination vs. the crystal structure on $\mathrm{CPCM} \varepsilon$ (right), from $\varepsilon=1$ to $\varepsilon=14$.

Table S14. Dependence of CAM-B3LYP predicted $\mathrm{Cu}-\mathrm{N}_{\mathrm{NHOH}}, \mathrm{Cu}-\mathrm{N}_{\mathrm{SO}}$, and $\mathrm{Cu}-\mathrm{Cl}$ distance and RMSD of the inner sphere of coordination (all $\mathrm{N}, \mathrm{Cl}$, and $\mathrm{Cu}$ atoms) vs. the crystal structure of $\mathbf{1}$ on the value of $\varepsilon$ used in CPCM corrections.

\begin{tabular}{|c|c|c|c|c|}
\hline $\mathrm{CPCM} \quad \varepsilon\left(\mathrm{F} \mathrm{m}^{-1}\right)$ & $\mathrm{d}\left(\mathrm{Cu}-\mathrm{N}_{\mathrm{NHOH}}\right)(\AA)$ & $\mathrm{d}\left(\mathrm{Cu}-\mathrm{N}_{\mathrm{SO} 2}\right)(\AA)$ & $\mathrm{d}(\mathrm{Cu}-\mathrm{Cl})(\AA \AA)$ & $\operatorname{RMSD}(\mathrm{Cu}, \mathrm{N}, \mathrm{Cl})(\AA)$ \\
\hline 1 & 2.65 & 2.77 & 2.33 & 0.04701 \\
\hline 1.5 & 2.62 & 2.76 & 2.35 & 0.04451 \\
\hline 2 & 2.60 & 2.75 & 2.37 & 0.04425 \\
\hline 2.5 & 2.59 & 2.74 & 2.38 & 0.04397 \\
\hline 3 & 2.58 & 2.73 & 2.40 & 0.04538 \\
\hline 4 & 2.57 & 2.72 & 2.41 & 0.0467 \\
\hline 6 & 2.56 & 2.71 & 2.43 & 0.04945 \\
\hline 9.08 & 2.55 & 2.71 & 2.44 & 0.05196 \\
\hline 20 & 2.53 & 2.70 & 2.46 & 0.05600 \\
\hline 40 & 2.53 & 2.70 & 2.46 & 0.05688 \\
\hline
\end{tabular}


Of the values tested, $\varepsilon=2.5$ best minimized the RMSD of the optimized geometry of 1 with respect to the crystal structure, with an RMSD of $0.04397 \AA$. Based on this study, the $\mathrm{Cu}-\mathrm{N}_{\mathrm{NHOH}}, \mathrm{Cu}-\mathrm{N}_{\mathrm{SO} 2}$, and $\mathrm{Cu}-\mathrm{Cl}$ distances, as modelled at the CAM-B3LYP/ZORA-Def2-TZVP level of theory, are clearly sensitive to environmental effects. This suggests that the geometry in DCM solution likely varies from the crystal structure, so the crystal structure geometry is not a perfect metric for method benchmarking. The fact that a structure with the small inner sphere RMSD value of $0.04397 \AA$ can be found at the small value of $\varepsilon=2.5$, appropriate for a crystal of a neutral molecule, however, supports the validity of the choice of the CAM-B3LYP/ZORA-Def2-TZVP level of theory.

It should be noted that the hydrogen bond distances (the $\mathrm{Cl}-\mathrm{H}_{\mathrm{NHOH}}$ and $\mathrm{Cl}-\mathrm{O}_{\mathrm{NHOH}}$ distances) remained relatively constant with respect to $\mathrm{CPCM} \varepsilon$. Interestingly, the $\mathrm{Cu}-\mathrm{Cl}$ bond distance appeared to be inversely correlated to the $\mathrm{Cu}-\mathrm{N}_{\mathrm{NHOH}}$ and $\mathrm{Cu}-\mathrm{N}_{\mathrm{SO} 2}$ distances (see Figure S20), suggesting a possible trans effect of the Cu$\mathrm{N}_{\mathrm{SO} 2}$ distance on the $\mathrm{Cu}-\mathrm{Cl}$ bond length.

Since $\varepsilon=2.5$ best minimized the inner sphere RMSD with respect to the crystal structure, geometries of 1 calculated using this value of $\varepsilon$ were used the XAS TD-DFT calculations, in order to approximate the geometry of the solid. The value $\varepsilon=2.5$ was also applied in all XAS TD-DFT calculations, however the geometry of used for ${ }^{3} \mathbf{2}$ and ${ }^{1} \mathbf{2}_{\text {AFC }}$ was calculated at value $\varepsilon=9.08$ since $\mathbf{2}$ was measured in DCM solution in all experiments. Spin density plots, showing the corresponding values from Mulliken spin population analyses, are shown in Figure S22 and Figure S23. All plots were generated using the orca_plot interactive program. All surfaces were visualized with Chemcraft. ${ }^{[23]}$

A comparison of the key calculated properties of the three possible models of $\mathbf{2}$, namely ${ }^{\mathbf{1}} \mathbf{2},{ }^{\mathbf{3}} \mathbf{2}$, and ${ }^{\mathbf{1}} \mathbf{2}_{\mathrm{AFC}}$ are shown in Table S15. At the CAM-B3LYP/ZORA-Def2-TVP level of theory, ${ }^{3} \mathbf{2}$ is calculated to be $1.22 \mathrm{kcal} / \mathrm{mol}$ lower in energy than ${ }^{1} \mathbf{2}_{\mathrm{AFC}}$. Although this suggests a ${ }^{\mathbf{3}} \mathbf{2}$ ground state, this energy gap is far too small to rule out ${ }^{1} \mathbf{2}_{\mathrm{AFC}}$ as the ground state. Moreover, spin-state energies are known to exhibit a near-linear dependence on the amount of Hartree-Fock exchange included in the functional ${ }^{[24]}$, thus a range separated hybrid functional like CAM-B3LYP, which has a minimum HF exchange of $19 \%{ }^{[20]}$ would be expected to overestimate the stability of the triplet solution ${ }^{3} \mathbf{2}$. 
Table S15. A comparison of the key calculated properties of the different configurations of $\mathbf{2}$ examined in this study.

\begin{tabular}{|c|c|c|c|c|c|c|c|c|}
\hline geometry & $\begin{array}{l}\text { binding } \\
\text { mode }\end{array}$ & $\begin{array}{l}\text { Mulliken spin } \\
\text { population on } \\
\mathrm{Cu}\end{array}$ & $\begin{array}{l}\text { Mulliken } \\
\text { spin } \\
\text { population } \\
\text { on } \mathrm{N}\end{array}$ & $\begin{array}{l}\text { Mulliken } \\
\text { spin } \\
\text { population } \\
\text { on } 0\end{array}$ & $\mathrm{~d}\left(\mathrm{Cu}-\mathrm{N}_{\mathrm{NO}}\right)(\AA)$ & $\begin{array}{l}d(N-O) \\
(\AA)\end{array}$ & $\begin{array}{l}\mathrm{N}_{\mathrm{NO}}-\mathrm{Cu}-\mathrm{Cl} \\
\text { angle }\end{array}$ & $\begin{array}{l}\Delta \mathrm{E}\left({ }^{2} \mathbf{3}_{\mathrm{SCF}}\right)^{a} \\
(\mathrm{kcal} / \mathrm{mol})\end{array}$ \\
\hline $\begin{array}{l}{ }^{3} \mathbf{2} \\
\text { optimized } \\
\text { geometry }\end{array}$ & $\eta 1-N$ & 0.57 & 0.49 & 0.52 & 1.98 & 1.28 & $155.72^{\circ}$ & 0.00 \\
\hline $\begin{array}{l}{ }^{1} \mathbf{2}_{\mathrm{AFC}} \\
\text { optimized } \\
\text { geometry }\end{array}$ & $\eta^{1}-N$ & -0.60 & 0.28 & 0.42 & 1.98 & 1.28 & $155.55^{\circ}$ & +1.22 \\
\hline $\begin{array}{l}{ }^{1} \mathbf{2} \\
\text { optimized } \\
\text { geometry }\end{array}$ & $\eta^{2}-N, O$ & 0.000 & 0.000 & 0.000 & $\begin{array}{l}\mathrm{d}\left(\mathrm{Cu}-\mathrm{N}_{\mathrm{NO}}\right)= \\
2.02 \\
\mathrm{~d}\left(\mathrm{Cu}-\mathrm{O}_{\mathrm{NO}}\right)= \\
2.11\end{array}$ & 1.25 & $\begin{array}{l}140.58^{\circ} \\
104.29^{\circ}\end{array}$ & +10.1 \\
\hline
\end{tabular}

${ }^{a}$ difference in energy between SCF E of ${ }^{3} 2$ and that of the geometry in question.

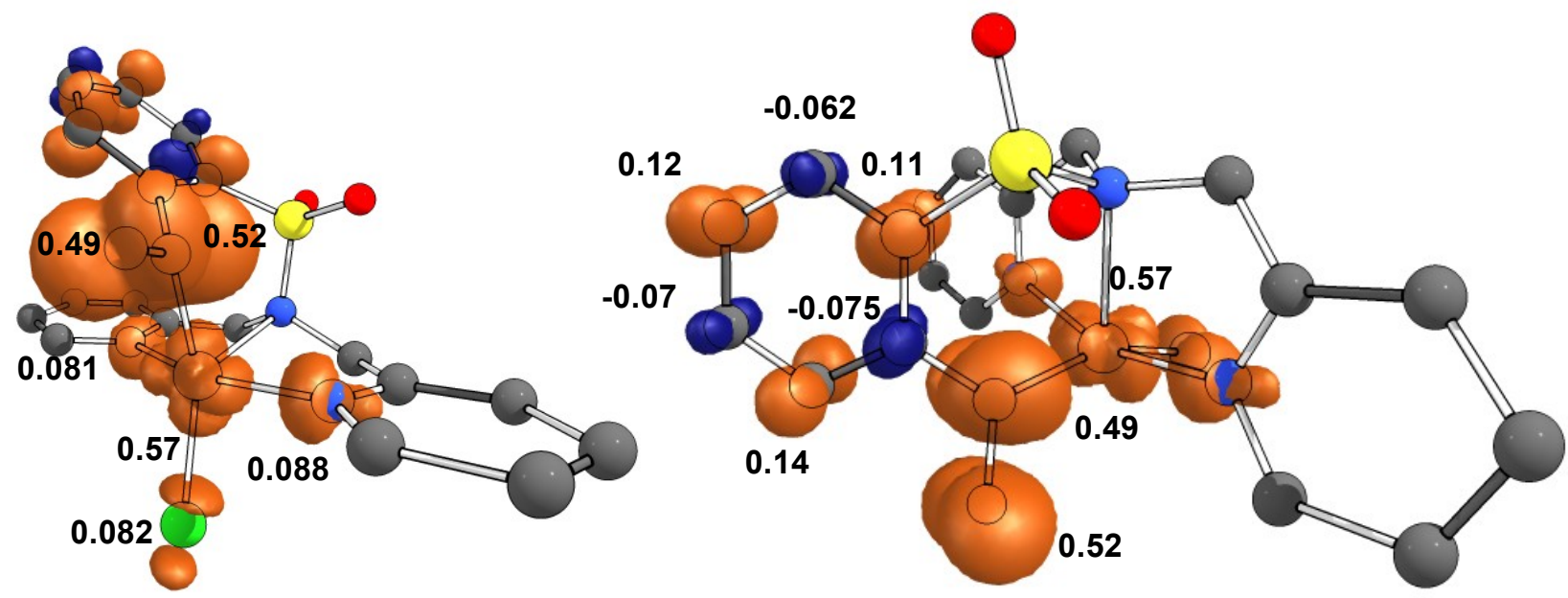

Figure S22. Spin density plot of optimized ${ }^{3} 2$ geometry showing corresponding Mulliken spin populations.

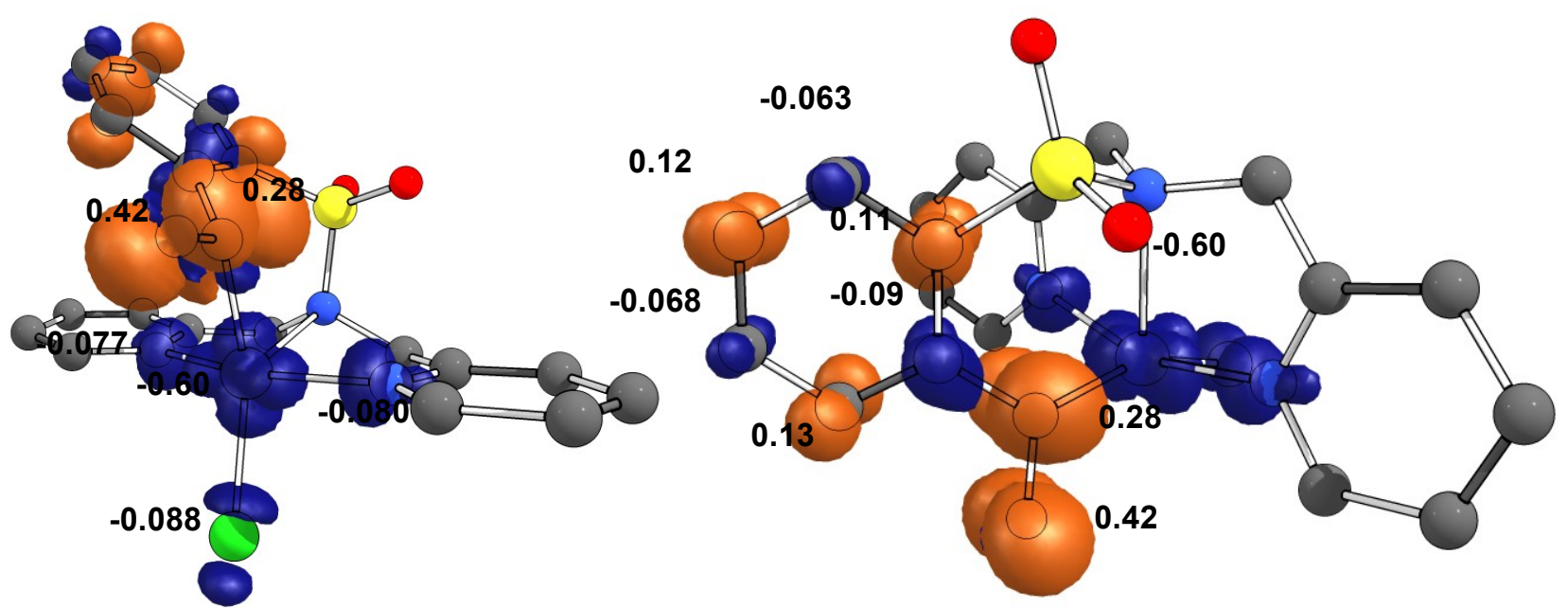

Figure S23. Spin density plot of optimized ${ }^{1} \mathbf{2}_{\text {AFC }}$ geometry showing corresponding Mulliken spin populations. 


\section{b) Spectroscopic calculations}

All spectroscopic calculations were performed at the same level of theory decided upon in the method validation phase (section 15a), but the finer Grid7 integration grade was selected both for initial and final integration in order to minimize numerical error. Valence (UV-Vis) TD-DFT calculations were performed using 50 roots, while core (Cu K-edge XAS) TD-DFT calculations were performed using 60 roots (see section 15c, VIIXII). The resulting calculated spectra were plotted using the orca_mapspc utility with a peak width at halfmaximum of $1.55 \mathrm{eV}$ for the TD-DFT-calculated $1 \mathrm{~s}$ excitations, corresponding to the known natural line width for the $\mathrm{Cu} \mathrm{K}$-edge ${ }^{[25]}$, and a broadening of $4000 \mathrm{~cm}^{-1}$ for the TD-DFT calculated valence excitations, corresponding to the value obtained from the Gaussian fit of the experimental UV-Vis of 2 shown in Figure S13.

The resulting calculated $\mathrm{CU}$ K-edge XAS spectra are shown in Figure S24-Figure S26, alongside the difference densities associated with the states of interest and the corresponding canonical acceptor orbitals for the excited state configurations with the largest $\mathrm{Cl}$ expansion coefficients. These spectra show qualitative agreement with the experimental $\mathrm{Cu}$ K-edge XAS of $\mathbf{1}$ and $\mathbf{2}$, however the calculations predict no feature that should distinguish ${ }^{\mathbf{1}} \mathbf{2}_{\mathrm{AFC}}$ and ${ }^{\mathbf{3}} \mathbf{2}$ by $\mathrm{Cu}$ K-edge XAS. the calculated spectra are shifted to slightly higher energies than those seen in the experimental spectra, as is often observed with TD-DFT-calculated Cu K-edge XAS. The calculated spectrum of $\mathbf{1}$ is shifted by $3.6 \mathrm{eV}$ from the experimental value of $8982.4 \mathrm{eV}$ to $8985 \mathrm{eV}$, while the calculated spectra of ${ }^{1} \mathbf{2}_{\mathrm{AFC}}$ and ${ }^{\mathbf{3}} \mathbf{2}$ are shifted by $4.8 \mathrm{eV}$ from the experimental value for $\mathbf{2}$ of $8985.0 \mathrm{eV}$ to 8989.8 $\mathrm{eV}$. In the TD-DFT calculated XAS, the edge shift from 1 to 2 is $4.8 \mathrm{eV}, 2.2 \mathrm{eV}$ greater than the experimental edge shift of $2.6 \mathrm{eV}$. Although the calculated XAS show qualitative agreement with the experimental XAS, reproducing the shape of the spectra and the overall presence of the edge shift from $\mathbf{1}$ to $\mathbf{2}$, these significant quantitative discrepancies highlight the limitations of single reference TD-DFT calculations for calculation of species such as $\mathbf{2}$, which is of a class of compounds known to have particularly strong multireference character $^{[26],[27]}$. Moreover, this discrepancy suggests that the DFT method used herein overestimates the oxidation of the $\mathrm{Cu}^{\prime \prime}$ in presence of a $\mathrm{k}-\mathrm{N}-(\mathrm{ArNO})^{--}$, therefore, despite good agreement with the geometry, experimentally verified by the EXAFS fit shown in section 14, the level of theory used in this study is likely failing to properly represent both the ground state and excited state electronic structures of 2 . These limitations in mind, the TD-DFT spectra and the corresponding density difference plots allow us to tentatively make the assignment of the pre-edge feature seen in the experimental Cu K-edge spectrum of 2 at $8977.6 \mathrm{eV}$ as a $3 \mathrm{~d} \leftarrow 1$ s transition into the $\mathrm{d}$-hole produced by oxidation of the Cu center to $\mathrm{Cu}^{\prime \prime}$.

Figure S27 shows a comparison of the TD-DFT-calculated UV-Vis spectrum of ${ }^{3} \mathbf{2}$ and $\mathbf{1}$ to the experimental UV-Vis spectra of $\mathbf{2}$ and $\mathbf{1}$ shown in Figure S10. Once again, there is qualitative agreement with the experimental spectra, with states 6 and 7 being assigned to the shoulder and peak seen experimentally at $14900 \mathrm{~cm}^{-1}$ and $19700 \mathrm{~cm}^{-1}$. Based on the difference density plots, shown in Figure S28, we tentatively assign 
the shoulder as an inter-ligand charge transfer (ILCT) between the singly occupied $\pi^{*}$ orbital of the (ArNO) ${ }^{\circ-}$ moiety and the aromatic $\pi^{*}$ system, and the peak as a ligand-to-metal charge transfer (LMCT) from the singly occupied $\pi^{*}$ orbital of the (ArNO) $)^{--}$moiety to the $\mathrm{Cu}^{\prime \prime} \mathrm{d}$-hole. The agreement between the TD-DFT and the experimental data are reasonable but cannot properly describe the electronic complexity of the multireference ground state that would be most appropriate for such systems.
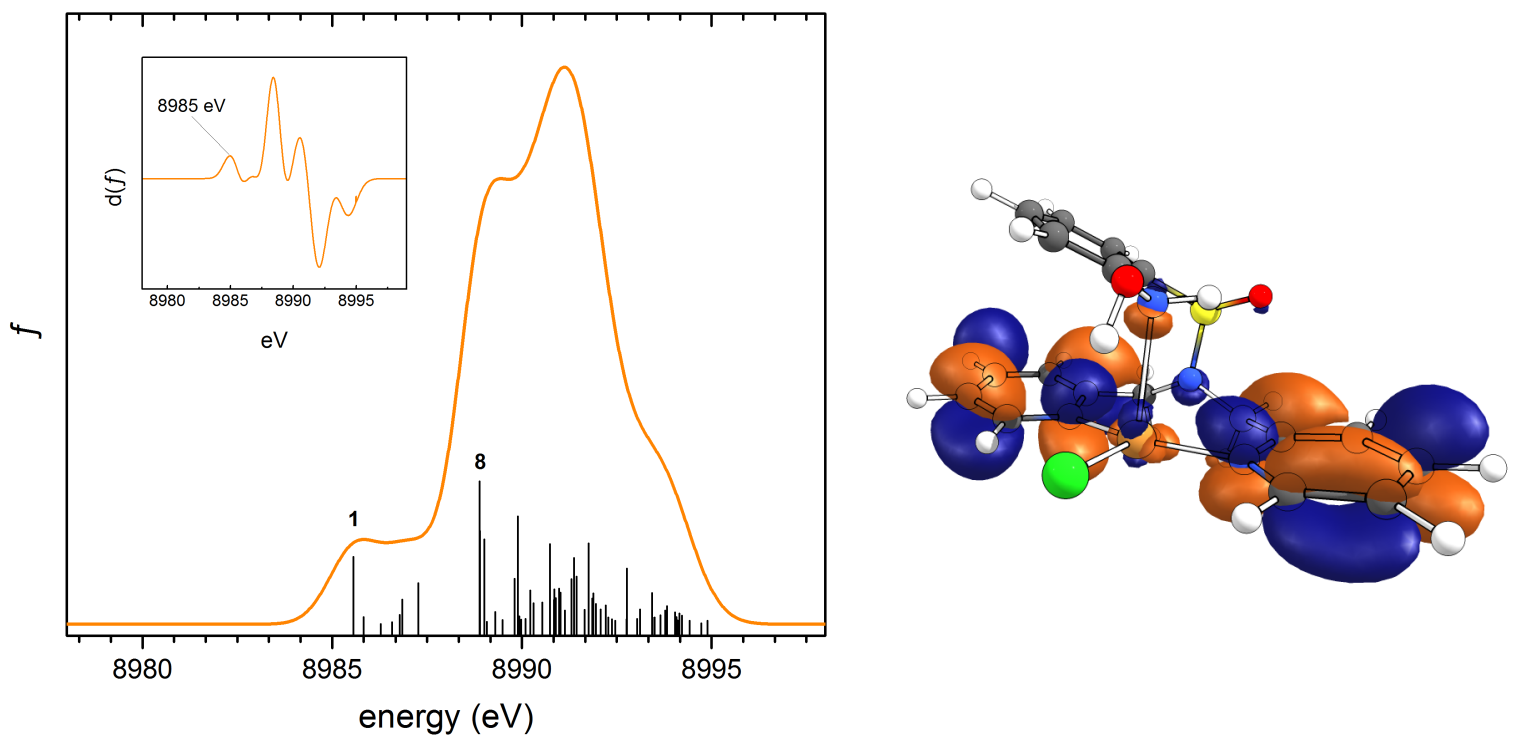

Figure S24. TD-DFT-calculated pre-edge and rising edge of XAS of 1. Calculation was performed with CPCM $\varepsilon=$ 2.5 using geometry from optimization of 1 with CPCM $\varepsilon=2.5$ (left) and the canonical acceptor orbital of the excited state configuration of state 1 with the largest $\mathrm{Cl}$ expansion coefficient, plotted with a contour value of 0.03 (right).
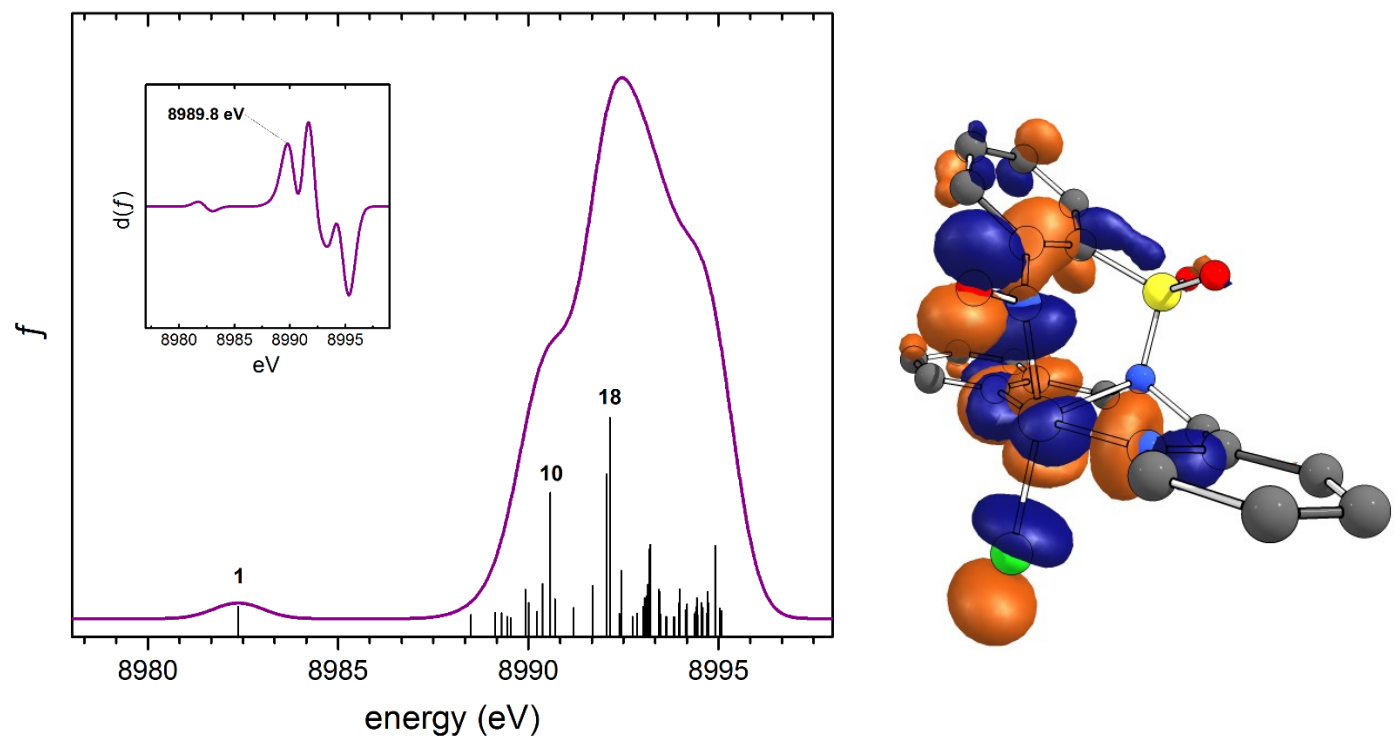

Figure S25. TD-DFT-calculated pre-edge and rising edge of XAS of ${ }^{3}$ 2. Calculation was performed with $\mathrm{CPCM} \varepsilon=$ 2.5 using geometry from optimization of ${ }^{3} 2$ with $C P C M \varepsilon=9.08$ (DCM) (left) and the canonical acceptor orbital of the excited state configuration of state 1 with the largest $\mathrm{Cl}$ expansion coefficient, plotted with a contour value of 0.03 (right). 

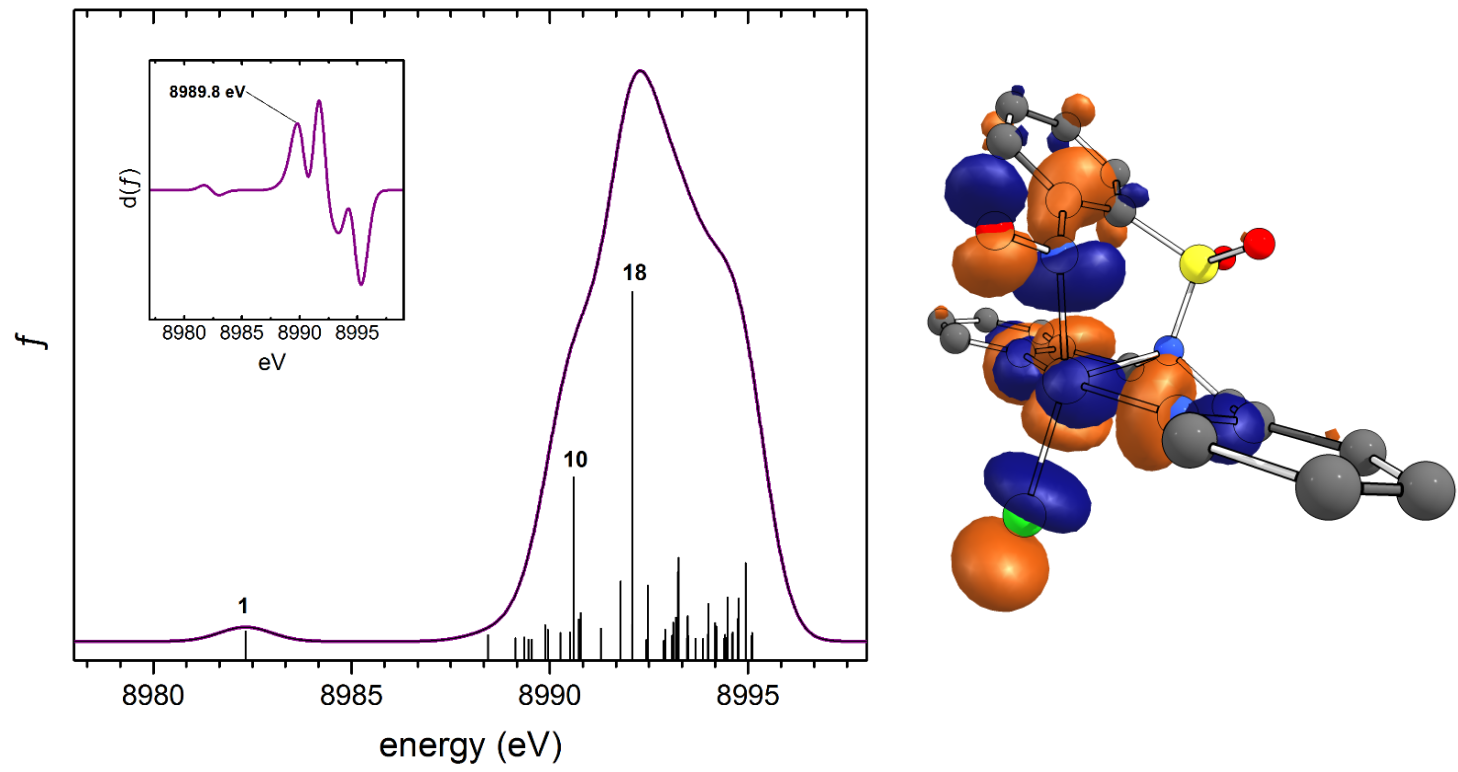

Figure S26. TD-DFT-calculated pre-edge and rising edge of XAS of ${ }^{1} \mathbf{2}_{\text {AFC. }}$. Calculation was performed with CPCM $\varepsilon=2.5$ using geometry from optimization of ${ }^{1} \mathbf{2}_{\mathrm{AFC}}$ with $\mathrm{CPCM} \varepsilon=9.08$ (DCM) (left) and the canonical acceptor orbital of the excited state configuration of state 1 with the largest $\mathrm{Cl}$ expansion coefficient, plotted with a contour value of 0.03 (right).
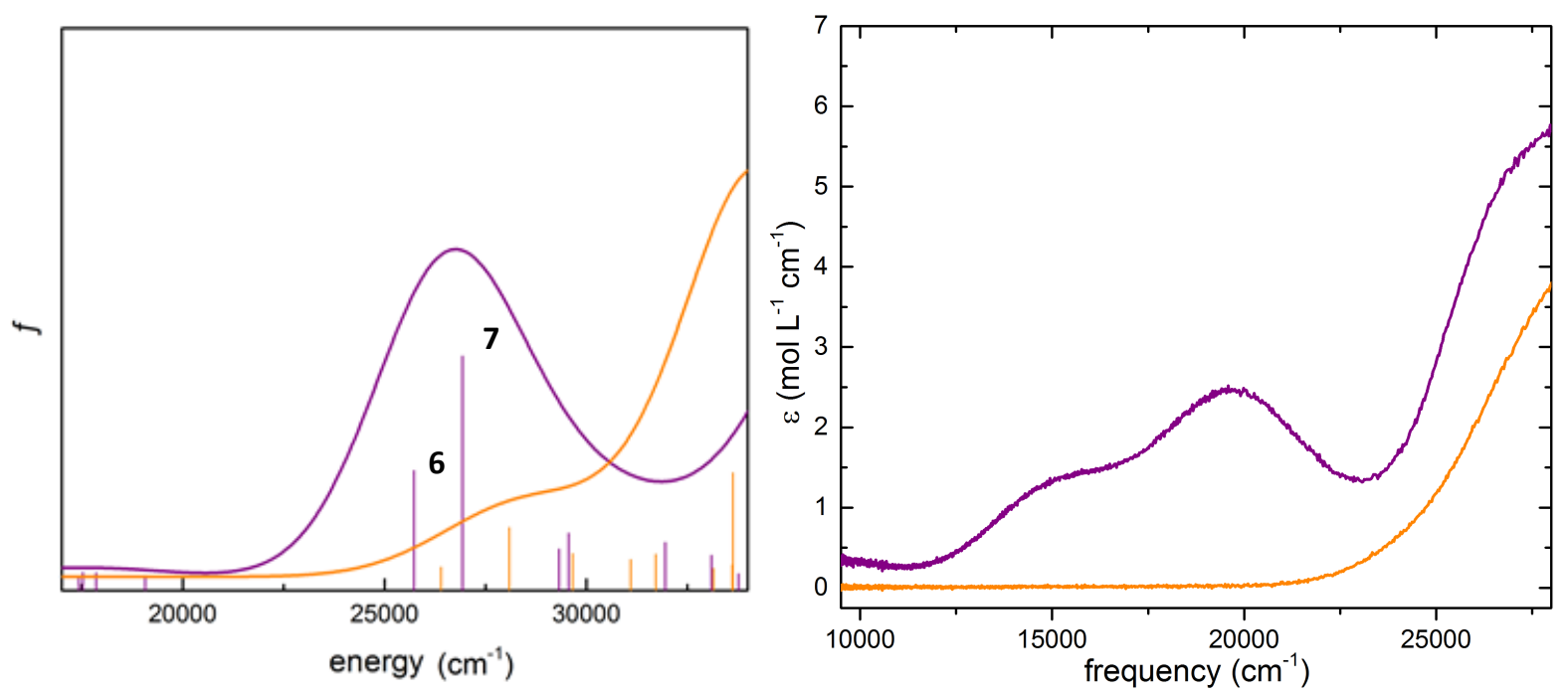

Figure S27. A comparison of the TD-DFT-calculated UV-Vis spectrum of ${ }^{3} \mathbf{2}$ and $\mathbf{1}$ using both geometries and excited states calculated with CPCM $\varepsilon=9.08$ (DCM) (left) to the experimental UV-Vis spectra of 2 and $\mathbf{1}$ (shown earlier in Figure S10). See also the Gaussian deconvolution of the spectrum of $\mathbf{2}$ shown in Figure S13. 
a)

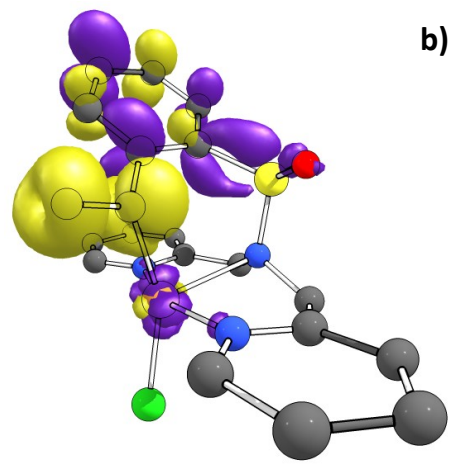

b)

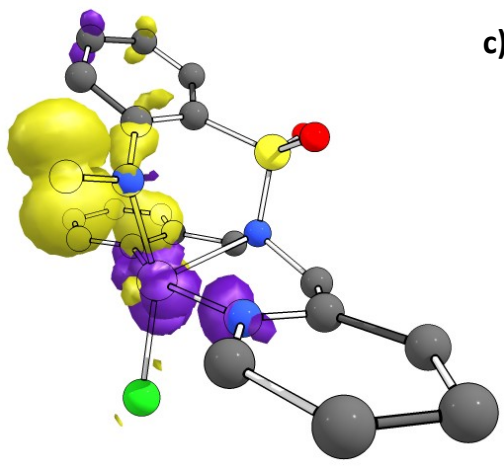

c)

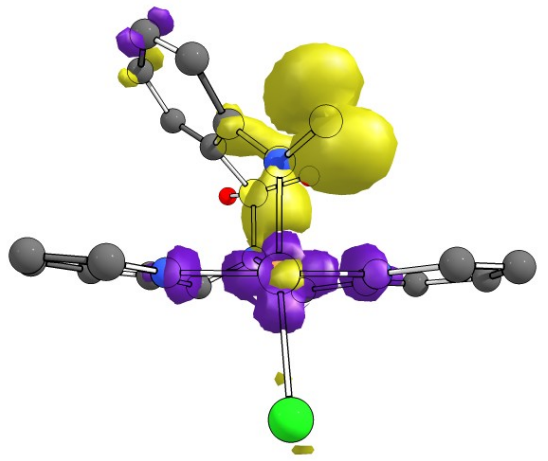

Figure S28. Difference density plots of (a) state 6 and (b) state 7 (c), plotted with contour values of 0.003 , showing a different view of the same plot) of the TD-DFT-calculated UV-Vis spectrum of ${ }^{3} 2$ shown in Figure S21. State 6 is assigned as an ILCT and state 7 is assigned as an LMCT.

\section{c) Example input sections}

\section{Geometry optimization of 1 using GGA functionals}

! RKS BP86 ZORA-def2-TZVP SARC/J RI D3BJ

! Grid5 FinalGrid6 ZORA TightSCF CPCM Opt

! PrintBasis

! PAL8

$\% \mathrm{cpcm}$

epsilon 9.08

surfacetype vdw_gaussian

end

* xyzfile $01 \mathrm{NHOH}-b p 86 . x y z$

\section{Geometry optimization of ${ }^{3} \mathbf{2}$ using GGA functionals}

! UKS BP86 ZORA-def2-TZVP SARC/J RI D3BJ

! Grid5 FinalGrid6 ZORA TightSCF CPCM Opt

! PrintBasis

! PAL8

$\%$ cpem

epsilon 9.08

surfacetype vdw_gaussian

end

* xyzfile 03 NO-bp86.xyz

III. Geometry optimization of ${ }^{1} \mathbf{2}_{\text {AFC }}$ using GGA functionals 
! UKS BP86 ZORA-def2-TZVP SARC/J RI D3BJ

! Grid5 FinalGrid6 ZORA TightSCF CPCM Opt

! PrintBasis

! PAL8

$\%$ cpem

epsilon 9.08

surfacetype vdw_gaussian

end

$\%$ scf

FlipSpin 0 \#flips spin on the copper

FinalMs 0.0

end

$\%$ geom

ReducePrint false

end

* xyzfile 03 NO-bp86.xyz

IV. Geometry optimization of 1 using hybrid functionals

! RKS B3LYP ZORA-def2-TZVP SARC/J RIJCOSX D3BJ

! Grid5 FinalGrid6 GridX6 ZORA TightSCF CPCM Opt

! PrintBasis

! PAL8

$\%$ cpem

epsilon 9.08

surfacetype vdw_gaussian

end

* xyzfile 01 NHOH-b3lyp.xyz

V. Geometry optimization of ${ }^{3} \mathbf{2}$ using hybrid functionals

! UKS BP86 ZORA-def2-TZVP SARC/J RIJCOSX D3BJ

! Grid5 FinalGrid6 GridX6 ZORA TightSCF CPCM Opt

! PrintBasis

! PAL8

$\%$ cpem

epsilon 9.08

surfacetype vdw_gaussian 
end

* xyzfile 03 NO-bp3lyp.xyz

\section{Geometry optimization of ${ }^{\mathbf{1}} \mathbf{2}_{\mathrm{AFC}}$ using hybrid functionals}

! UKS BP86 ZORA-def2-TZVP SARC/J RIJCOSX D3BJ

! Grid5 FinalGrid6 GridX6 ZORA TightSCF CPCM Opt

! PrintBasis

! PAL8

$\%$ cpem

epsilon 9.08

surfacetype vdw_gaussian

end

$\% \operatorname{scf}$

FlipSpin 0 \#flips spin on the copper

FinalMs 0.0

end

$\%$ geom

ReducePrint false

end

* xyzfile 03 NO-b3lyp.xyz

VII. Valence (UV-Vis) TD-DFT calculations for 1

! RKS CAM-B3LYP ZORA-def2-TZVP SARC/J RIJCOSX

! Grid7 NoFinalGrid GridX6 ZORA TightSCF CPCM MORead

! LargePrint PrintBasis UNO PAL8

$\%$ cpcm

epsilon 9.08

refrac 1.424

surfacetype vdw_gaussian

end

\%moinp "NHOH-cam-b3lyp-x6-reoriented.gbw"

$\%$ maxcore 10000

$\%$ tddft

maxdim 10

nroots 50

DoNTO true 
end

\%output

Print [ P_Basis ] 2

Print $\left[\mathrm{P}_{-} \mathrm{MOs}\right] 1$

end

* xyzfile $01 \mathrm{NHOH}$-cam-b3lyp-x6-reoriented.xyz

VIII. Valence (UV-Vis) TD-DFT calculations for ${ }^{3} 2$

! UKS CAM-B3LYP ZORA-def2-TZVP SARC/J RIJCOSX

! Grid7 NoFinalGrid GridX6 ZORA TightSCF CPCM MORead

! LargePrint PrintBasis UNO PAL8

$\%$ cpem

epsilon 9.08

refrac 1.424

surfacetype vdw_gaussian

end

\%moinp "NO-triplet-cam-b3lyp-reoriented.gbw"

$\%$ maxcore 10000

$\%$ tddft

maxdim 10

nroots 50

DoNTO true

end

\%output

Print[ P_Basis ] 2

Print[ P_MOs ] 1

end

* xyzfile 03 NO-triplet-cam-b3lyp-x6-reoriented.xyz

IX. Valence (UV-Vis) TD-DFT calculations for ${ }^{1} \mathbf{2}_{\text {AFC }}$

! UKS CAM-B3LYP ZORA-def2-TZVP SARC/J RIJCOSX

! Grid7 NoFinalGrid GridX6 ZORA TightSCF CPCM MORead

! LargePrint PrintBasis UNO PAL8

$\%$ cpem

epsilon 9.08

refrac 1.424

surfacetype vdw_gaussian 
end

\%moinp "NO-fs0-cam-b3lyp-reoriented.gbw"

$\%$ maxcore 10000

$\%$ tddft

$\operatorname{maxdim} 10$

nroots 50

DoNTO true

end

\%output

Print [ P_Basis ] 2

Print $\left[\mathrm{P}_{-} \mathrm{MOs}\right] 1$

end

* xyzfile $01 \mathrm{NO}$-fs0-cam-b3lyp-x6-reoriented.xyz

\section{Core (Cu K-edge XAS) TD-DFT calculations for 1}

! RKS CAM-B3LYP ZORA-def2-TZVP SARC/J RIJCOSX

! Grid7 NoFinalGrid GridX6 ZORA TightSCF CPCM MORead

! LargePrint PrintBasis UNO PAL8

$\% \mathrm{cpcm}$

epsilon 2.5

surfacetype vdw_gaussian

end

\%moinp "NHOH-eps2_5-x6-reoriented.gbw"

$\%$ maxcore 10000

$\%$ tddft

$\operatorname{maxdim} 10$

nroots 60

DoNTO true

orbwin $[0]=0,0,-1,-1$

DoQuad true

end

\%output

Print[ P_Basis ] 2

Print $\left[\mathrm{P}_{-} \mathrm{MOs}\right] 1$

end

* xyzfile 01 NHOH-eps2_5-x6-reoriented.xyz 


\section{Core (Cu K-edge XAS) TD-DFT calculations for ${ }^{3} \mathbf{2}$}

! RKS CAM-B3LYP ZORA-def2-TZVP SARC/J RIJCOSX

! Grid7 NoFinalGrid GridX6 ZORA TightSCF CPCM MORead

! LargePrint PrintBasis UNO PAL8

$\%$ cpem

epsilon 2.5

surfacetype vdw_gaussian

end

\%moinp "NO-triplet-eps9_08-x6-reoriented.gbw"

$\%$ maxcore 10000

$\%$ tddft

$\operatorname{maxdim} 10$

nroots 60

DoNTO true

orbwin $[0]=0,0,-1,-1$

orbwin[1] $=0,0,-1,-1$

DoQuad true

end

\%output

Print $\left[\mathrm{P}_{-}\right.$Basis $] 2$

Print $\left[\mathrm{P}_{-} \mathrm{MOs}\right] 1$

end

*xyzfile 03 NO-triplet-eps9_08-x6-reoriented.xyz 


\section{Core (Cu K-edge XAS) TD-DFT calculations for ${ }^{3} \mathbf{2}$}

! RKS CAM-B3LYP ZORA-def2-TZVP SARC/J RIJCOSX

! Grid7 NoFinalGrid GridX6 ZORA TightSCF CPCM MORead

! LargePrint PrintBasis UNO PAL8

$\%$ cpem

epsilon 2.5

surfacetype vdw_gaussian

end

\%moinp "NO-fs0-eps9_08-x6-reoriented.gbw"

$\%$ maxcore 10000

$\%$ tddft

$\operatorname{maxdim} 10$

nroots 60

DoNTO true

orbwin $[0]=0,0,-1,-1$

orbwin[1] $=0,0,-1,-1$

DoQuad true

end

\%output

Print $\left[\mathrm{P}_{-}\right.$Basis $] 2$

Print $\left[\mathrm{P}_{-} \mathrm{MOs}\right] 1$

end

* xyzfile 01 NO-fs0-eps9_08-x6-reoriented.xyz 


\section{d) Cartesian coordinates}

I. $\left[\left(\mathrm{L}^{\mathrm{NHOH}}\right) \mathrm{CuCl}\right](1)$ geometry optimized at the CAM-B3LYP/ZORA Def2-TZVP level of theory with $\mathrm{CPCM} \varepsilon=$ 1.00

\begin{tabular}{|c|c|c|c|}
\hline$u$ & 4.095444 & -0.766215 & 13.854289 \\
\hline $\mathrm{Cl}$ & 4.438837 & -3.066942 & 13.927811 \\
\hline$S$ & 1.344424 & 1.755407 & 12.743913 \\
\hline 0 & 1.589811 & -2.647168 & 12.919699 \\
\hline $\mathrm{H}$ & 2.475496 & -2.941625 & 13.248517 \\
\hline ○ & 0.496203 & 1.230667 & 13.777821 \\
\hline 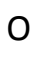 & 1.092625 & 3.073042 & 12.2397 \\
\hline IV & 1.699647 & -1.264696 & 12.848899 \\
\hline $\mathrm{H}$ & 1.109910 & -0.826950 & 13.545564 \\
\hline $\mathrm{N}$ & 2.876633 & 1.678303 & 13.381089 \\
\hline v & 4.817062 & -0.111004 & 12.120702 \\
\hline IV & 3.241627 & -0.244580 & 15.578749 \\
\hline$C$ & 1.581615 & -0.731436 & 11.584652 \\
\hline C & 1.693245 & -1.535317 & 10.449549 \\
\hline t & 1.833225 & -2.594944 & 10.589277 \\
\hline$c$ & 1.601395 & -0.983945 & 9.191232 \\
\hline $\mathrm{H}$ & 1.679559 & -1.634150 & 8.329567 \\
\hline C & 1.397185 & 0.377967 & 9.009146 \\
\hline $\mathrm{H}$ & 1.309697 & 0.796369 & 8.016940 \\
\hline C & 1.307694 & 1.189981 & 10.116309 \\
\hline $\mathrm{H}$ & 1.158234 & 2.255376 & 10.019737 \\
\hline C & 1.415293 & 0.652212 & 11.392848 \\
\hline C & 5.398053 & -1.030880 & 11.3468 \\
\hline $\mathrm{H}$ & 5.577317 & -1.987771 & 11.820038 \\
\hline C & 5.721584 & -0.793630 & 10.027163 \\
\hline $\mathrm{H}$ & 6.188396 & -1.572831 & 9.442507 \\
\hline C & 5.417817 & 0.437936 & 9.481353 \\
\hline $\mathrm{H}$ & 5.637251 & 0.654466 & 8.444578 \\
\hline C & 4.811271 & 1.386991 & 10.280276 \\
\hline $\mathrm{H}$ & 4.537759 & 2.355061 & 9.884866 \\
\hline C & 4.530298 & 1.083912 & 11.599572 \\
\hline C & 3.949372 & 2.141063 & 12.506189 \\
\hline $\mathrm{H}$ & 4.754166 & 2.496999 & 13.148451 \\
\hline $\mathrm{H}$ & 3.623666 & 2.993101 & 11.906435 \\
\hline & 2.945089 & 2.044083 & $14.7983 \varepsilon$ \\
\hline & 2.300957 & 2.896316 & 15.0216 \\
\hline
\end{tabular}




$\begin{array}{llll}\text { H } & 3.970193 & 2.361207 & 14.984740 \\ \text { C } & 2.636044 & 0.929351 & 15.762529 \\ \text { C } & 1.799446 & 1.155111 & 16.839419 \\ \text { H } & 1.296473 & 2.106818 & 16.933563 \\ \text { C } & 1.598516 & 0.147630 & 17.762187 \\ \text { H } & 0.939927 & 0.301891 & 18.606330 \\ \text { C } & 2.241189 & -1.061399 & 17.577786 \\ \text { H } & 2.113223 & -1.881862 & 18.268678 \\ \text { C } & 3.045680 & -1.220816 & 16.469007 \\ \text { H } & 3.544570 & -2.156089 & 16.250107\end{array}$


II. [( $\left.\left.{ }^{\mathrm{NHOH}}\right) \mathrm{CuCl}\right](1)$ geometry optimized at the CAM-B3LYP/ZORA Def2-TZVP level of theory with CPCM $\varepsilon$ $=2.50$

\begin{tabular}{|c|c|c|c|}
\hline $\mathrm{Cu}$ & 0.000000 & 0.000000 & 0.000000 \\
\hline $\mathrm{Cl}$ & -0.935416 & 0.033025 & -2.075219 \\
\hline$S$ & 3.081643 & -0.100724 & 1.448809 \\
\hline 0 & -1.089303 & -0.432601 & 2.478842 \\
\hline 0 & 2.865811 & -1.451725 & 1.877930 \\
\hline $\mathrm{O}$ & 4.433290 & 0.380891 & 1.385193 \\
\hline $\mathrm{N}$ & 0.000000 & 0.000000 & 1.964638 \\
\hline $\mathrm{N}$ & 2.400011 & 0.000000 & -0.075134 \\
\hline $\mathrm{N}$ & 0.414610 & 1.988413 & -0.044817 \\
\hline $\mathrm{N}$ & 0.382289 & -1.968385 & -0.089699 \\
\hline$C$ & 0.800312 & 0.809418 & 2.758450 \\
\hline$C$ & 0.243792 & 1.537885 & 3.811349 \\
\hline $\mathrm{H}$ & -0.804073 & 1.392967 & 4.026235 \\
\hline$C$ & 1.002800 & 2.439616 & 4.525357 \\
\hline $\mathrm{H}$ & 0.543110 & 3.002170 & 5.327453 \\
\hline$C$ & 2.339642 & 2.647845 & 4.212239 \\
\hline $\mathrm{H}$ & 2.929978 & 3.366032 & 4.763177 \\
\hline$C$ & 2.919821 & 1.911771 & 3.198637 \\
\hline $\mathrm{H}$ & 3.967686 & 2.027923 & 2.967398 \\
\hline$C$ & 2.169445 & 0.989149 & 2.482148 \\
\hline$C$ & -0.483980 & 2.911732 & 0.290251 \\
\hline $\mathrm{H}$ & -1.478973 & 2.553407 & 0.517248 \\
\hline$C$ & -0.168067 & 4.251088 & 0.356000 \\
\hline $\mathrm{H}$ & -0.924640 & 4.970108 & 0.633893 \\
\hline$C$ & 1.129841 & 4.637859 & 0.072055 \\
\hline $\mathrm{H}$ & 1.418396 & 5.678783 & 0.127218 \\
\hline$C$ & 2.058147 & 3.675010 & -0.273959 \\
\hline $\mathrm{H}$ & 3.083982 & 3.937505 & -0.491251 \\
\hline$C$ & 1.664770 & 2.351330 & -0.329645 \\
\hline$C$ & 2.627022 & 1.275304 & -0.764973 \\
\hline $\mathrm{H}$ & 2.464629 & 1.092979 & -1.826658 \\
\hline $\mathrm{H}$ & 3.653329 & 1.620587 & -0.645281 \\
\hline$C$ & 2.567045 & -1.229638 & -0.870555 \\
\hline $\mathrm{H}$ & 3.587191 & -1.610787 & -0.827174 \\
\hline $\mathrm{H}$ & 2.368982 & -0.948789 & -1.904192 \\
\hline$C$ & 1.601208 & -2.321392 & -0.490544 \\
\hline$C$ & 1.959460 & -3.651344 & -0.607130 \\
\hline $\mathrm{H}$ & 2.959478 & -3.911266 & -0.924828 \\
\hline
\end{tabular}




$\begin{array}{llll}\mathrm{C} & 1.030523 & -4.625687 & -0.300290 \\ \mathrm{H} & 1.290343 & -5.672269 & -0.384791 \\ \mathrm{C} & -0.230261 & -4.246212 & 0.127637 \\ \mathrm{H} & -0.982662 & -4.976266 & 0.387694 \\ \mathrm{C} & -0.514960 & -2.901715 & 0.220896 \\ \mathrm{H} & -1.479390 & -2.545131 & 0.554754\end{array}$


III. [( $\left.\mathrm{L}^{\mathrm{NHOH}}\right) \mathrm{CuCl}$ (1) geometry optimized at the CAM-B3LYP/ZORA Def2-TZVP level of theory with CPCM $\varepsilon$ $=9.08$

$\begin{array}{llll}\mathrm{Cu} & 0.000000 & 0.000000 & 0.000000 \\ \mathrm{Cl} & -2.436890 & 0.024792 & 0.081034 \\ \mathrm{~S} & 3.026010 & -0.033941 & 2.262184 \\ \mathrm{O} & -1.331806 & -0.117787 & 2.941668 \\ \mathrm{H} & -1.832210 & -0.080109 & 2.093556 \\ \mathrm{O} & 2.584694 & -1.319964 & 2.737730 \\ \mathrm{O} & 4.408703 & 0.306563 & 2.452695 \\ \mathrm{~N} & 0.000000 & 0.000000 & 2.546296 \\ \mathrm{H} & 0.485409 & -0.869246 & 2.733548 \\ \mathrm{~N} & 2.624980 & 0.000000 & 0.662544 \\ \mathrm{~N} & 0.562792 & 1.893434 & -0.176996 \\ \mathrm{~N} & 0.522258 & -1.913444 & -0.067552 \\ \mathrm{C} & 0.648274 & 1.124749 & 3.031243 \\ \mathrm{C} & -0.065261 & 2.208264 & 3.537226 \\ \mathrm{H} & -1.140052 & 2.141288 & 3.587002 \\ \mathrm{C} & 0.593380 & 3.339680 & 3.972186 \\ \mathrm{H} & 0.012695 & 4.164461 & 4.364267 \\ \mathrm{C} & 1.976879 & 3.433786 & 3.920909 \\ \mathrm{H} & 2.484449 & 4.321773 & 4.269041 \\ \mathrm{C} & 2.697836 & 2.378993 & 3.406383 \\ \mathrm{H} & 3.774264 & 2.426412 & 3.334532 \\ \mathrm{C} & 2.047565 & 1.238217 & 2.953292 \\ \mathrm{C} & -0.394208 & 2.825588 & -0.229700 \\ \mathrm{H} & -1.402863 & 2.454169 & -0.345614 \\ \mathrm{C} & -0.131127 & 4.173932 & -0.123840 \\ \mathrm{H} & -0.943329 & 4.884766 & -0.171547 \\ \mathrm{C} & 1.177848 & 4.579641 & 0.059134 \\ \mathrm{H} & 1.424339 & 5.627547 & 0.164707 \\ \mathrm{C} & 2.167165 & 3.619007 & 0.118536 \\ \mathrm{H} & 3.200775 & 3.893459 & 0.276678 \\ \mathrm{C} & 1.829828 & 2.283141 & -0.010604 \\ \mathrm{H} & 2.926535 & 1.248080 & -0.041488 \\ \mathrm{H} & 3.105515 & 0.988626 & -1.083712 \\ \mathrm{H} & 2.876681 & -1.260172 & -0.050520 \\ & 3.829280 & -1.701504 & 0.243517 \\ \mathrm{H} & -1.001412 & -1.104470 \\ & -2.296254 & 0.080027\end{array}$




$\begin{array}{llll}\text { C } & 2.135217 & -3.622023 & 0.277037 \\ \text { H } & 3.173822 & -3.888633 & 0.413712 \\ \text { C } & 1.142730 & -4.581530 & 0.310106 \\ \text { H } & 1.390929 & -5.622373 & 0.468976 \\ \text { C } & -0.171627 & -4.183657 & 0.146819 \\ \text { H } & -0.984944 & -4.894581 & 0.167251 \\ \text { C } & -0.437541 & -2.843259 & -0.031769 \\ \text { H } & -1.448911 & -2.476672 & -0.140722\end{array}$


IV. triplet $\left[\left(\mathrm{L}^{\mathrm{NO}}\right) \mathrm{CuCl}\right]\left({ }^{3} 2\right)$ geometry optimized at the CAM-B3LYP/ZORA Def2-TZVP level of theory with $\mathrm{CPCM} \varepsilon=9.08$

\begin{tabular}{|c|c|c|c|}
\hline $\mathrm{Cu}$ & 0.000000 & 0.000000 & 0.000000 \\
\hline $\mathrm{Cl}$ & -0.935416 & 0.033025 & -2.075219 \\
\hline$S$ & 3.081643 & -0.100724 & 1.448809 \\
\hline 0 & -1.089303 & -0.432601 & 2.478842 \\
\hline 0 & 2.865811 & -1.451725 & 1.877930 \\
\hline 0 & 4.433290 & 0.380891 & 1.385193 \\
\hline $\mathrm{N}$ & 0.000000 & 0.000000 & 1.964638 \\
\hline $\mathrm{N}$ & 2.400011 & 0.000000 & -0.075134 \\
\hline $\mathrm{N}$ & 0.414610 & 1.988413 & -0.044817 \\
\hline $\mathrm{N}$ & 0.382289 & -1.968385 & -0.089699 \\
\hline C & 0.800312 & 0.809418 & 2.758450 \\
\hline C & 0.243792 & 1.537885 & 3.811349 \\
\hline $\mathrm{H}$ & -0.804073 & 1.392967 & 4.026235 \\
\hline C & 1.002800 & 2.439616 & 4.525357 \\
\hline $\mathrm{H}$ & 0.543110 & 3.002170 & 5.327453 \\
\hline C & 2.339642 & 2.647845 & 4.212239 \\
\hline $\mathrm{H}$ & 2.929978 & 3.366032 & 4.763177 \\
\hline C & 2.919821 & 1.911771 & 3.198637 \\
\hline $\mathrm{H}$ & 3.967686 & 2.027923 & 2.967398 \\
\hline C & 2.169445 & 0.989149 & 2.482148 \\
\hline C & -0.483980 & 2.911732 & 0.290251 \\
\hline $\mathrm{H}$ & -1.478973 & 2.553407 & 0.517248 \\
\hline C & -0.168067 & 4.251088 & 0.356000 \\
\hline $\mathrm{H}$ & -0.924640 & 4.970108 & 0.633893 \\
\hline C & 1.129841 & 4.637859 & 0.072055 \\
\hline $\mathrm{H}$ & 1.418396 & 5.678783 & 0.127218 \\
\hline C & 2.058147 & 3.675010 & -0.273959 \\
\hline $\mathrm{H}$ & 3.083982 & 3.937505 & -0.491251 \\
\hline C & 1.664770 & 2.351330 & -0.329645 \\
\hline C & 2.627022 & 1.275304 & -0.764973 \\
\hline $\mathrm{H}$ & 2.464629 & 1.092979 & -1.826658 \\
\hline $\mathrm{H}$ & 3.653329 & 1.620587 & -0.645281 \\
\hline C & 2.567045 & -1.229638 & -0.870555 \\
\hline $\mathrm{H}$ & 3.587191 & -1.610787 & -0.827174 \\
\hline $\mathrm{H}$ & 2.368982 & -0.948789 & -1.904192 \\
\hline C & 1.601208 & -2.321392 & -0.490544 \\
\hline C & 1.959460 & -3.651344 & -0.607130 \\
\hline $\mathrm{H}$ & 2.959478 & -3.911266 & -0.924828 \\
\hline
\end{tabular}




$\begin{array}{llll}\mathrm{C} & 1.030523 & -4.625687 & -0.300290 \\ \mathrm{H} & 1.290343 & -5.672269 & -0.384791 \\ \mathrm{C} & -0.230261 & -4.246212 & 0.127637 \\ \mathrm{H} & -0.982662 & -4.976266 & 0.387694 \\ \mathrm{C} & -0.514960 & -2.901715 & 0.220896 \\ \mathrm{H} & -1.479390 & -2.545131 & 0.554754\end{array}$




\section{BS singlet $\left[\left(\mathrm{L}^{\mathrm{NO}}\right) \mathrm{CUCl}\right]\left({ }^{1} 2_{\mathrm{AFC}}\right)$ geometry optimized at the CAM-B3LYP/ZORA Def2-TZVP level of theory}

with $\mathrm{CPCM} \varepsilon=9.08$

\begin{tabular}{|c|c|c|c|}
\hline $\mathrm{Cu}$ & 0.000000 & 0.000000 & 0.000000 \\
\hline $\mathrm{Cl}$ & -0.940463 & 0.029962 & -2.069873 \\
\hline$S$ & 3.068899 & -0.113666 & 1.517508 \\
\hline 0 & -1.182765 & -0.242497 & 2.417685 \\
\hline 0 & 2.832333 & -1.461556 & 1.944661 \\
\hline $\mathrm{O}$ & 4.428145 & 0.348486 & 1.467851 \\
\hline $\mathrm{N}$ & 0.000000 & 0.000000 & 1.984438 \\
\hline $\mathrm{N}$ & 2.402761 & 0.000000 & -0.013167 \\
\hline $\mathrm{N}$ & 0.392304 & 1.974642 & -0.030911 \\
\hline $\mathrm{N}$ & 0.386942 & -1.971785 & -0.094637 \\
\hline$C$ & 0.774901 & 0.859269 & 2.758454 \\
\hline$C$ & 0.197411 & 1.652751 & 3.750662 \\
\hline $\mathrm{H}$ & -0.861924 & 1.546591 & 3.926877 \\
\hline$C$ & 0.954075 & 2.559851 & 4.460949 \\
\hline $\mathrm{H}$ & 0.478645 & 3.169549 & 5.218221 \\
\hline$C$ & 2.309569 & 2.711758 & 4.201913 \\
\hline $\mathrm{H}$ & 2.899528 & 3.431126 & 4.751780 \\
\hline$C$ & 2.906620 & 1.922815 & 3.238897 \\
\hline $\mathrm{H}$ & 3.964285 & 2.005584 & 3.040117 \\
\hline$C$ & 2.157395 & 0.996170 & 2.527524 \\
\hline$C$ & -0.525663 & 2.889676 & 0.274104 \\
\hline $\mathrm{H}$ & -1.523087 & 2.521226 & 0.472208 \\
\hline$C$ & -0.224663 & 4.231693 & 0.345938 \\
\hline $\mathrm{H}$ & -0.996004 & 4.943667 & 0.600258 \\
\hline$C$ & 1.077325 & 4.630240 & 0.099510 \\
\hline $\mathrm{H}$ & 1.354114 & 5.674004 & 0.160559 \\
\hline C & 2.024776 & 3.675946 & -0.216953 \\
\hline $\mathrm{H}$ & 3.053589 & 3.948622 & -0.405627 \\
\hline$C$ & 1.647631 & 2.347968 & -0.280277 \\
\hline$C$ & 2.635040 & 1.282969 & -0.687831 \\
\hline $\mathrm{H}$ & 2.510515 & 1.105190 & -1.755396 \\
\hline $\mathrm{H}$ & 3.652772 & 1.640081 & -0.533873 \\
\hline$C$ & 2.587642 & -1.223331 & -0.815136 \\
\hline $\mathrm{H}$ & 3.608694 & -1.600373 & -0.758647 \\
\hline $\mathrm{H}$ & 2.404072 & -0.936768 & -1.849939 \\
\hline$C$ & 1.619516 & -2.320188 & -0.456491 \\
\hline C & 1.989630 & -3.648519 & -0.554135 \\
\hline 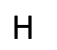 & 3.000541 & -3.903661 & -0.839598 \\
\hline
\end{tabular}




$\begin{array}{llll}\mathrm{C} & 1.058277 & -4.627195 & -0.269355 \\ \mathrm{H} & 1.327404 & -5.672548 & -0.338479 \\ \mathrm{C} & -0.217796 & -4.253078 & 0.115747 \\ \mathrm{H} & -0.973637 & -4.986356 & 0.356071 \\ \mathrm{C} & -0.513669 & -2.909824 & 0.191271 \\ \mathrm{H} & -1.492566 & -2.559543 & 0.487961\end{array}$

\section{References}

[1] B. Ravel, M. Newville, in J. Synchrotron Radiat., 2005, pp. 537-541.

[2] J. J. Rehr, J. J. Kas, F. D. Vila, M. P. Prange, K. Jorissen, Phys. Chem. Chem. Phys. 2010, 12, 5503-5513.

[3] F. Neese, Wiley Interdiscip. Rev. Comput. Mol. Sci. 2012, 2, 73-78.

[4] E. Van Lenthe, E. J. Baerends, J. G. Snijders, E. Van Lenthe, E. J. Baerends, J. G. Snijders, J. Chem. Phys. 1993, 99, 4597-4610.

[5] C. Van Wüllen, J. Chem. Phys. 1998, 109, 392-399.

[6] S. Grimme, S. Ehrlich, L. Goerigk, J. Comput. Chem. 2011, 32, 1456-1465.

[7] F. Weigend, Phys. Chem. Chem. Phys. 2006, 8, 1057-1065.

[8] D. Aravena, F. Neese, D. A. Pantazis, J. Chem. Theory Comput. 2016, 12, 1148-1156.

[9] A. D. Becke, Phys. Rev. A 1988, 38, 3098-3100.

[10] J. P. Perdew, Phys. Rev. B 1986, 33, 8822-8824.

[11] J. Tao, J. P. Perdew, V. N. Staroverov, G. E. Scuseria, Phys. Rev. Lett. 2003, 91, 146401.

[12] V. N. Staroverov, G. E. Scuseria, J. Tao, J. P. Perdew, J. Chem. Phys. 2003, 119, 12129-12137.

[13] S. Grimme, J. Phys. Chem. A 2005, 109, 3067-3077.

[14] A. D. Becke, J. Chem. Phys. 1993, 98, 5648-5652.

[15] C. Lee, W. Yang, R. G. Parr, Phys. Rev. B 1988, 37, 785-789.

[16] S. H. Vosko, L. Wilk, M. Nusair, Can. J. Phys. 1980, 58, 1200-1211.

[17] J. P. Perdew, M. Ernzerhof, K. Burke, J. Chem. Phys. 1996, 105, 9982-9985.

[18] C. Adamo, V. Barone, J. Chem. Phys. 1999, 110, 6158-6170.

[19] N. Mardirossian, M. Head-Gordon, Phys. Chem. Chem. Phys. 2014, 16, 9904-9924.

[20] T. Yanai, D. P. Tew, N. C. Handy, Chem. Phys. Lett. 2004, 393, 51-57.

[21] N. Mardirossian, M. Head-Gordon, J. Chem. Phys. 2016, 144, 241110.

[22] A. Najibi, L. Goerigk, J. Chem. Theory Comput. 2018, 14, 5725-5738.

[23] Chemcraft - graphical software for visualization of quantum chemistry computations. https://www.chemcraftprog.com

[24] F. Neese, Coord. Chem. Rev. 2009, 253, 526-563.

[25] M. O. Krause, J. H. Oliver, J. Phys. Chem. Ref. Data 1979, 8, 329-338.

[26] W. Jiang, N. J. Deyonker, A. K. Wilson, J. Chem. Theory Comput. 2012, 8, 460-468.

[27] A. P. De Lima Batista, A. G. S. De Oliveira-Filho, S. E. Galembeck, Phys. Chem. Chem. Phys. 2017, 19, 13860-13867. 